\title{
Competition and Relational Contracts: Evidence From Rwanda's Coffee MiLls*
}

\author{
Rocco Macchiavello \\ Warwick University
}

\author{
Ameet Morjaria \\ LSE \& Harvard University \\ JOB MARKET PAPER
}

January $2015^{\dagger}$

\begin{abstract}
Business transactions often occur in the absence of enforceable contracts. To sustain trade in such cases, parties rely on relational contracts (RC). Introducing competition might change exit options, thus undermining the ability to sustain RC. To examine the impact of competition in procurement of inputs, we exploit the prevalence of RC between processing mills and farmers in Rwanda's coffee sector. We implement a census of all mills and farmers to capture the features of the RC binding them. We then develop a RC model to capture the incentive problems between mills and farmers. The model is used to predict how competition affects RC, the mill's performance, and farmer outcomes. Since the location of mills is endogenous, an engineering model is estimated for the optimal placement of mills to instrument for competition in each locality. We find that competition between mills undermines RC by increasing the mill's processing costs, lowering the mill's capacity utilization and reducing the quality of coffee cherries received by the mill. Competition constraints the farmer's credit and input choices and reduces farmer's wellbeing. The findings highlight that in weak contracting settings, the value $\mathrm{RC}$ generates can be hampered by competition. The evidence provides a rationale for policies commonly observed historically across developing countries, such as zoning regulations and monopsony licensing, and emphasizes the importance of promoting contractual enforcement in agricultural value chains in order to reap the benefits of competition.
\end{abstract}

${ }^{*}$ This project would not have been possible without the collaboration of the many staff members at the Rwanda National Agricultural Exporting Board (NAEB). Without implicating them, we are especially grateful to Alex Kanyankole, Celestin Gatarayiha, Eric Ruganintwali, Jacques Mutabazi, Faustin Nizeymana and Malliavin Nzamurambaho. We thank our survey team of 20 led by Eric Rukwaya, Badrou Bazambanza, Laetitia Umutoniwase and Vincent Uwimana. We are especially grateful to Oriana Bandiera, Tim Besley, Robin Burgess, Bob Gibbons, Gerard Padró i Miquel and John Sutton for their invaluable advice and guidance. We thank Hunt Allcott, David Atkin, Nick Bloom, Gharad Bryan, Lorenzo Casaburi, Tarek Ghani, Chang-Tai Hsieh, Asim Ijaz Khwaja, Raul Sanchez de la Sierra, Orie Shelef, Steve Tadelis, Fabian Waldinger and Chris Woodruff as well as conferences and seminar participants at AEA 2015 (Boston), SSDEV (Italy), DIME-CEGA (Kigali), European Winter Econometric Society Meeting (Madrid), ISNIE 2014 (Duke), BREAD Junior Pre-Conference (LSE), Bristol, Gothenborg, Harvard (Development Lunch, IO, WCFIA, Government, Faculty Retreat), Imperial, LSE, Nottingham, NBER Org Meeting (Stanford), NEUDC (BU), Nova SBE, Oxford, Warwick and Wesleyan for helpful comments and suggestions. Financial support from IGC Rwanda and Harvard Academy Scholars Program is gratefully acknowledged. Morjaria thanks NAEB in Rwanda and LSE-STICERD for its hospitality where he worked on parts of this project. The views expressed here are those of the authors alone and do not reflect those of DFID or any of the other organizations acknowledged here. Updates will be posted to https://sites.google.com/site/ameetmorjaria/

${ }^{\dagger}$ Macchiavello, email: r.macchiavello@warwick.ac.uk; Morjaria (corresponding author): email: amorjaria@wcfia.harvard.edu 


\section{Introduction}

When contracts are hard to enforce, parties can rely on relationships, or "relational contracts", to sustain trade (Greif $(1989,1993)$, MacLeod (2007)). Building and managing relational contracts is increasingly seen as a key aspect of management (see, e.g., Gibbons and Henderson (2012)) yet, there is limited systematic evidence on the scope and relevance of relational contracts (Gil and Zanarone 2014). Building and sustaining relational contracts, however, requires rents (MacLeod and Malcomson (1989), Baker et al. (2002), Levin (2003)). Introducing competition might change exit options of parties, thus a tension between the positive effects of competition and the ability to sustain relational contracts (Kranton (1996) and Ghosh and Ray (1996)). ${ }^{1}$

Analyzing the relationship between competition and relational contracts faces two main challenges: the lack of credible measures of appropriate relational practices and the endogeneity of market structure. This paper seeks to address both challenges using coffee mills in Rwanda as a case study. Besides its intrinsic interest, the context presents a number of advantages. ${ }^{2}$ First, multiple contractual imperfections in agricultural value chains in developing countries (see, e.g., Binswanger and Rosenzweig (1982), Bardhan (1989), Fafchamps (2004)) make relationships salient. At the same time, the focus on a single sector with a simple technology allows to measure a number of appropriate relational practices. ${ }^{3}$ Second, we take advantage of an engineering model for the optimal placement of mills to instrument for the competition faced by mills in sourcing coffee from farmers. Estimates of the engineering model yield a specific score for the suitability of mill placement for each spatial location (defined in our analysis at the one square $\mathrm{km}$ resolution) in Rwanda. Controlling for placement suitability and cost drivers within the mill's catchment area, competition is instrumented with average suitability scores around the mill's catchment area. ${ }^{4}$

Section 2 provides industry background and presents the data. After describing

\footnotetext{
${ }^{1}$ A similar tension has been highlighted in other contexts, e.g., the relationship between competition and innovation (Aghion et al. (2005)) and in the relational banking literature (Petersen and Rajan $(1994,1995))$. In both cases rents are required for efficiency.

${ }^{2}$ Coffee mills share many aspects of first stage processing with other agricultural value chains in developing countries. The coffee sector accounts for 30\% of Rwanda's exports, approximately $15 \%$ of its GDP and employs nearly $10 \%$ of the population.

${ }^{3}$ We implemented a survey of all coffee mills in Rwanda during the 2012 harvest season. See Data Appendix for details on the survey.

${ }^{4}$ The identification strategy combines ideas from two different literatures. GIS data and technological features are used to construct instruments in the evaluation of infrastructure literature (see, e.g., Duflo and Pande (2008) and Lipscomb et al. (2013)). Following Bramoulle' et al. (2009) an emerging literature uses neighbors ('s neighbors) to estimate peer effects, of which competition is a special case. Bloom et al. (2014) uses neighbors' local council political marginality to instrument for hospital closures in the UK's NHS system.
} 
the technology and summary statistics for mills in Rwanda, measures of relational contracting are introduced. Due to lack of inputs (ferilizers), credit, saving and insurance markets, spot market transactions in which mills and farmers simply exchange coffee cherries (the produce) for cash at harvest time do not guarantee efficiency. Efficient trade requires mills and farmers to establish "interlinked transactions" in which a complex bundle of promises involving services before harvest, at harvest and post harvest is exchanged. Farmers and mills, however, do not have access to legal instruments to enforce these promises. The extent to which trade between mills and farmers is efficient depends on the quality of the relationship between the parties.

We focus on three key aspects of relational contracts: inputs and loans provided by the mill to the farmers before harvest, cherries sold on credit by the farmers to the mill at harvest time, and second payments and assistance from the mill to the farmers post-harvest. We measure each practice from the mill's manager and farmers perspective and aggregate them up into standardized z-scores. We document three facts. First, there is dispersion in the use of relational contracts across mills. Second, relational practices before, during and post harvest are positively correlated with each other. Third, relational contracts correlate positively with mill's capacity utilization and negatively with processing unit costs. This gives us confidence that the measures of relational contracts are picking up appropriate management practices in the industry.

Section 3 presents a simple theoretical framework. The framework captures the key aspects described in the background section. The model highlights how competition reduces parties ability to sustain relational contracting, rather than parties demand for it. Whether competition destroys relationships or not depends on parameters. When it does, however, the model delivers a number of clustered predictions: (1) a decrease in the use of all practices, (2) a decrease in mill's aggregate capacity utilization, (3) a decrease in either inputs provided and/or effort by the farmer, and (4) an ambiguous effect on prices and farmer's welfare.

The empirical sections test the predictions of the model. Section 4 presents the main results on the effects of competition on relational contracts. Competition is defined as the number of mills within a certain distance from each mill. OLS results are presented first. Competition negatively correlates with a broad spectrum of relational practices described above. These correlations, however, could be driven by omitted factors and reverse causality considerations that could bias OLS results in an a priori ambiguous direction.

To address these concerns, the IV identification strategy is introduced. We make 
use of an engineering model that lists out the criteria required for the optimal placement of mills in Rwanda. These criteria were documented prior to the exponential growth in the entry of mills in the country. We operationlize the engineering my assembling ortho-photos (high resolution aerial photogrpahy at 25 meter pixels) of Rwanda. First, the four criteria specified in the engineering model are validated in our assembled data. Second, a score for the suitability of mill's placement at the one square km level is obtained. The score (or the individual components of the engineering model and their interactions) is aggregated at the level of the mill's catchment area and surrounding areas to construct the instruments. The exclusion restriction is satisfied if, controlling for placement suitability and cost drivers within the mill's catchment area, suitability for entry around the mill's catchment area affects mill's operation only through its direct impact on competition.

The IV strategy yields a very strong first stage. Second, reduced form results find evidence of a negative relationship between the suitability for mill placement around the mill's catchment area and the use of relational contracts by the mill. Third, IV results confirm the negative impact of competition on the use of relational contracts. A negative impact of competition is found for essentially all individual relational practices. An additional mill within a 10 kilometers radius from the mill reduces the overall relational contract score by 0.1 standard deviations. This effect is equivalent to a jump up or down of $15 \%$ in the relational contracts ranking for the average mill. The estimates imply that the impact of an additional mill on relational contracts decreases with its distance to the mill and vanishes at approximately 10 kilometers. The IV point estimates are, in absolute value, larger than the OLS estimates, possibly due to omitted factors driving both entry and ability to sustain relational contracts (or to measurement error). Competition negatively impacts measures of the "overall" quality of the relationship between the mills and the farmers, measured through World Value canonical survey questions on trust. ${ }^{5}$

When competition leads to the breakdown of relationships, the model predicts a number of additional effects. These are tested in Section 5. The section explores the effects of competition on mill's and farmer's outcomes. As predicted by the model, the breakdown of relationships is associated with worse outcomes at the mill level. Mills suffer lower and more irregular capacity utilization. This leads to an increase in the

\footnotetext{
${ }^{5}$ We explore the robustness of the IV findings through a number of robustness checks, including: i) alternative definitions of the catchment areas size (both defined exogenously or using individual mill specific information), ii) alternative strategies to construct the IV (including using individual score components to run over-identification tests), iii) alternative measures of competition, including aggregate capacity installed and distance to nearby mills.
} 
processing cost to produce one unit of output, driven by labour costs. ${ }^{6}$

The model predicts an ambiguous effect on farmers welfare. If anything, we find a negative impact of competition on farmers' outcomes. Due to lack of appropriate saving technology, farmers process parts of the coffee harvest at home unless they can receive sizeable post-harvest payments from the mills as part of the relational contract. Consistent with this mechanism, competition reduces farmer's share of cherries sold to mills and increases the likelihood of reporting that home processing is used to have cash when needed at the end of the season. Competition instead, doesn't increase prices received by farmers, nor aggregate use of inputs (though farmers pay a higher share) or yields. An overall index of farmers' job satisfaction is reduced by competition. We also detect moderate negative impacts on coffee quality originating from farmer's reduced effort/lack of inputs (rather than mill processing). The evidence rejects the hypothesis that competition reduces farmers' demand for the bundle of services exchanged through relational contracts. Finally, Section 6 discusses additional placebo tests and Section 7 offers concluding remarks and policy implications. ${ }^{7}$

Besides its relationship with the management literature described above, this paper contributes to the literature on contractual relationships between firms in developing countries. $^{8}$ The paper shares with McMillan and Woodruff (1999), Banerjee and Duflo (2000), Macchiavello and Morjaria (2013) and emphasis on relational contracts. McMillan and Woodruff (1999) and Banerjee and Duflo (2000) also rely on cross-sectional survey evidence, but do not consider the importance of competition. Macchiavello and Morjaria (2013) infer the importance of relational contracts exploiting detailed transaction level data and a negative shock in the value chain of cut-flower exports. Fafchamps $(2000,2004,2006)$ has documented the importance of informal relationships between firms in Africa and elsewhere. ${ }^{9}$ The paper also contributes to a rich literature on interlinked transactions in agricultural value chains in developing countries. Bardhan (1989), Ray and Sengupta (1991), Mukherjee and Ray (1995), Ghosh et al.

\footnotetext{
${ }^{6}$ This occurs despite aggregate excess supply of cherries in most localities (also further illustrated by two-thirds of Rwandan coffee being exported as low value which is not being processed by the mills). Higher labour costs arise from irregular supply of coffee cherries and adjustment costs in the amount of labour employed by the mill and are not due to direct competition for workers.

${ }^{7}$ The cross sectional nature of the identification strategy raises concerns if, holding conditions at the mill placement site constant, better managed mills strategically are placed in areas with less suitable neighboring environments. Evidence from manager's characteristics, the order of entry in the industry, and entry that occurred after our survey in 2013 and 2014 support the validity of our identification strategy.

${ }^{8}$ Gil and Zanarone (2014) provide an excellent review of empirical work on relational contracts.

${ }^{9}$ Banerjee and Munshi (2004), Andrabi et al. (2006), Munshi (2010) and Macchiavello (2010) are examples of studies on contractual relationships in a development context, but with rather different focuses.
} 
(2000) and Kranton and Swamy (2008) provide early theoretical analysis. A nascent empirical literature is investigating interlinked transactions involving firms. Blouin and Macchiavello (2013) analyzes interlinked contracts between foreign buyers and exporting coffee mills using loans and contract level data from a specialized international lender. Casaburi and Macchiavello (2014) conduct a number of experiments to study the implications of farmers' demand for delayed payments on contractual arrangements and market structure. Casaburi and Reed (2013) study interlinked transactions between smaller traders and farmers while Ghani and Reed (2014) study the effect of the entry of additional ice suppliers on the relationships between small ice distributors and fishermen. In both cases, competition appears to be associated with an increase in the amount of credit intermediated along the supply chain. ${ }^{10}$

\section{Industry Description}

\subsection{Industry Background and Data Sources}

\section{Coffee Processing}

The life of the coffee we consume starts as a cherry (similar in size to cranberries), the coffee cherry is the fruit of the coffee tree. The cherries are ripe when they change color from green to red, at which point they should be harvested. The harvest season typically lasts for three to four months. The timing of the harvest season varies by country and, within country, by region depending on altitude, soil and rainfall patterns. Coffee cherries are picked by hand, a labor intensive process that requires significant care and effort. Coffee cherries, even from the same coffee tree, do not get ripen for harvest all at once. While less laborious, harvesting cherries all at once compromises quality.

The pulp of the coffee cherry is removed leaving the seed or bean which is then dried to obtain parchment coffee. There are two processing methods to obtain parchment coffee: the dry method and the wet method. In the dry method cherries are cleaned using rocks and then dried on mats. This process is done by the farmers at home. In the wet method, instead, cherries are brought at the mill within few hours of harvest (less than 5 hours) otherwise the cherries start to fermentate and rot. The wet method requires specific equipment and substantial quantities of water. After the cherry skin and some of the pulp are removed with a pressing machine, cherries are then sorted by

\footnotetext{
${ }^{10}$ Porto et al. (2011) survey a rich policy oriented literature documenting how episodes of market liberalization have compromised efficiency in export oriented agricultural chains. Little and Watts (1994) offers a review of contract farming from a development studies perspective.
} 
immersion in water. The bean is then left to ferment, typically for around 30 hours, to remove the remaining skin. The fermentation process has to be carefully monitored to prevent the coffee from acquiring undesirable flavors. When the fermentation is complete, the coffee is thoroughly washed with clean water. The beans are then spread out on tables and frequently turned by hand until completely and uniformly dry. ${ }^{11}$

The processing method has a significant effect on the flavor of coffee once roasted and brewed. The wet method delivers higher consistency and quality which is reflected in prices. Wet method processed coffee (known as fully washed coffee) is sold at a substantial price premium (around 40\%) relative to dry processed coffee both as parchment and as green coffee at the export gate. ${ }^{12}$

\section{Coffee Mills in Rwanda}

Coffee has been an important contributor to Rwanda's economy for several decades. Coffee became widespread in the late 1930s following five waves of mandatory coffeetree planting imposed by the Belgian colonial administration in an attempt to increase revenue collection from its Rwanda-Urundi colonies (see, e.g., Blouin (2014)). At independence, in 1962, coffee represented $55 \%$ of Rwanda's exports against minerals $(37 \%)$, pyrethrum $(3 \%)$ and tea $(2 \%)$. Decline in coffee exports started in the mid 1980s, accelerated with the demise of the International Coffee Agreement in 1989 (and the subsequent collapse of coffee prices in the global market) and reached its peak with the political instability leading to the 1994 genocide. Since the end of the genocide the sector has steadily recovered. At the time of our survey in 2012, there are around 350,000 farmers, mostly small holders, growing coffee in Rwanda and coffee accounted for almost $30 \%$ of exports. The number of mills has increased from only one active in 2001 to more than 200 active during our survey in 2012 (see Figure 1). It is estimated that the coffee sector accounts for between $12 \%$ and $15 \%$ of Rwanda's gross domestic product.

The sector still faces challenges. Total installed capacity in 2012 would have allowed the country to process around $70 \%$ of the harvested coffee. Export data for coffee harvested in 2012 show that only $35 \%$ of the exported coffee volumes was washed, i.e. processed through the mills. In recent years, despite further entry of mills, the number

\footnotetext{
${ }^{11}$ In other countries, beans are spread out in patios and raked. Drying coffee on tables, the only method used in Rwanda, improves quality but increases cost and labor significantly. After the drying process is completed the coffee is hulled at a dry mill before exports by other downstream firms.

${ }^{12} \mathrm{~A}$ decomposition of margins along Rwanda's value chain definitively confirms that, despite the higher processing costs, the wet method creates significantly higher value added along the chain. See Macchiavello and Morjaria (2014) for details.
} 
of operating mills has remained stable. ${ }^{13}$

\section{Data Description}

The empirical analysis combines survey data collected through a census of mills with detailed administrative and extracted and assembled GIS data collected from a number of different sources (see Data Appendix for additional details). The survey was designed by the authors in collaboration with the National Agricultural Exporting Board (NAEB) and was implemented by one of the authors towards the end of the 2012 harvest season, between May and July 2012. The survey covered all mills operating that season. Each survey team was trained by one of the authors and was led by a qualified coffee personnel from NAEB. The mill's manager, the main coffee collector, five randomly selected farmers and four randomly selected workers were interviewed at each mill. The survey covered personal characteristics from all respondents, the main aspects of each respondent's job and relationship with the mill, and a comprehensive overview of the mill's operations including financial and geographic details. Finally, at each mill a representative sample of the mill's output, the coffee parchment was obtained to be physically and chemically analyzed in the coffee board's quality laboratory in Kigali. ${ }^{14}$

The mill survey is matched with administrative data obtained from the coffee board and other agencies. There are three main sets of data. First, we assembled a high resolution (at the 1 square $\mathrm{km}$ spatial unit) GIS database with information on geographic, climatic and infrastructure characteristics for the whole of Rwanda. This is essential to construct environmental controls variables and estimate the engineering model for mill placement. Second, we matched the Rwanda coffee census conducted in 2008/9 with the GIS data. The census covers all farmers in Rwanda (circa. 350,000) and includes farmers' village location. ${ }^{15}$ This provides basic information about trees and production at a highly disaggregated level for places with and without mills.

\footnotetext{
${ }^{13}$ The number of installed [operating] mills has been 199 [190] in 2011, 214 [197] in 2012, 222 [202] in 2013 and 229 [199] in 2014. During this period the volumes and share of fully washed coffee have remained substantially stable.

${ }^{14}$ The response rate was nearly $100 \%$. Due to heavy rain it was not possible to reschedule the survey with just one mill.

${ }^{15}$ Rwanda is administratively divided into 4 provinces, 30 districts, 416 sectors, 2148 cells and 14482 villages. The average village is smaller than 2 square $\mathrm{km}$. This allows us a precise match of the coffee census to the GIS data.
} 


\subsection{The Operation of Mills}

\section{Descriptive Statistics}

Given typical firms size distribution in developing countries (see, e.g., Hsieh and Olken (2014)) coffee mills are large firms. Table 1 reports summary statistics for mills in Rwanda. The average mill employs slightly more than 80 employees and a supplier base of more than 300 small holders farmers. The employment figures leave mills comfortably in the right tail of the firm size distribution in Rwanda (see, e.g., Söderbom and Kamarudeen (2013)).

In 2012 the sector in Rwanda was almost equally split between 111 privately owned mills and 103 cooperatives. Relative to cooperative, private mills tend to be larger, have lower utilization rates, higher unit costs and more professional managers. ${ }^{16}$

Mills in Rwanda differ in terms of capacity size. Capacity can be calculated from three aspects of the capital stock invested in the mill: $i$ ) the number of disks in the pulping machine, $i i$ ) the metric cubic capacity of the water tanks, and iii) the surface area of drying tables. Figure 2 reports seasonal capacity estimates for each mill from administrative records. ${ }^{17}$ There is large dispersion in installed capacity. The smallest mills have estimated capacity of approximately 100 or 150 tons per season. The bulk of the mills are medium sized with capacity of 500 tons per season. A handful of mills have higher capacity.

\section{Relational Contracts in the Industry}

We now turn to a description of the use of relational contracts in the industry. Given the lack of enforceable contracts and the poor functioning of markets in rural areas (including markets for inputs, extension services, credit, savings and insurance) a well-established literature in development economics has documented the prevalence of interlinked transactions in rural settings (see, e.g., Binswanger and Rosenzweig (1986), Bardhan (1989)). Our mill and farmer survey focused on different aspects of these interlinked transactions. We refer to each aspect as a "practice". We distinguish between practices that are relevant pre-harvest season, at harvest season and postharvest season. For each of these practices, we asked both the farmers and the manager about their use at the mill. We refer to the relational contract as the overall set of practices used by the mill and the farmers.

Table 2 presents summary statistics. Before harvest, the mill might have an advan-

\footnotetext{
${ }^{16}$ These differences, however, are largely driven by a less than $20 \%$ of cooperatives assisted by the NGO TechnoServe that operates smaller mills.

${ }^{17}$ We reconstruct capacity figures from the capital census in the survey and obtain similar figures.
} 
tage in providing fertilizers, loans, extension services and other inputs, to the farmers. Approximately $20 \%$ of the farmers report to have received fertilizers from the mill and a similar percentage reports to have received loans. While a higher share of managers report to have provided fertilizers to (some) farmers, the figure for loans is similar. ${ }^{18}$

At harvest time, the main aspect of the relational contract is whether cherries are sold on credit to the mill. First, if farmers lack access to a saving technology, they will prefer part of their revenues from coffee to be paid at a later data. Consistently with this hypothesis, a substantial share of farmers reports that one of the two main advantages of home processing is that it allows to sell output when they need the cash. Second, access to working capital credit to finance the purchase of cherries is one of the main operational constraints faced by mills. Purchasing on credit from farmers potentially reduces mill's financial requirements. Approximately $10 \%$ of the farmers report to have sold cherries on credit while $30 \%$ of the managers report to have purchased some quantity of cherries on credit.

The credit provided by farmers comes in two different ways. First, credit can be very short-term credit, in which case the farmer is paid within a week or so. Second, credit can be implicitly extended to farmers by mills offering a "second payment", typically in the form of a linear bonus depending on volumes sold, at the end of the harvest season. ${ }^{19}$ A relatively high proportions of farmers (70\%) received a second payment at the end of the harvest season. These figures are broadly consistent with what reported by managers: $45 \%$ of mills report to have made second payments in the past. Another way in which mills can deliver help to farmers is by helping them in the case of bulky, or unexpected expenses. Among farmers, $64 \%$ expect to be able to access help from the mill in case of need while $75 \%$ of mills managers report to help farmers with occasional loans for expenses.

Following the predictions of the model, the empirical analysis mainly focuses on the following practices: $i$ ) before harvest, did the farmer receive inputs from the mill?, $i i$ ) at harvest, did the farmer sell on credit?, iii) post harvest, are there second payments made to the farmer? For each of the three aspects, we focus on both the manager and the farmer answers. After standardizing the responses, we construct scores for the intensity of the relationship before, during and after harvest time by taking the average of the responses given by the manager and the farmers. We give equal weight to the

\footnotetext{
${ }^{18}$ Some discrepancy is to be expected, as the mill is asked about all of the farmers that supply to the mill in its catchment area, the farmer on the other hand is asked about these practices with regards to this particular mill.

${ }^{19}$ Second payments are relatively more common among cooperatives. From a legal point of view members own the coop and might receive a second payment in the form of distributed profits.
} 
responses from the manager and the average response from the farmers. While we report OLS and IV results for individual practices and sub-period scores (pre-harvest, harvest and post-harvest), our main variable of interest is an overall "relational" score which includes both these and additional practices. ${ }^{20}$

There is a certain amount of heterogeneity across mills in the use of relational contracts. The overall relational score ranges from -1.22 to +1.35 and, naturally, greater dispersion is observed in individual scores. The pre-harvest, harvest and postharvest score are also positively correlated with each other as displayed in Figure 3. The correlation is stronger between pre-harvest and post-harvest, and slightly weaker with the harvest score.

\section{Dispersion in Unit Costs and Capacity Utilization of Mills}

Mills are characterized by a relatively simple technology. It takes approximately $5.50 \mathrm{kgs}$ of coffee cherries to produce $1 \mathrm{Kg}$ of parchment coffee. ${ }^{21}$ We shall follow industry practices and benchmark the relative efficiency of mills focusing on the costs of producing $1 \mathrm{Kg}$ of parchment (unit costs). The direct costs of purchasing coffee cherries typically accounts for approximately $60 \%$ to $70 \%$ of unit costs. By working through the mills accounts at the end of the season together with the mill managers, we obtained accurate measures of unit costs and their breakdown across components. For descriptive purposes we decompose unit costs of mill $i$ as follows:

$$
U C_{i}=\left(P_{i}^{k g} \times C R_{i}\right)+O C_{i}
$$

where $U C_{i}$ are the unit costs, $P_{i}^{k g}$ is an average price per kilogram of cherries paid by the mill (including estimates for second payments), $C R_{i}$ is the conversion ratio at the mill and $O C_{i}$ are other costs, mainly labour, finance, transport and procurement. ${ }^{22}$

Appendix Figure 1 and Appendix Table 1 document the dispersion in unit costs across mills and its components. Appendix Figure 1 shows that a significant proportion of the dispersion in unit costs is explained by differences in geographic characteristics of the area in which the mill operates (suitability for coffee, availability of trees, elevation, slope, etc.) and by installed capacity. After purging the data from differences in costs driven by these factors, the figure still displays significant dispersion in unit costs (the $90 / 10$ percentile ratio is equal to 1.5$)$.

\footnotetext{
${ }^{20}$ Results are also robust to including a larger set of relational contract measures (unreported).

${ }^{21}$ The exact conversion ratio depends by coffee variety and other geographical factors affecting the organic properties of coffee.

${ }^{22}$ Labour, transport and procurement costs are easy to compute from the accounts. As usual, capital costs require additional assumptions.
} 
Appendix Table 1 decomposes unit costs. As expected, there is no dispersion in the conversion ratio $C R_{i}(90 / 10$ ratio is lower than 1.1$)$. There is more dispersion in the prices paid to farmers (90/10 ratio equal to 1.32 ). The bulk of the dispersion, therefore, originates in the components of unit costs which are more directly influenced by management: labour, capital, procurement and logistic. Here we find a 90/10 ratio equal to 2.32 .

Capacity utilization is an important correlate of unit costs. As a summary statistic, we measure utilization as the total amount (in tons) of cherries processed during the harvest season divided by the total capacity installed. ${ }^{23}$ Consistently with Appendix Table 1, Figure 4 documents significant dispersion in utilization rates during the 2012 harvest season. Leaving aside inactive mills (those that had zero capacity utilization, and hence did not process any cherries), the median mill has a capacity utilization around $50 \% .^{24}$

Figure 5 shows that, conditional on a host of geographic characteristics and mill controls, the relational contracts score, capacity utilization and unit costs are correlated with each other. Prima facie, the measure of relational contracts captures aspects of managerial practices appropriate in this industry.

\section{Theory}

This section lays out a simple theoretical framework to illustrate the main forces at work in the empirical context we examine. First, we present the set up of the model. Besides describing preferences and technology, we illustrate interlinked transactions between mills and farmers when contracts are perfectly enforceable. We then study the contractual outcomes between the mill and the farmers under different scenarios. First we examine a monopolist mill that can only rely on spot transactions with the farmers. We then explore the rationale for and the conditions under which relational contracts between the monopolist mill and the farmers in the surrounding areas are feasible. We then introduce competition from another mills. While the impact of competition on the mill's costs is shown to be unambiguously negative, the exact mechanisms at work and the final impact on prices paid to farmers depend on parameters. We conclude

\footnotetext{
${ }^{23}$ The mill seasonal theoretical capacity is computed assuming a certain length of the season. While we do not have mill downtime, we are computing alternative measures of capacity utilization using weekly tons of cherries purchases from the mills. Preliminary results confirm the simpler analysis reported here.

${ }^{24}$ Capacity under-utilization is not driven by lack of available cherries to process. Highly disaggregated estimates of local production derived from the coffee census suggest that the majority of localities have installed capacity lower than potential local production.
} 
the section discussing extensions and alternative frameworks.

\section{$3.1 \quad$ Set-Up}

A mill operates in an area populated by a unit mass of identical farmers, indexed $i \in[0,1]$. Each farmer produces a quantity of coffee cherries $q$. Time is represented by an infinite sequence of seasons, indexed $t=0,1,2 \ldots, \infty$. Within each season, there are three subperiods, corresponding to pre-harvest (sub-indexed by 0 ), harvest (subindexed by 1) and post-harvest (sub-indexed by 2). The quantity $q$ becomes available at harvest. Farmers derive utility from consumption at harvest, $c_{1}$, and post-harvest, $c_{2}$, with preferences given by $\min \left\{c_{1}, c_{2}\right\}$. These preferences capture in a parsimonious way farmers' demand for within-season consumption smoothing. ${ }^{25}$ The mill is risk neutral and only cares about expected (discounted) profits. All parties have a discount factor $\delta<1$ across seasons while, for simplicity, there is no discount within season.

Coffee cherries $q$ must be processed immediately after harvest. Once processed, cherries can be stored up to the following post-harvest period. Two technologies are available: home processing and wet processing. Both technologies yield one unit of output for each unit of cherries. Home processing is performed by the farmer at home and, for simplicity, we assume this process has no additional cost. The farmer can sell home processed coffee at an exogenous price $\rho$ at harvest and post-harvest. Denote by $q_{\rho 1}$ and $q_{\rho 2}$ the quantities the farmer sell on the home processed market at harvest and post-harvest time respectively. Wet processing requires cherries to be given to the mill immediately at harvest time. Let us denote with $q_{m}(i)$ the quantity sourced by the mill from each farmer $i$. The aggregate quantity sourced by the mill is then given by $Q=\int_{0}^{1} q_{m}(i) d i$. The mill has en exogenously given installed capacity, C. The mill incurs additional processing unit costs, such as transport, labour, etc., denoted $c(Q)>0$. The mill is a price taker in the downstream and in other input (e.g., capital, labour) markets. We assume $c^{\prime}(Q) \leq 0$ provided the mills operates below capacity, $\mathbf{C}$, i.e., $Q \leq \mathbf{C}$, and $c(q)=\infty$ otherwise. Relative to home processing, wet processing increases the value of output in the downstream market. Each unit of output sold by the mill yields $v>\rho$.

Finally, during pre-harvest season, the mill and the farmer can undertake specific investments to enhance production. Specifically, the mill can extend inputs (such as training, fertilizers, loans) to the farmers at cost $\kappa$ per farmer. If the farmer exerts

\footnotetext{
${ }^{25}$ Provided preferences display a demand for consumption smoothing within season, the specific functional form of the utility function can be relaxed at the cost of slightly more tedious algebra without altering the main insight of the analysis.
} 
effort, at personal costs $e$, to use the inputs provided by the mill correctly, the quality of wet-processed coffee is increased and its value enhanced by a factor $\lambda$. We make the following assumption on the parameters:

\section{Assumption 1: $2 \frac{\kappa+e}{\lambda q}>v>\max \left\{\rho+c(0), \frac{\kappa+e}{\lambda q}\right\}$.}

The assumption $v>\rho+c(0)$ guarantees that wet processing is efficient. The assumption $v>\frac{\kappa+e}{\lambda q}$ guarantees that the mill and the farmers' investments during pre-harvest are efficient. The assumption $2 \frac{\kappa+e}{\lambda q}>v$ simplifies exposition by reducing the number of cases to be considered, without substantially altering the results.

\subsection{Benchmark Case: Perfect Contract Enforcement}

We begin by considering the case of perfect contract enforcement. When contracts are perfectly enforceable, parties can commit to promises and effort decisions are contractible. For simplicity, let us assume that at the beginning of each pre-harvest season the mill makes a take-it-or-leave-it offer to every single farmer $i$. Specifically, the mill offers a contract $\mathcal{C}^{i}=\left\{\mathbf{I}_{k}^{i}, \mathbf{I}_{e}^{i}, q_{m}^{i}, P_{1}^{i}, P_{2}^{i}\right\}$ specifying whether farmer $i$ receives inputs or not, $\mathbf{I}_{k}^{i} \in\{0,1\}$, whether farmer $i$ must exert effort, $\mathbf{I}_{e}^{i} \in\{0,1\}$, the quantity to be sold by farmer $i$ to the mill at harvest, $q_{m}^{i}$, as well as payments from the mill to farmer $i$ at harvest, $P_{1}^{i}$, and post harvest, $P_{2}^{i}$ - the so called "second payment". ${ }^{26}$ Each farmer $i$ independently decides whether to accept or reject the contract. If the farmer reject the contracts, she harvests quantity $q$, process it at home, and sell it on the market at harvest and post-harvest time to maximize her utility. Denote the value of this choice by $u^{i}$. If the farmer accepts, all elements of the contract must then be respected by all parties. Denote by $u_{\mathcal{C}}^{i}$ the utility of farmer $i$ from accepting a contract $\mathcal{C}$. Let us focus on a symmetric solution in which all farmers are offered the same contract $\mathcal{C}^{i}$. The mill offers the contract that maximizes profits subject to the feasibility constraint and the farmers' participation constraints, i.e.,

$$
\begin{gathered}
\max _{\mathbf{I}_{k}, \mathbf{I}_{e}, q_{m}, P_{1}, P_{2}}\left(\left(1+\lambda \mathbf{I}_{k} \mathbf{I}_{e}\right) v-c\left(q_{m}\right)\right) q_{m}-\left(P_{1}+P_{2}\right)-\mathbf{I}_{k} \kappa \\
\text { s.t. } u_{\mathcal{C}} \geq \quad u \text { and } q_{m} \leq q .
\end{gathered}
$$

\footnotetext{
${ }^{26}$ While the analysis under the benchmark case of perfect contracting is straightforward, an appropriate definition of the contract terms is useful to compare outcomes across scenarios and to match the predictions of the model to the measurement of interlinked transactions in the empirical analysis.
} 
First, let's derive the farmer's outside option $u$. A farmer that process at home the entire produce $q$ sells on the market $q_{\rho 1}$ at harvest and stores $q_{\rho 2}$ until post harvest to maximize her utility. Given assumptions, the farmer sells half of her produce at harvest and half at post harvest, i.e., $q_{\rho 1}=q_{\rho 2}=q / 2$, obtaining utility $\min \left\{c_{1}, c_{2}\right\}=\rho q / 2$. Second, the farmer's participation constraint must be binding. By assumption 1, i) the feasibility constraint must also be binding at the optimum, i.e., $q_{m}=q$, and $i i$ ) the optimal contract specifies that the mill pays the cost $\kappa$, i.e., $\mathbf{I}_{k}=1$, and that the farmer exerts effort $e$, i.e., $\mathbf{I}_{e}=1$. Finally, the cheapest way for the mill to satisfy the farmer's participation constraint is to equate farmer's consumption in the harvest and post-harvest seasons. Given $q_{m}=q$, the firm must set $P_{1}=P_{2}=P$ such that $P-e=\rho q / 2$. In sum,

Observation 1: Under perfect contract enforcement 1) the mill provides inputs to all farmers, 2) all farmers exert effort resulting in high quality, 3) farmers only sell to the mill, 4) the mill pays both a spot price and a second payment, 5) the net present value of the price paid by the mill and the second payment is larger than what farmers obtain in the market, 6) the mill's unit costs of processing cherries are lowest given local growing and operating conditions.

\subsection{Monopoly Mill under Spot Market Transactions}

We now turn to the case in which formal contracts between the mill and the farmers are not enforceable. As is well known, when this is the case, the mill and the farmers might rely on a relational contract in order to sustain efficient trade. Before turning to the analysis of the repeated relationship, however, it is instructive to consider the case in which the mill and the farmers only rely on spot transactions, i.e., contracts are enforced only within a subperiod. The timing of events is now as follows. First, the mill sets $\mathbf{I}_{k}$ deciding whether to pay $\kappa$. Then the farmer decides whether to exert effort, $\mathbf{I}_{e}$. Then harvest is realized. The mill posts a unit price for the harvest season, $p_{1}$, and promises an additional second payment, $P_{2}$, for the post-harvest season. ${ }^{27}$ Given the posted prices and her beliefs, the farmer decides how much to sell to the mill and how much to process at home (and, if any quantity is processed at home, when to sell it).

\footnotetext{
${ }^{27}$ We abstract from the potential hold-up problem implied by the perishability of the cherries. Cherries are typically brought to the mill gate or purchased at collection sites, rather than collected at the farmer's gate. The mill collector could hold-up the farmer and renegotiate price downward. Modeling this additional friction would only strengthen the logic of our results. Note also that in this simple environment there is no loss in generality in assuming the mill posts unit prices rather than non-linear price schedules.
} 
At post-harvest time, the mill decides whether to pay the second transfer promised to the farmer, if any.

The model has to be solved by backward induction. In the absence of a future relationship, the mill always defaults on any payment promised for post-harvest. The farmer, therefore, doesn't believe any promise of second payment and bases her decision entirely on the posted price at harvest time. Suppose the mill has posted a price $p_{1}$ at harvest time. Given $p_{1}$, farmers decide how much to supply to the mill. The farmer equates consumption at harvest, $c_{1}=p_{1} q_{m}+\rho q_{\rho 1}$, with post-harvest consumption, $c_{2}=\left(q-q_{m}-q_{\rho 1}\right) \rho$ subject to the constraint $q_{m}+q_{\rho 1}+q_{\rho 1} \leq q$. The farmer's supply curve is then given by

$$
q_{m}\left(p_{1}\right)=\left\{\begin{array}{lr}
0 & \text { if } p_{m} \leq \rho \\
\frac{\rho}{p_{1}+\rho} q & \text { otherwise }
\end{array} .28\right.
$$

The mill, taking as given the supply curve of each farmer, sets $p_{1}$ to maximize profits. The mill's problem is given by

$$
\begin{array}{r}
\max _{p_{1}}\left(\left(1+\lambda \mathbf{I}_{k} \mathbf{I}_{e}\right) v-c\left(Q\left(p_{1}\right)\right)-p_{1}\right) Q\left(p_{1}\right) \\
\text { s.t., } q_{m}=q_{m}\left(p_{1}\right) \text { for each farmer } i \text { and } Q\left(p_{1}\right) \leq \mathbf{C} .
\end{array}
$$

Given $c^{\prime}(\cdot) \leq 0$, the mill optimal solution is to set $p_{1}=\rho$ and source as many cherries as possible from each farmer, i.e., $q_{m}=q / 2$. Finally, the price posted by the mill and the farmer's sales decision at harvest are independent of the value of the cherries. As a result, the farmer has no incentive to exert effort, i.e., $\mathbf{I}_{e}=0$, and, consequently, the mill offers no input during the pre-harvest season, i.e., $\mathbf{I}_{k}$. In sum,

Observation 2: Under spot transactions 1) the mill does not provide inputs to the farmers, 2) farmers do not exert effort to enhance quality, 3) farmers sell only a fraction of their produce to the mill, 4) the mill does not pay any second payment, 5) the net present value of the price paid by the mill and the second payment is larger than what farmers obtain in the market, 6) the mill's unit costs of processing cherries are higher than under full contract enforcement.

\footnotetext{
${ }^{28}$ Note that for $p_{1} \geq \rho$ the farmer supply curve to the mill is decreasing in the price offered by the mill $p_{1}$. The extreme complementarity assumed in the farmers' preferences implies that the income effect always dominates the substitution effect. While this specific property of the farmer's supply curve can be overturned by assuming less extreme demand for savings, the intuition for the main results remains valid provided there is some demand for saving the farmers satisfy by engaging in home processing.
} 


\subsection{Relational Contracts with a Monopoly Mill}

We now consider (symmetric) relational contracts between the mill and the farmers. When contracts are not enforceable, the relationship between the mill and the farmer faces a two-sided moral hazard problem. First, the farmer must be incentivized to exert effort. Second, the station must be incentivized to keep promises of second payments. A relational contract is a plan $\mathcal{C}^{R}=\left\{\mathbf{I}_{k}^{t}, \mathbf{I}_{e}^{t}, q_{m}^{t}, P_{1}^{t}, P_{2}^{t}\right\}_{t=0,1, \ldots}^{\infty}$ that specifies investment and effort decisions, $\mathbf{I}_{k}^{t}$ and $\mathbf{I}_{e}^{t}$, quantities to be delivered at harvest, $q_{m}^{t}$, and payments at harvest and post-harvest, $P_{1}^{t}$ and $P_{2}^{t}$, for all future seasons. Parties agree to break up the relationship and obtain their outside options forever following any deviation. We are interested in deriving conditions under which a stationary relational contract in which $i$ ) in the pre-harvest season both the mill and the farmer invest, i.e., $\mathbf{I}_{k}^{t}=1$ and $\left.\mathbf{I}_{e}^{t}=1, i i\right)$ farmers sell a quantity $q_{m}$ to the mill, and iii) the mill make payments $P_{1}$ and $P_{2}$ at harvest and post-harvest seasons to each farmer, can be sustained. We assume that if either $a$ farmer (by, e.g., selling a quantity lower than $q_{m}^{t}$ and/or not exerting effort) or the mill (by, e.g., defaulting on the agreed second payment $P_{2}$ to any farmer) renege on any contract, both parties revert back to trading using spot transactions forever. ${ }^{29}$

Let us denote the seasonal profits of the mill along the stationary equilibrium by $\pi_{r}$. Denote with $\pi_{s}$ the profits of the mill under spot transactions. The incentive compatibility constraint of the mill is given by

$$
\frac{\delta}{1-\delta}\left[\pi_{r}-\pi_{s}\right] \geq P_{2}
$$

Denoting with $u_{r}$ the monetary utility of the farmer along the stationary equilibrium and by $u_{s}$ the monetary utility of the farmer following a defection, the farmer exerts effort if

$$
u_{r}-u_{s} \geq e
$$

and sell the stipulated quantity to the mill if

$$
u_{r} \geq u_{s} .
$$

\footnotetext{
${ }^{29}$ Although the assumption that all farmers punish the mill following a deviation against any farmer can be relaxed, with a continuum of farmers, individual relational contracts in which punishment is carried out only by the farmer who was cheated on might not exist. Indeed, an important advantage of large organizations is precisely the greater reputation enabled by collective punishment, see, Ghatak et al. (2014) for a model and Casaburi and Macchiavello (2014) for an empirical illustration. Levin (2002) provides an analysis of multilateral relational contracts with a finite number of agents.
} 
The mill offers a relational contract to maximize profits subject to the three incentive constraints above. First, notice that constraint (7) is implied by (6). Second, at the mill's optimum, it has to be that (6) binds. Third, as derived in the previous section, $u_{s}=\rho q / 2$, and, therefore, $\pi_{s}=\frac{q}{2}\left(v-\rho-c\left(\frac{q}{2}\right)\right)$. Fourth, the cheapest way for the mill to achieve a certain level of utility for the farmer is to equalize farmer's consumption at each harvest and post-harvest. Along the equilibrium path we must have $P_{1}+\rho q_{\rho_{1}}=P_{2}+\rho q_{\rho 2}=\mathbf{P}$. Denoting with $q_{r}$ the quantity sold to the mill, constraint (6) implies that $\mathbf{P} \geq \rho q / 2+e$. Substituting the constraint (6) into the the mill's incentive compatibility constraint (5), the problem of the mill is to source the maximum quantity $q_{r}$ subject to

$$
\frac{\delta}{1-\delta}\left[(1+\lambda) v q_{r}-c\left(q_{r}\right)-e-\kappa-(v q / 2-c(q / 2))\right] \geq P_{2} .
$$

Note that, for any $q_{r}<q$ the mill has an incentive to reduce $P_{2}$ to a minimum in order to relax the incentive constraint. A necessary condition for this is for the farmer to only sell the residual quantity equal to $q-q_{r}$ in the post-harvest season. That is, in equilibrium, the farmer never sells to the market during harvest time. The constraint can therefore be rewritten as $P_{1}=P_{2}+\rho\left(q-q_{r}\right)$ and, using (6), we obtain $P_{2}=\rho\left(q_{r}-q / 2\right)+e$. It is then easy to show that, if any relational contract can be sustained at all, it must have $q_{r}=q \cdot{ }^{30}$ In sum,

Observation 3: There exists a critical threshold $\delta_{r}<1$ such that if $\delta \geq \delta_{r}$ a relational contract between the mill and the farmer is sustainable. The relational contract than achieves the efficient outcome and transactions occur as described in the perfect contract enforcement case.

\subsection{Relational Contracts Under Competition}

We now consider the case in which a competing mill locates nearby the existing monopolist and can, potentially, try to source cherries from the same farmers at harvest season. We assume this new mill competes only by offering spot transactions in a particular season. ${ }^{31}$ As usual, some of the results in this type of models depend on

\footnotetext{
${ }^{30}$ For suppose that there exists a $\widetilde{q}_{r} \in(q / 2, q)$ such that constraint (8) is satisfied. The first part of assumption 1 guarantees that the slope of the left hand side of the constraint must be steeper than the slope of the right hand side for $\widetilde{q}_{r}$ to exist. A contradiction. Note that the assumption can be relaxed just at the cost of keeping track of an additional case with interior solution, without gaining much further insight.

${ }^{31}$ The logic of the results is strengthened if farmers believe the new mill to compete through spot transactions in future seasons as well. The assumption allows a more concise exposition.
} 
the exact way in which the competition protocol is specified (see, e.g., Tirole (1998)). Rather than focusing on a specific protocol and fully characterize the resulting equilibrium, let us simply focus on deriving conditions under which the threat of competition makes any relational contract between the mill and the farmers unsustainable. Denote with $\mathbf{p}_{0}$ the highest price the competing mill is willing to pay in a spot transaction. If the farmer accepts the offer, she would need to sell $\mathbf{q}_{0}$ to the competing mill and set $\mathbf{p}_{0} \mathbf{q}_{0}=\left(q-\mathbf{q}_{0}\right) \rho$.

Depending on $\mathbf{p}_{0}$, there are two cases, depending on whether it is more costly to induce the farmer to exert effort or to prevent side-selling. For competition to alter the conditions under which a relational contract is sustainable, it has to be that the side-selling constraint is harder to satisfy (see footnote below). The no side-selling constraint for the farmer is given by

$$
P_{r}+\frac{\delta}{1-\delta} u_{r} \geq \frac{q \rho \mathbf{p}_{0}}{\left(\mathbf{p}_{0}+\rho\right)}+\frac{\delta}{1-\delta} u_{s}
$$

The mill will offer a relational contract in which (9) binds. Substituting for the corresponding values of $u_{r}$ and $u_{s}$ the binding constraint gives the minimum transfer the mill must pay to prevent competition. This is given by, $P_{r} \geq(1-\delta) \frac{q \rho \mathbf{p}_{0}}{\left(\mathbf{p}_{0}+\rho\right)}+$ $\delta(\rho q / 2+e) .{ }^{32}$ We can, therefore, rewrite the incentive constraint of the mill as

$$
\frac{\delta}{1-\delta}\left[(1+\lambda) v q_{r}^{c}-c\left(q_{r}^{c}\right)-e-\kappa-(v q / 2-c(q / 2))\right] \geq P_{2}^{c} .
$$

The mill incentive compatibility constraint under competition (10) is harder to satisfy than (8). This implies that there exists a threshold $\delta_{c} \in\left(\delta_{r}, 1\right)$ such that if $\delta<\delta_{c}$ either no relational contract can be satisfied at all, or the relational contract offered by the mill has a quantity $q_{r}^{c}$ lower than optimal.

When the mill cannot offer a sustainable relational contract, the two mills compete using spot transactions. To avoid a lengthy characterization of the resulting equilibrium (which depends on the exact specification of the competition protocol), we confine ourselves to an informal discussion of the market outcomes when firms compete in spot transactions. First, since the mills are not able to offer a relational contract, there is no market price at which the farmer sells all the production at harvest. This is because

\footnotetext{
${ }^{32}$ Recall the incentive constraint to induce effort is given by $P_{r} \geq(\rho q / 2+e)$. For (9) to be the binding constraint, we must have $\mathbf{p}_{0} \geq \underline{\mathbf{p}}_{0}=\rho \frac{(\rho q / 2+e)}{(q \rho / 2-e)}$. Note, however, that $\underline{\mathbf{p}}_{0}$ can be smaller than $(1+\lambda) v-c(q / 2)$. In other words, competition can bite on the relational contract even if the competing mill's willingness to pay is lower than the one of the mill offering the relational contract (e.g., because of transport costs).
} 
the farmer has a demand for post-harvest income that spot market competition, no matter how intense, simply cannot meet. Hence, quantity sold at harvest, aggregate capacity utilization and mill efficiency must be lower than under a relational monopoly.

Second, the effects of competition on observed prices is ambiguous. On the one hand, competition between the mills implies a tendency for prices to increase. This is true both when the relational contract is sustainable (and competition simply increases the outside option of the farmer), as well as when competition destroys the relationship. On the other hand, note that when the relationship is destroyed, mills and, therefore, farmers will no longer have incentives to invest in pre-harvest inputs and effort. Since prices under monopoly compensate farmers for the effort, observed prices at harvest might fall as a result of competition. ${ }^{33}$ In sum,

Observation 4: There exists a critical threshold $\delta_{c} \in\left(\delta_{r}, 1\right)$ such that if $\delta \in$ $\left(\delta_{c}, \delta_{r}\right)$ a relational contract between the mill and the farmer is sustainable under monopoly but is not sustainable under competition. When this happens, competition destroys interlinked transactions between the mill and the farmer: 1) the mill doesn't provide inputs, 2) farmers do not exert effort to enhance quality, 3) farmers sell only a fraction of their produce to the mill (and aggregate capacity utilization decreases), 4) the mill does not pay any second payment, 5) the net present value of the price paid by the mill and the second payment might be lower than what farmers obtain in the market, 6) the mill's unit costs of processing cherries are higher than under a monopolist.

\subsection{Extensions and Discussion}

The framework developed above, while highly stylized, captures the essential features of the market and illustrates the key mechanisms at work. We now discuss a number of extensions that would enrich the framework, without altering the main conclusions. First, we have abstracted from spatial heterogeneity and transport costs. The framework can easily be extended to accommodate them. When this is the case, a catchment area is endogenously defined. Under monopoly, the mill would be able to sustain relational contracts with farmers nearby, since transport costs are lower. With farmers far away, the mill might be able to only engage in spot market transactions. An increase in competition can be modeled as a reduction in the distance between two mills. This would contract the region in which the mill is able to sustain relational contracts.

\footnotetext{
${ }^{33}$ We discuss below the implications for farmers' welfare.
} 
Introducing spatial heterogeneity would also open the door to a richer, and more nuanced, analysis of the impact of competition on farmers' welfare. In the model above, farmers earn no rent under both spot market transactions and relational contracts (in both cases the participation constraint binds). Farmers, therefore, can only weakly benefit from competition: even when it destroys relationships with the mill, competition might increase prices received by farmers in a spot market. Under spatial heterogeneity, if the mill cannot (perfectly) discriminate the relational contracts offered to farmers in different locations, only the participation constraint of the marginal farmer binds. Inframarginal farmers earn rents from the relational contract. When this is the case, competition can actually reduce the welfare of (some) farmers. ${ }^{34}$

An extension closely related to spatial competition would focus on search costs. As is well known, in models of search there is a tendency towards inefficient entry: the marginal entrant does not take into account the externality imposed on competitors who spend resources to visit farmers that have already sold to other buyers. Search costs could provide a micro-foundation for decreasing unit costs of processing/procurement. The inefficiency associated with search frictions, however, can be eliminated in models of competitive search. In these models mills post (and commit to) prices and farmers direct their search towards mills accordingly. We do not have systematic evidence on whether mills commit to posted prices or, instead, frequently renegotiate prices downwards once the farmer has brought cherries to the collection centre. In the empirical analysis we do not find a strong effect of competition on transport and procurement costs and, therefore, abstract from this channel in the model. ${ }^{35}$

It is well known, see e.g., Mankiw and Whinston (1986), that in industries with large fixed capital costs and business stealing effects there is a tendency towards excessive entry. ${ }^{36}$. While Mankiw and Whinston (1986) focus on oligopolistic competition between sellers, it is straightforward to recast their analysis in terms of oligopolistic buyers competing for inputs. Differentiation, which in our context naturally arises both from spatial competition as well as from relational contracting, mitigates the

\footnotetext{
${ }^{34}$ We believe the assumption that mills cannot perfectly price discriminate across farmers to be empirically relevant case, certainly at the level of spatial disaggregation at which we conduct the empirical analysis.

${ }^{35}$ We conjecture that hold-up from the mills is not a first order concern. The harvest season lasts several weeks and a mill might find it difficult to source cherries in later weeks if it holds-up farmers earlier on in the season. While temptations to hold-up increase closer to the end of the harvest, stations operating below capacity might be in a hurry to secure sufficient supply, i.e., the cost of a bargaining break down also increase.

${ }^{36} \mathrm{~A}$ recent literature in this area investigates the possibility that market entry may be socially inefficient by using the current structure of the U.S. real estate brokerage, see for instance, Hsieh and Moretti (2003)
} 
tendency towards excessive entry in the industry. In this sense, we point out that entry per se affects the degree of differentiation. ${ }^{37}$

Finally, we have also abstracted from mills' credit/liquidity constraints. Evidence collected through our survey suggests that at least $60 \%$ of the mills operating in 2012 were credit constrained. Credit constraints exacerbate the mechanisms highlighted in the model. Under relational contracting, the mill can pay part of the costs of sourcing cherries post-harvest, once sales have been realized. When relational contracting with the farmers breaks down, the mill has to pay the entire costs of sourcing cherries upfront. These funds must be borrowed, and a credit constrained mill might not be able to obtain the necessary liquidity. Credit constraints might also limit the impact of competition on spot market prices, as bidding for higher prices is more costly. Finally, competition might reduce the profits of the mill even when it doesn't destroy relational contracting with farmers. If retained earning from past profits allow firms to reduce borrowing requirements, the negative effects of competition might operate dynamically through this additional channel.

\subsection{Summary of Predictions}

We conclude this section summarizing the main empirical predictions. The entry of an additional mill in the market might:

1. Reduce the amount of interlinked transactions between the mill and the farmers and, more generally, worsen the relationships between the mill and the farmers,

2. Reduce capacity utilization and increase the processing unit cost of the mill,

3. Fail to increase prices paid to farmers,

4. The increase in processing unit costs of the mills could stem from increases in one or more of the following: i) procurement, transport costs, ii) labour costs, iii) finance costs.

\footnotetext{
${ }^{37}$ Unless mills perfectly collude, in which case the aggregate quantity of cherries sourced doesn't increase with additional entry, the Mankiw and Whinston (1986) framework implies prices paid to farmers increase even when an additional entrant lowers social surplus. In the empirical analysis we fail to find support for this prediction, suggesting that additional mechanisms to those in Mankiw and Whinston (1986) are at play in our context.
} 


\section{Empirical Results}

We now turn to the relationship between competition and relational contracts. First, we describe our baseline measure of competition. Second, we present OLS estimates. Given concerns that the OLS might not yield unbiased estimates, we describe the construction of our instruments for competition. This requires estimating an engineering model for the optimal placement of mills. After validating the first stage, we present the main IV results and a battery of robustness checks.

\subsection{Measuring Competition}

The baseline measure of competition is the number of mills within a $10 \mathrm{kms}$. radius from the mill. The reason behind the choice is as follows. Defining competition faced by a given mill requires a definition of the mill's catchment area. To fix ideas, let the catchment area be given by the area around the mill such that, if the mill bought most of the cherries produced in the area, it would operate at full capacity. A radius of 3.5 $\mathrm{Km}$ (measured in Euclidian distance) provides an appropriate estimate of the average mill's catchment area. Consider a conservative buffer that stretches the catchment area to a radius of 5 kilometers. ${ }^{38}$ In most cases, this provides an upper bound on how far the mill purchases cherries. If all mills were symmetric, then, a mill would face competition from all surrounding mills within a 10 kilometer radius (see Figure 6). Figure 7 illustrates the distribution, across mills, of the number of mills within a 10 kilometer radius. There is significant heterogeneity, with quite a few isolated mills and the average mill having 6 competitors.

In the survey, we asked the mill's manager the number of other mills that purchase inside the mill catchment area and at the nearest collection site used by the mill. The average mill faced competition from about 2 other mills at the nearest collection site and from 6 within the catchment area. The correlation coefficient between the survey measure and the number of mills within $10 \mathrm{~km}$ radius is 0.77 and highly significant.

Mills are heterogeneous with respect to installed capacity, local growing conditions and availability of roads. This might suggest using a mill specific measure of competition. Competition could be defined taking into account capacity, growing conditions and local roads. Besides its simplicity, the baseline measure of competition presents an advantage from a measurement error point of view. To the extent that the baseline measure suffers from measurement error, OLS results will be biased towards zero. On the other hand, defining competition taking into account mill's specific conditions

\footnotetext{
${ }^{38}$ These figures are confirmed by survey evidence.
} 
might introduce other sources of bias either upward or downward. In the interest of expositional simplicity, OLS results are presented using only the baseline measure. When presenting the main IV analysis, however, robustness checks are performed along a number of alternative assumptions and notions of competition.

\subsection{Competition and Relational Contracts: OLS Estimates}

We begin by exploring the OLS relationship between competition and relational practices. We run regressions at the individual farmer and at the mill level. For brevity, we illustrate only the mill specification. The farmer specification also includes farmer's individual controls. ${ }^{39}$ Denote with $y_{i}$ the outcome of interest and by $C_{i}$ competition experienced by mill $i$. The OLS specification is given by

$$
y_{i}=\alpha+\beta C_{i}+\eta X_{i}+\gamma Z_{i}+\varepsilon_{i}
$$

where $X_{i}, Z_{i}$ are vectors of controls at the mill level $(i)$ and $\varepsilon_{i}$ is an error term. The vector $X_{i}$ includes mill level controls: capacity installed, age and type (cooperative vs. private) of the mill. The vector $Z_{i}$ includes controls for potential drivers of the mill's performance within $5 \mathrm{~km}$ radius from the mill. These controls include geographic (both in level and in their polynomials): elevation, slope, length of river, coordinates, historical suitability for coffee, density of coffee trees and length of roads. ${ }^{40}$ For sake of comparability with IV specifications, we bootstrap standard errors.

The model predicts the following practices to be part of the relational contract: $i$ ) pre-harvest loan and fertilizers from the mill to the farmer, $i i$ ) cherries sold on credit by the farmer to the mill, iii) (expectation of) second payments at the end of the harvest season and other forms of assistance from the mill to the farmers. These are also our main outcomes of interest. Results are presented using both farmers' and manager's answers. Table 3 presents the results. Columns 1, 2 and 3 focus on pre-harvest aspects of the relational contract. Competition negatively correlates with both farmers and manager reporting that the mill has given fertilizers and other inputs to the farmer. Columns 4, 5 and 6 focus on whether at harvest time farmers sell to the mill on credit. While all the coefficients are negative, the relationship is not statistically significant. Finally, Columns 7, 8 and 9 focus on post harvest aspects of the relational contract. We find that competition negatively correlates with farmer's expectation to receive a

\footnotetext{
${ }^{39}$ Farmer's controls are age, gender, place of birth, education level, cognitive skills, distance from mill and farm size.

${ }^{40}$ There are 178 mills in the survey. The list of potential control variables is large and many controls are highly correlated with each other.
} 
second payment at the end of the season and with mill reporting to help farmers in case of need. Finally, Column 10 presents results using the overall relational score that combines all practices. Taken together, the OLS results present a negative correlation between competition and the use of relational contracts. ${ }^{41}$

The OLS results are consistent with the predictions of the model. The results, however, could be biased due to a number of concerns and cannot be interpreted as conclusive evidence of a negative impact of competition on relational contracts. Unobserved local conditions suitable for establishing relational contracts with farmers might also be (or correlate with) suitable conditions for establishing a mill. In this case the OLS coefficient is upward biased. Conversely, potential entrants might locate next to poorly run mills that score badly on relational contracts. In this case, the OLS coefficient is biased downward.

\subsection{Construction of the Instrument: Entry Model}

Given the concerns discussed above, we now turn to an IV strategy to investigate the causal impact of competition on relational contracts. The ideal instrument is a variable that, conditional on controls included in the model, $i$ ) strongly correlates with competition (first stage), and ii) does not influence the operations of the mill (in particular on the prevalence of relational contracts) other than through its effect on competition (exclusion restriction). To construct instruments we combine $i$ ) the spatial nature of competition embedded in the notion of catchment area defined above, and $i i$ ) drivers of location suitability for mill placement (henceforth, "suitability") at a high resolution spatial level derived from an engineering model. ${ }^{42}$ Conditional on suitability within the mill's catchment area, competition is instrumented with suitability around the mill's catchment area. To operationalise the idea, we need several steps:

i) Define the catchment area and the area around it,

ii) Define suitability at a highly disaggregated spatial level,

iii) Aggregate suitability at the catchment area and surrounding area.

\footnotetext{
${ }^{41}$ Similar results are obtained for pre-harvest loans and access to loans in case of help. The correlation between competition and training is insignificant.

${ }^{42}$ Duflo and Pande (2008) and Lipscomb et al. (2012) provide early examples of research that combine GIS data and technological features to estimate the impact of infrastructure. Our identification strategy is more closely related to ideas in the literature estimating peer effects in network data (see, e.g., Bramoulle' et al. (2009), Acemoglu et al. (2014)) and to Bloom et al. (2014) on the effects of competition on the efficiency of U.K. hospitals.
} 


\section{Defining Catchment and Surrounding Areas}

Let us first consider the definition of the catchment area. There is a trade-off. On the one hand, we want to guarantee that conditions in the areas around the catchment area, which we use to construct the instrument, do not correlate with the mill's operations. This suggests defining a large catchment area. On the other hand, we want the instrument to predict the number of competing mills in the neighborhood of the mill. As mills are unlikely to be affected by competition from other mills located far away, this calls for a catchment area which is not too large. Given the discussion above, we consider the $5 \mathrm{~km}$ radius around the mill as "large", but "not too large", catchment area. Consequently, the instruments will be given by suitability between 5 and $10 \mathrm{~km}$ from the mill, conditional on suitability (and other controls) within the $5 \mathrm{~km}$ radius catchment area. ${ }^{43}$

\section{Deriving Location Specific Suitability}

We now derive suitability of a mill placement at a high resolution spatial level. We take advantage of an engineering model for the optimal placement of mills. In the early years of the industry, a program coordinated by USAID together with engineers, agronomists and soil specialists developed an engineering model for the optimal placement of mills in Rwanda (see, USAID 2006). The model was intended to recommend suitable sites for the placement of mills based on a vector of characteristics to be aggregated into a score. The score summarizes at a high spatial resolution, the suitability of a given location for the establishment of a mill. The model was never implemented because the required GIS in particular high resolution ortho-photos were not available. While regulating bodies (and, possibly, investors) might have had knowledge of the criteria specified in the model, entry was not restricted to locations satisfying the criteria. Using remote sensing and GIS tools on ortho-photos (aerial photographs at the $25 \mathrm{~m}$ resolution) we extract all the information required to implement the model for the whole of Rwanda, at the resolution of 1 square kilometer.

From a technical point of view, mills need to be located nearby coffee producing areas, roads and sources of water. The engineering model specified the following criteria:

Criterion \#1: Outside National Parks, Reserves and other protected areas (e.g. Lakes, Aquatic sites)

Criterion \#2: In sectors (administrative unit) with at least 30,000 coffee trees,

\footnotetext{
${ }^{43}$ The robustness checks section explores specifications that take more/less conservative boundaries; allow for mill specific boundaries; and use alternative measures of competition.
} 
Criteria \#3: Within 3 km's from a spring source, at an elevation between minus 10 and minus 30 meters from the spring,

\section{Criteria \#4: Within 1 kilometer of a road.}

For each 1 square km grid in Rwanda (henceforth, "grid") we define dummies for whether it satisfies each criteria or not. ${ }^{44}$ We utilize these dummy variables (and their interactions) to predict the actual placement of mills at the grid level. There are thousands of potential grids where mills could have entered and 213 in which a mill has entered. For each grid we obtain a score summarizing the suitability of that particular location based on the engineering model. Finally, the predicted scores are aggregated at the mill level taking averages within the mill's catchment area and the area around it as defined above.

Figure 8, Panel A illustrates spatial variation in the engineering model's criteria, the dark grey grid boxes are ineligible for entry due to their land cover. The lightest green illustrates grid boxes that satisfy the number of trees necessary for entry, the brightest green areas highlight where the grid boxes satisfy all the criteria (trees, availability of water and roads). Dots depict presence of a mill.

All mills that have entered satisfy criteria \#1 and \#2 (see Figure 8, Panel B for the illustration for criterion \#2). Grids not satisfying these two criteria are given a score equal to zero. Notice that criterion \#2 is defined at the level of the sector to which the 1 square kilometer grid belongs. Sectors are administrative units with an area of approximately 50 square km's. Hence the inclusion of the corresponding dummy still allows to control for a much more highly disaggregated measure of tree density at the grid level.

Table 4 reports results for the remaining two criteria within the sample of grids satisfying criteria \#1 and \#2. ${ }^{45}$ Column 1 considers presence of spring, Column 2 roads, Column 3 includes both and Column 4 the interaction between the two. In all specifications controls include polynomials in distances to spring and roads, elevation, average slope in the grid, density of coffee trees (or suitability for coffee), longitude, latitude and the interactions of these variables. Results support the engineering model. Even conditioning on a sample of eligible grids and a large number of potentially confounding factors, criteria \#3 and \#4 and their interaction predict the placement of mills. We use Table 4, Column 4 to predict for each grid a suitability score. Figure 8, Panel C, illustrates the predicted score from the model. Darker blue grid boxes

\footnotetext{
${ }^{44}$ Criteria \#3 is operationalized with a dummy requiring the grid to have at least one fifth of its area area within the relevant distance and elevation bandwidth from a spring.

${ }^{45}$ We also exclude built-up areas and water bodies (lakes, dams, riverine).
} 
indicate high probability of entry. Red dots display the presence of a mill.

\section{Endogenity concern of Criterion \#2}

Criterion \#2 simply requires a grid box to be placed in a sector with enough coffee trees. A concern that could violate the identification strategy is if farmers could adjust their investment decisions and plant more coffee trees as a response to more competition/better relational contracting. We would like to argue that this is of little concern. The average coffee tree takes close to 5 years before it is ready to harvest its first full crop. In Rwanda from our field experience farmers typically allow up to 8 years before they harvest. Further the coffee processing industry has only been in existence for the last 10 years (referenced to when we conducted our survey in 2012), and the bulk of entry (three-quarters) has taken place after 2005.

In our empirical section we use the 2008/09 coffee census, as it allows us to geolocate the presence of coffee trees at the 2 square $\mathrm{km}$ resolution (basically at the village level), if we compared the 2008/09 coffee census with the only other coffee census conducted in Rwanda, which was in 1999 (just prior to the start of the industry) we find that the growth in productive coffee trees (the census defines this as those trees which are 3-30 years) is only $7 \%{ }^{46}$ These aggregates suggest that growth in coffee trees for the decade 1999-2009 has been limited. ${ }^{47}$

\section{Aggregating Suitability and Discussion}

Having obtained a score at each 1 square $\mathrm{km}$ grid of Rwanda, we take averages of the score, its individual components and interactions and additional controls within the catchment area and the surrounding area. Conditional on the score and other controls within the $5 \mathrm{~km}$ catchment area, the instrument is given by the average suitability score within 5 to $10 \mathrm{~km}$ area from the mill (akin to cross-section surface of a donut).

A number of important remarks are in order. First, although some of the criteria display discontinuities, due to aggregation at the mill level the identification strategy doesn't (necessarily) rely on these discontinuities. Second, in our baseline specifications we use the suitability score as an instrument, we report robustness results in which we use individual score components (and their interactions) as instruments and

\footnotetext{
${ }^{46}$ Further a related concern could be that moreacreageunder coffee (more competition and increase in world price might encourage areas to be converted to grow coffee) however area under coffee has grown only by $7.80 \%$ over the period $1999-2009$.

${ }^{47}$ Two further robustness checks are planned (i) digitization of the 1999 coffee census to be used instead of the 2008/09 census, a substantial task as the census is largely in paper format and administrative boundaries have changed half-hazaradly, (ii) the coffee trees concern could be side-stepped completely by exploiting the soil conditions conducive for coffee, we have digitized the soil survey at an extremely detailed resolution and could operationalize this as opposed to criterion \#2.
} 
show that results are virtually unchanged. The summary score presents the obvious advantage that it can easily be illustrated in Figures and Tables. Utilizing individual criteria and their interactions, however, provides us with multiple instruments and the potential to run over-identification tests. Third, since the score is a predicted variable, bootstrapped standard errors are reported. ${ }^{48}$

\subsection{IV: First Stage, Reduced Form and Main Results First Stage and Reduced Form}

We instrument for competition using the predicted score from the engineering model in the area between $5-10 \mathrm{~km}$. Specifically, the first stage is given by

$$
C_{i}=\alpha+\widehat{\beta} S_{i}^{5 / 10}+\beta S_{i}^{5}+\widehat{\gamma}_{0} X_{i}+\widehat{\gamma} Z_{i}+\mu_{i}
$$

where $S_{i}^{5 / 10}$ is the average predicted score in the neighbors of mill's $i$ catchment area (5-10 km) and $S_{i}^{5}$ is the score inside the catchment area. The vectors $X_{i}$ and $Z_{i}$ includes controls as described above. The exclusion restriction is satisfied if, conditional on local costs drivers within $5 \mathrm{~km}$ radius, average suitability in the $5-10 \mathrm{~km}$ area is uncorrelated with other determinants of mill's operations.

The predicted score strongly correlates with the number of mills within $10 \mathrm{~km}$ from the mill. Figure 8 illustrates the partial regression plot between the number of mills within $10 \mathrm{~km}$ of a mill and the instrument. Panel A is without controls and Panel B is with controls for $S_{i}^{5}, X_{i}$ and $Z_{i}$. The results show a strong first stage with a 0.76 R-square.

Figure 9 plots the reduced form relationship between the relational contracts score and the instrument. There is a strong negative and statistically significant relationship between the two. The intuition behind the identification strategy is best illustrated in Figure 10. We run a reduced form regression between (the log of) operational unit costs and the average suitability scores at $1,2,3, \ldots 15 \mathrm{kms}$. from the mill. The regression includes all controls. Figure 10 reports a non parametric illustration of the estimated coefficients. A high suitability score in the proximity of the mill correlates with lower costs of operating the mills. This ought to be expected if the criteria for

\footnotetext{
${ }^{48}$ We have tried a number of alternative specifications, including i) creating a linear score with the number of criteria satisfied in each grid box; ii) creating a linear score with weights from the engineering model documents (see USAID (2006)); iii) predicting the score using an OLS model, iv) omitting to control for tree density at the grid level. These alternative methods produce virtually identical results. By construction, our instrument only relies on cross-sectional variation across sites Section 6 addresses concerns arising from dynamic strategic entry considerations.
} 
the engineering model are indeed relevant. Beyond a certain distance, however, a high score positively correlates with unit costs: better conditions are associated with worse outcomes. We argue that the score between 5 and $10 \mathrm{kms}$, rather than capturing other channels that affect mill's operations, has a (reduced form) negative impact on mill's outcomes because it attracts more competitors.

\section{Main Results: Effects of Competition on Relational Contracts}

Table 5 presents the results in a more formal regression framework. Column 1 reports the OLS coefficient and confirms the negative correlation between the relational contract score and competition found in Column 10 of Table $3 .{ }^{49}$ Column 2 reports the first stage confirming the results in Figure 8 Panel B. Column 3 reports the reduced form specification and confirms the results in Figure 9. There is a negative and highly significant relationship between the suitability score within 5 to $10 \mathrm{kms}$ and the relational contract score. Finally, Column 4 reports the IV estimates. The results confirm the negative impact of competition on relational contracts. An additional mill within $10 \mathrm{kms}$ from the mill reduces the relational contract score by 0.1 standard deviations. This effect is equivalent to a jump up or down of fifteen percentiles in the relational contracts ranking for the average mill. The comparison between Column 1 and Column 4 shows that the OLS coefficient is upward biased relative to the IV estimates. This is consistent with either measurement error, or with the source of bias in the OLS being the presence of unobserved features that correlate with both entry of competitors and with relational contracts.

Table 6 reports IV results considering the individual practices separately. Columns 1 and 2 focus on pre-harvest investments (fertilizers and inputs given to the farmer). Columns 3 and 4 focus on farmers selling cherries on credit to the mill at harvest time. Finally, Columns 5 and 6 consider post-harvest promises, in the form of second payments and help promised to the farmer in case of needs. Across all the six, we find that competition reduces the extent to which the practice is used by the mill. ${ }^{50}$

The evidence suggests that competition reduces the amount of relational contracts between the mill and the farmers. Table 7 presents corroborating evidence based on questions regarding trust. The survey posed trust questions adapted from the World Value Surveys to both farmers (Columns 1 to 4 ) and managers (Columns 5 to 8 ). We

\footnotetext{
${ }^{49}$ Estimates are marginally different from those in Table 3, Column 10 since suitability score within $5 \mathrm{~km}$ is now added as a control.

${ }^{50}$ Unreported results show that competition increases managers' reported sourcing from farmers that have received fertilizers and loans from other mills. This can be interpreted as direct evidence for the kind of poaching, or side-selling, that is the key mechanisms leading to relationship breakdown in the model.
} 
asked questions about trust in co-worker, farmers, coffee collectors. ${ }^{51}$ We find that competition lowers farmers' trust in mill's management and coffee collectors (Column 3 and 4). Similarly, we find that managers report lower trust towards farmers when there is more competition (Column 7). We also asked questions about generic trust and trust in family and neighbors. A placebo test find no effect of competition on these generic dimensions of trust.

\subsection{Robustness of IV Estimates}

Table 8 reports a number of robustness checks. For comparison, Column 1 reproduces the baseline specification of Column 4, Table 5. Columns 2 and 3 explore the robustness of the results to alternative sizes of the catchment and surrounding areas. Column 2 considers a catchment area with radius of $3.5 \mathrm{kms}$ and competition from mills within $7 \mathrm{~km}$. Column 3 considers a catchment area with radius of $7 \mathrm{kms}$ and competition from mills within $15 \mathrm{kms}$. The results are robust to these changes: competition has a negative impact on the relational score. The estimated coefficients are -0.136 for competitors within $7 \mathrm{kms}$. (Column 2), -0.085 for competitors within $10 \mathrm{kms}$. (Column 1), and -0.036 for competitors within $15 \mathrm{kms}$. (Column 3). The IV identifies a weighted average of the effects of additional competitors within the corresponding radius. The results imply that the impact of an additional competitor decreases with its distance from the mill. Using the observed frequency of competitors at various distances, we can parametrize the relationship between the average effect of an additional entrant and its distance from the mill. The results suggests that additional competitors beyond $10 \mathrm{Kms}$. do not affect relational contracts. ${ }^{52}$

Columns 1 to 3 assume exogenously given sizes for the catchment and surrounding areas. Columns 4 and 5 define the catchment areas taking into account mill's and location specific characteristics. Column 4 defines the size of the catchment area as the area around the mill that has the potential to produce twice as many tons of cherries than those needed by the mill to operate at full capacity. We match the number of trees from the census, measured at the village level, with the one square $\mathrm{km}$ grids around the mill. We assign to each tree an estimated production based on local geographic characteristics to reflect differences in potential production across localities. Based

\footnotetext{
${ }^{51}$ Since farmers were interviewed at the mill and there is only one manager in each mill, we did not ask farmers about their trust in the manager in order to avoid embarrassment and misreporting. Following suggestions from our local enumerator team, we asked about trust in "people from Kigali". This is meant to capture attitudes towards business people with whom the farmer has a subordinate relationship.

${ }^{52}$ Using operational unit costs as dependent variables implies identical results.
} 
on the estimated potential production in the surrounding areas and on the installed capacity, each mill is assigned to one of the three groups defined in Columns 1 to 3 . The results are, again, robust. Columns 1 to 4 define the mill's catchment area as the area within a certain Euclidian distance. Rwanda, however, is characterized by a hilly terrain and by highly heterogeneous density of roads across locations. Column 5 , therefore, defines the catchment area to be the convex hull of the points that can be reached traveling $7 \mathrm{kms}$ by road from the mill. Results are, again, robust to this specification and very comparable to those obtained in Column 1.

Columns 1 to 5 use average suitability score in the area around the mill to instrument for competition. Column 6, instead, uses as instruments the four different criteria, averaged across all grids in the area surrounding the catchment area. The results confirm the evidence from the previous specifications. This approach provides multiple instruments to perform over-identification tests. The test fails to reject the hypothesis of exogenous instruments. ${ }^{53}$

Columns 1 to 6 treat competitors symmetrically by defining competition as the number of mills within a certain area. Columns 7 and 8 explore the robustness of the results to the use of alternative measures of competition. Column 7 measures competition using the total capacity installed by mills within $10 \mathrm{kms}$ radius. While the F-test is somewhat weaker, possibly due to the noisier measure of competition, a negative effect of competition on relational contracts is confirmed. Columns 1 through 7 have measured competition exploiting differences in the number of neighboring mills within areas of a certain size. An alternative approach is to measure (the inverse of) competition by asking how far are the first $N$ neighbors from the mill. This is done in Column 8 where competition is defined as distance to the seventh nearest station. ${ }^{54}$ Results are robust to this different definition of competition.

\section{Additional Predictions: Mills and Farmers Outcomes}

The model predicted that competition might decrease the use of relational contracts. The IV estimates show that competition decreases the use of relational contracts. When this happens, the model delivers a cluster of additional predictions on both mill

\footnotetext{
${ }^{53}$ Multiple score instruments can be obtained, at the cost of additional assumptions, as follows. Define the catchment area to be $3.5 \mathrm{~km}$ radius (as in Column 2) and consider competition from mills within $10 \mathrm{kms}$. (as in Column 1). We can use the average suitability scores between 3.5 and $7 \mathrm{kms}$. and between 7 and $15 \mathrm{kms}$. as separate instruments. The results yield very similar point estimates, stronger F-test and, again, fail to reject the hypothesis of exogenous instruments.

${ }^{54}$ The choice of the seventh station is made for comparison with the baseline specification, since the average number of mills within a $10 \mathrm{kms}$. radius is around 6.5 .
} 
and farmers' outcomes. This section tests those additional predictions.

\section{$5.1 \quad$ Effects on Mills}

Table 9 explores mill level outcomes. The model predicts $i$ ) higher processing unit costs and ii) lower capacity utilization. Columns 1 to 4 explore components of unit costs. Column 1 shows that unit costs increase by $3.5 \%$ as a result of an additional mill within $10 \mathrm{kms}$. Column 2 shows no effect on prices paid to farmers. Column 3 presents a placebo: as expected, competition has no effect on the conversion ratio from coffee cherries to processed parchment, a parameter of the production function. Columns 2 and 3 combined imply that competition has no effect on the costs of cherries. Using (1), total unit costs can be decomposed into direct cost of cherries and processing costs. Accordingly, Column 4 shows that processing unit costs increase as a result of competition by approximately $7 \%$. Capacity utilization measured as the total amount (in tons) of cherries processed during the harvest season divided by the total capacity installed. Column 5 confirms that an additional entrant reduces capacity utilization by almost $8 \%$. This is a large effect given that the average capacity utilization in the industry is around $50 \%{ }^{55}$ Column 6 shows that the number of weeks the mill is open is not affected by competition. Column 7 lastly shows that competition increases the likelihood the manager reports to have had days with too few cherries to process

In Appendix Table 2 Columns 1 to 5 we explore these aspects further. Processing costs can be further decomposed into costs of labour, capital, transport, procurement and other costs. Column 1 shows that labour unit costs increase by $11 \%{ }^{56}$ Unit labour costs increase if $i$ ) capacity utilization is, as predicted by the model, lower (and more irregular) and $i i$ ) there are costs to adjust labour to insufficient/irregular supply of cherries. Columns 2 and 3, however, show that competition increases the likelihood the manager reports to have had days with too few cherries to process and with either too little or too many workers relative to the amount of cherries available. Lower, and more irregular, capacity utilization leads to an increase in unit labour costs only if the mill cannot perfectly adjust hired labour to availability of cherries. Survey evidence confirms this to be the case. Firms do not completely turn down workers when there aren't enough cherries. The vast majority of seasonal workers is paid either bi-weekly or monthly, rather than daily. Stations do revise employment plans frequently (65\% weekly or more often) depending on the dynamics of cherry procurement and market

\footnotetext{
${ }^{55}$ Since we only surveyed active mills, these results do not include the extensive margin. We find that competition is also associated with the mill likelihood of operating.

${ }^{56}$ We do not find significant effects of competition on the other sources of costs.
} 
conditions. Hiring plans, however, are not adjusted freely. Contractual arrangements between mills and workers are somewhat sticky and also include elements of relational contracting. The employment relationship, for example, display elements of relational insurance. For example, $73 \%$ of stations answer they would turn down only some (and $12 \%$ none) of workers if there was very little cherries to process. Answers from interviewed workers confirm this. While competition affects some hiring practices (e.g., rehiring workers they already know), it doesn't affect this aspect nor the frequency of payments between mills and workers. Mills cannot perfectly adjust labour at a short notice at no cost. ${ }^{57}$ Competition could increase unit labour costs if mills compete for labour at harvest time. This is highly unlikely in these densely populated rural areas in which there are many more farmers available to work as employees than jobs. Columns 4 and 5 confirm that competition between stations has no impact on wage rates nor on the likelihood the manager reports to experience difficulties in hiring workers.

\section{$5.2 \quad$ Effects on Farmers}

The model emphasizes how competition destroys relationships by making it harder to satisfy incentive compatibility constraints. When this happens, the model predicts $i$ ) an ambiguous effect on prices paid to farmer, ii) a drop in the share of cherries sold to mills (since farmers can't rely on mill's second payments to smooth cash flows), iii) lower (or more expensive) input use. The simplest version of the model with homogenous farmers implies that competition always weekly increases farmers welfare. A simple extension with heterogenous farmers yield ambiguous predictions regarding the effect of competition on farmer's welfare.

Table 10 explores the effect of competition on a number of farmer's outcomes. Column 1 confirms the finding of Column 2 in Table 9: competition has no effect on prices received by farmers. Columns 2 and 5 provide direct support to the main mechanism in the model: competition reduces the share of cherries sold to mills (Column 2) and, accordingly, increases the likelihood farmers list having cash at the end of harvest as one of the main advantages of home processing (Column 5). Note that the former result implies that the aggregate volume of cherries processed by mills might decrease as a result of additional entry. Column 3 shows that amount spent on inputs (slightly) increases, possibly to compensate (unreported) reduction in the inputs received from the mill. Column 4 finds no impact of competition on yields, measured as production

\footnotetext{
${ }^{57}$ Competition does not appear to alter the relational contracts between the workers and the farmers. Unlike cherries, for which there is intense competition, there just is excessive supply of workers in the market.
} 
per tree. This is unsurprising given the duration it takes for coffee trees to produce (close to 8 years). Finally, Column 6 aggregates a number of general questions on farmer's job satisfaction and finds a negative impact of competition on the overall score. $^{58}$ In sum, the available evidence rejects the hypothesis that farmers benefit from competition (and, if anything, shows an overall negative impact).

\section{$5.3 \quad$ Effects on Quality}

Finally, the model predicts that when competition leads to relationship breakdown the quality of the cherries produced might suffer. A representative sample of the processed coffee from each mill is obtained. Each sample of parchment coffee was inspected and "cupped" at the national coffee board's laboratory in Kigali under the supervision of one of the authors. Quality scores focus on a number of physical characteristics and defects that emerge following the roasting process. Defects in the lot can be characterized depending on their most likely origin: genetics, farmer's practices and mill processing (or a combination).

Table 11 presents the results. Columns 1 to 3 focus on physical examination. While we do not find any effect of competition on the quality dimensions which depend on the mill processing (parchment to green coffee conversion and moisture range), competition has a negative impact on bean size which can be directly linked to farmers not harvest cherries with the appropriate fertilizers (NPK). Among the criteria tested through the analysis in the laboratory, competition has no impact on damages such as shells, floating beans and broken beans, which are under the control of the mill. However, competition increases severe insect damage which, again, originates from inadequate provision of insecticides to the farmer. The overall cupping score (and whether the lot gets a specialty grade) are negatively affected by competition, although the estimates are not precisely estimated.

\section{Discussion}

\subsection{Dynamic Entry}

The instrument for competition relies on cross-sectional variation in the suitability for mill placement around the mill's catchment area. Entry of new mills in the sector,

\footnotetext{
${ }^{58}$ The score aggregates farmers agreement (on a scale between 1 and 4 ) with the following statements: i) "job gives me a chance to do the things I do best", ii) "job requires that I work very fast", iii) "pay is good", $i v$ ) in my job I learn new things, $v$ ) I am treated with respect, vi) I have a lot freedom to decide how to do my work, vii) I find work stressful.
} 
however, happens over time. It is therefore important to pause and consider whether dynamic aspects of the entry decisions might invalidate the identification strategy. The main threat is posed by the possibility that, conditional on conditions at available locations, forward looking entrants strategically locate in areas with worse surroundings anticipating they will face lower competition in the future. In other words entrants are able to locate "oasis" and surround themselves in areas which are not conducive for additional mill arrival. This section presents three pieces of evidence suggesting that these considerations are unlikely to be of importance.

First, we can check how the order of entry (i.e. the year mills enetered) correlates with the suitability score within 5 and 5 to $10 \mathrm{~km}$ from the actual entry location. We expect earlier entrants to locate in places with higher score within $5 \mathrm{kms}$ but to find no pattern with respect to the suitability score within 5 to $10 \mathrm{kms}$. Figure 12 lends support to this hypothesis. The figure plots the average score within 5 and 5 to $10 \mathrm{kms}$. against the order of entry. The Figure confirms that earlier entrants located in places with higher scores within $5 \mathrm{kms}$ and that later entrants had to settle for locations with lower score. The corresponding trend in the average score between 5 and $10 \mathrm{~km}$ is much less pronounced and likely driven by the correlation with the score within $5 \mathrm{~km}$. Indeed, once we control for the score within $5 \mathrm{kms}$, regression results show that the score between 5 and $10 \mathrm{kms}$. does not predict the order of entry. This is not surprising as in order to search for potential "oasis" managers would need to have an idea of the landscape close to 250 square $\mathrm{km}$ beyond their catchment area.

Second, we check whether less forward looking entrants locate mills nearby places in which there is subsequently more entry. If that was the case, the quality of a mill's management would negatively correlate with competition. Table 12 shows that competition has no effect on observable manager characteristics: age (Column 1); education (Column 2); cognitive ability, measured by simple Raven and numeracy tests (Column 3); tenure at the mill (Column 4); months worked for the station during the year (Column 5); training (Column 6); pay (Column 7) and incentives (Column 8) are all unaffected by the degree of competition. The results are confirmed when focusing on subsequent entry alone.

Finally, we exploit data from the two years following our survey and check whether, conditional on local suitability, unit costs of existing mills correlate with the location choice of new entrants. Table 13 reports the results. The unit of observation is a sector, the lowest level for which we have details about the location of new entrants. ${ }^{59}$

\footnotetext{
${ }^{59}$ Coincidentally, the average sector is approximately 60 square $\mathrm{km}$ and corresponds to an area with radius equal to $4.5 \mathrm{kms}$., very similar to the catchment area in the baseline specification.
} 
The left hand side variable takes a value of 1 if a new mill has entered that sector in 2013 or 2014 and zero otherwise. We are interested to check if unit costs of existing mills in 2012 predict the location decision. Since existing mills' unit costs are observed only where mills existed in 2012, dummies for the existence of mills in the sector in 2012 are separately included. Columns 1 and 2 fail to find any correlation between the presence of mills and subsequent entry. Because Columns 1 and 2 do not control for suitability for entry at the sector level, the effect of existing capacity on additional entry is likely to be biased upward. Column 3 controls for the average suitability score in the sector and finds that $i$ ) the score positively predicts entry, and $i i$ ) existing capacity in neighboring sectors is negatively correlated with entry. More importantly, unit costs of existing mills in the sector (or in neighboring sectors) do not predict entry. Finally, Column 4 controls for the additional components of the entry model and confirms the results.

In sum, we find no evidence that mills base their strategic entry decisions on $i$ ) the efficiency of existing mills and/or $i i$ ) the suitability for further entry in places 5 to 10 $\mathrm{km}$ beyond there chosen location. ${ }^{60}$

\section{Conclusion}

In settings where there is poor formal contracting institutions, parties rely on the future rents associated with long term relationships to deter short-term opportunism and facilitate trade. Empirical evidence on the structure of informal arrangements in supply relationships between firms has the potential to identify salient microeconomic frictions in specific contexts and inform policy, particularly in a development context. This paper presents an empirical study of the effect of competition on trade between mills and farmers on relational contracts in Rwanda's coffee sector, a context particularly well-suited to study informal relationships. We first measure the use of relational contracts in a sample of large firms. We than document the dispersion in the use of relational contracts, that there is complementarities between the relational contract practices and the use of relational contracts is correlated with firm's actual performance. In our setting mills are differentially exposed to competition for sourcing cherries. We find competition reduces the use of relational contracts as a result competition worsens mills and farmer's outcomes. The findings are consistent with the view

\footnotetext{
${ }^{60}$ Practically, investors are unlikely to enter in certain locations taking into account, beyond local conditions, the suitability of neighbor locations in an area that extends beyond the 78 square $\mathrm{km}$ implied by our baseline measure for the size of the catchment area.
} 
that monopsony rents help to sustain relational contracts, the effect of competition then are no longer in line with traditional wisdom of competition.

Our results demonstrate that in a second best world the benefits of competition are being hampered due to the presence of other market failures which the relational contracts were mitigating. A direct policy measure from our results, could be to improve contract enforcement. This can be first best, if improvement in contract enforcement are sufficiently large. While it might be too much of a task to improve the country's formal court system, technology could provide a short-cut to potentially reap the benefits. We are aware of a setting where this has occurred, Costa Rica. ${ }^{61}$ The conditions needed however to implement Costa Rica's model require a strong institutional environment (see Paige 1997 for details). In general other countries have introduced policies aimed at influencing spatial distribution of entrants (such as, zoning regulations, monopsony licenses, minimum distance rules). These are much easier to enforce but prone to abuse (for instance Kenya's collapse of the coffee sector when it introduced zoning). From a public policy perspective, the evidence rationalizes policies, such as zoning regulations, monopsony licensing and other entry restrictions, commonly observed in the developing world and emphasizes the importance of promoting contractual enforcement in agricultural value chains.

\footnotetext{
${ }^{61}$ While in Costa Rica commercialization of coffee is at the hands of the private sector, there is a strong supervision role played by the state via Instituto del Cafe de Costa Rica (ICAFE). ICAFE is mandated by an official Act to monitor and tracks the complete coffee value chain.
} 


\section{References}

[1] Aghion, P., Bloom, N., Blundell, R., Griffith, R., \& Howitt, P. (2005). "Competition and Innovation: an Inverted-U Relationship." The Quarterly Journal of Economics, 120(2), 701-728.

[2] Andrabi, T., M. Ghatak and A. Kwhaja (2006) "Subcontractors for Tractors: Theory and Evidence on Flexible Specialization, Supplier Selection, and Contracting", Journal of Development Economics, April 79 (2): 273-302.

[3] Baker, G., Gibbons, R., \& Murphy, K. J. (2002). "Relational Contracts and the Theory of the Firm." Quarterly Journal of Economics, 39-84.

[4] Banerjee, A. and E. Duflo (2000) "Reputation Effects and the Limits of Contracting: A Study of the Indian Software Industry", Quarterly Journal of Economics 115: 989-1017.

[5] Banerjee, A. and K. Munshi (2004) "How efficiently is capital allocated? Evidence from the knitted garment industry in Tirupur". Review of Economic Studies 71(1): $19-42$.

[6] Bardhan, P. (1983) "Labor-tying in a Poor Agrarian Economy: A Theoretical and Empirical Analysis", Quarterly Journal of Economics, 98 (3): 501-514.

[7] Bardhan, P. K. (Ed.). (1989). The economic theory of agrarian institutions (No. E10 B245). Oxford: Clarendon Press.

[8] Binswanger, H. P., \& Rosenzweig, M. R. (1982). Production Relations in Agriculture. J. Develop. Stud.

[9] Bloom, N., Sadun, R., \& Van Reenen, J. (2010). Recent advances in the empirics of organizational economics. Annu. Rev. Econ., 2(1), 105-137.

[10] Bloom, N., Genakos, C., Sadun, R., \& Van Reenen, J. (2012). Management practices across firms and countries. The Academy of Management Perspectives, 26(1), $12-33$.

[11] Bloom, N., Propper, C., Seiler, S., \& Van Reenen, J. (2014). The impact of competition on management quality: evidence from public hospitals, mimeo LSE

[12] Bloom, N. and J. Van Reenen (2007) "Measuring and Explaining Management Practices across Firms and Countries", Quarterly Journal of Economics, 122(4), pp. 1351-1408. 
[13] Bloom, N., B. Eifert, A. Mahajan, D. McKenzie and J. Roberts (2013) "Does Management Matter? Evidence from India", Quarterly Journal of Economics, 128(1), pp. 1-51.

[14] Blouin, A. (2014) "Culture and Contracts: The Historical Legacy of Forced Labour", mimeo.

[15] Blouin, A. and R. Macchiavello (2013) "Tropical Lending: International Prices, Strategic Default and Credit Constraints among Coffee Washing Stations" mimeo

[16] Bramoullé, Y., Djebbari, H., \& Fortin, B. (2009). Identification of peer effects through social networks. Journal of econometrics, 150(1), 41-55.

[17] Casaburi, L. and T. Reed (2013) "Interlinked Transactions and Pass-Through: Experimental Evidence from Sierra Leone", mimeo Stanford

[18] Casaburi, L. and R. Macchiavello (2014) "Interlinked Transactions, Saving Constraints, and Market Structure in Kenya Dairy Farming", mimeo Stanford

[19] Diamond, P. (1987) "Consumer differences and prices in a search model", Quarterly Journal of Economics, 429-436.

[20] Duflo, E., and Pande, R. (2007). Dams. The Quarterly Journal of Economics,122(2), 601-646.

[21] Fafchamps, M. (2000) "Ethnicity and Credit in African Manufacturing", Journal of Development Economics, 61(1): 205-235.

[22] Fafchamps, M. (2004) Market Institutions in Sub-Saharan Africa, MIT Press, Cambridge Mass.

[23] Fafchamps, M. (2006) "Spontaneous Markets, Networks and Social Capital: Lessons from Africa", mimeo Oxford.

[24] Ghani, T. and T. Reed (2014) "Competing for Relationships: Markets and Informal Institutions in Sierra Leone," mimeo Berkeley

[25] Gibbons, R., \& Henderson, R. (2012). What Do Managers Do?: Exploring Persistent Performance Differences Among Seemingly Similar Enterprises. Harvard Business School.

[26] Gibbons, R., \& Roberts, J. (Eds.). (2013). The Handbook of Organizational Economics. Princeton University Press. 
[27] Gil, R., \& Zanarone, G. (2014). Testing for the Interaction of Formal and Informal Contracts.

[28] Ghosh, P., Mookherjee, D., \& Ray, D. (2000). Credit rationing in developing countries: an overview of the theory. Readings in the theory of economic development, 383-401.

[29] Ghosh, P., \& Ray, D. (1996). Cooperation in community interaction without information flows. The Review of Economic Studies, 63(3), 491-519.

[30] Greif, A. (1989). "Reputation and Coalitions in Medieval Trade: Evidence on the Maghribi Traders." The Journal of Economic History, 49(04), 857-882.

[31] Greif, A. (1993). "Contract Enforceability and Economic Institutions in Early Trade: The Maghribi Traders' Coalition." American Economic Review, 525-548.

[32] Hosios, A. (1990) "On the efficiency of matching and related models of search and unemployment." The Review of Economic Studies 57.2: 279-298.

[33] Kranton, R. E. (1996). Reciprocal exchange: a self-sustaining system. The American Economic Review, 830-851.

[34] Kranton, R. E., \& Swamy, A. V. (1999). The hazards of piecemeal reform: British civil courts and the credit market in colonial India. Journal of Development Economics, 58(1), 1-24.

[35] Kranton, R., and Swamy, A. (2008). Contracts, hold-up, and exports: textiles and opium in colonial India. The American Economic Review, 967-989.

[36] Holmes, T. J., \& Schmitz Jr, J. A. (2010). Competition and Productivity: A Review of Evidence. Annu. Rev. Econ., 2(1), 619-642.

[37] Hsieh, C. and P. J. Klenow (2009) "Misallocation and Manufacturing TFP in China and India", Quarterly Journal of Economics, 124(4), pp. 1403-48.

[38] Hsieh, C. and B. Olken (2014) "The Missing 'Missing Middle", Journal of Economic Perspective, forthcoming

[39] Hsieh, C. and E. Moretti (2003) "Can Free Entry Be Inefficient? Fixed Commissions and Social Waste in the Real Estate Industry", Journal of Political Economy $111-5$. 
[40] Ichniowski, C., \& Shaw, K. (2012). Insider econometrics: a roadmap to estimating models of organizational performance. Handbook of Organizational Economics.

[41] Levin, J. (2003). Relational incentive contracts. The American Economic Review, 93(3), 835-857.

[42] Lipscomb, M., Mobarak, M. A., \& Barham, T. (2013). Development effects of electrification: evidence from the topographic placement of hydropower plants in Brazil. American Economic Journal: Applied Economics, 5(2), 200-231.

[43] Little, P. D., \& Watts, M. (Eds.). (1994). Living under contract: contract farming and agrarian transformation in sub-Saharan Africa. Univ of Wisconsin Press.

[44] Macchiavello, R. (2010) "Development Uncorked: Reputation Acquisition in the New Market for Chilean Wines in the UK", CEPR DP7698

[45] MacLeod, W. B. (2007). "Reputations, Relationships, and Contract Enforcement." Journal of Economic Literature, 595-628.

[46] MacLeod, W. B., \& Malcomson, J. M. (1989). Implicit contracts, incentive compatibility, and involuntary unemployment. Econometrica: Journal of the Econometric Society, 447-480.

[47] McMillan, J. and C. Woodruff (1999) "Inter rm Relationships and Informal Credit in Vietnam", Quarterly Journal of Economics, 114: 1285-1320.

[48] Mankiw, N. and M. D. Whinston (1986) "Free Entry and Social Inefficiency", The RAND Journal of Economics, 17(1), pp. 48-58.

[49] Mukherjee, A., \& Ray, D. (1995). Labor tying. Journal of Development Economics, $47(2), 207-239$.

[50] Mullainathan, S. and S. Sukhtankar (2014) "Ownership Structure and Economic Outcomes: The Case of Sugar Mills in India", mimeo

[51] Munshi, K. (2010) "The Birth of a Business Community: Historical Disadvantage and Contemporary Mobility in India", Review of Economic Studies, forthcoming.

[52] Nickell, S. J. (1996). Competition and corporate performance. Journal of political economy, 724-746.

[53] Petersen, M. A., \& Rajan, R. G. (1994). The benefits of lending relationships: Evidence from small business data. The journal of Finance, 49(1), 3-37. 
[54] Petersen, M. A., \& Rajan, R. G. (1995). The effect of credit market competition on lending relationships. The Quarterly Journal of Economics, 407-443.

[55] Porto, G. G., Chauvin, N. D., \& Olarreaga, M. (2011). Supply Chains in Export Agriculture, Competition, and Poverty in Sub-Saharan Africa. Centre for Economic Policy Research.

[56] Ray, D., \& Sengupta, K. (1991). Interlinkages and the Pattern of Competition.

[57] Söderbom, M. and S. Kamarudeen (2013) "Constraints and opportunities in Rwanda's industrial sector", International Growth Centre

[58] Syverson, C. (2011). What Determines Productivity?. Journal of Economic Literature, 49(2), 326-365.

[59] Syverson, C. (2004) "Product Substitutability and Productivity Dispersion", Review of Economics and Statistics, 86(2), pp. 534-50.

[60] Syverson, C. (2011) "What Determines Productivity?", Journal of Economic Literature, 49(2), pp. 326-365.

[61] World Bank (2008) "World Development Report: Agriculture for Development", World Bank 


\section{FIGURE 1: MILL PLACEMENT IN RWANDA, 2002-2012}
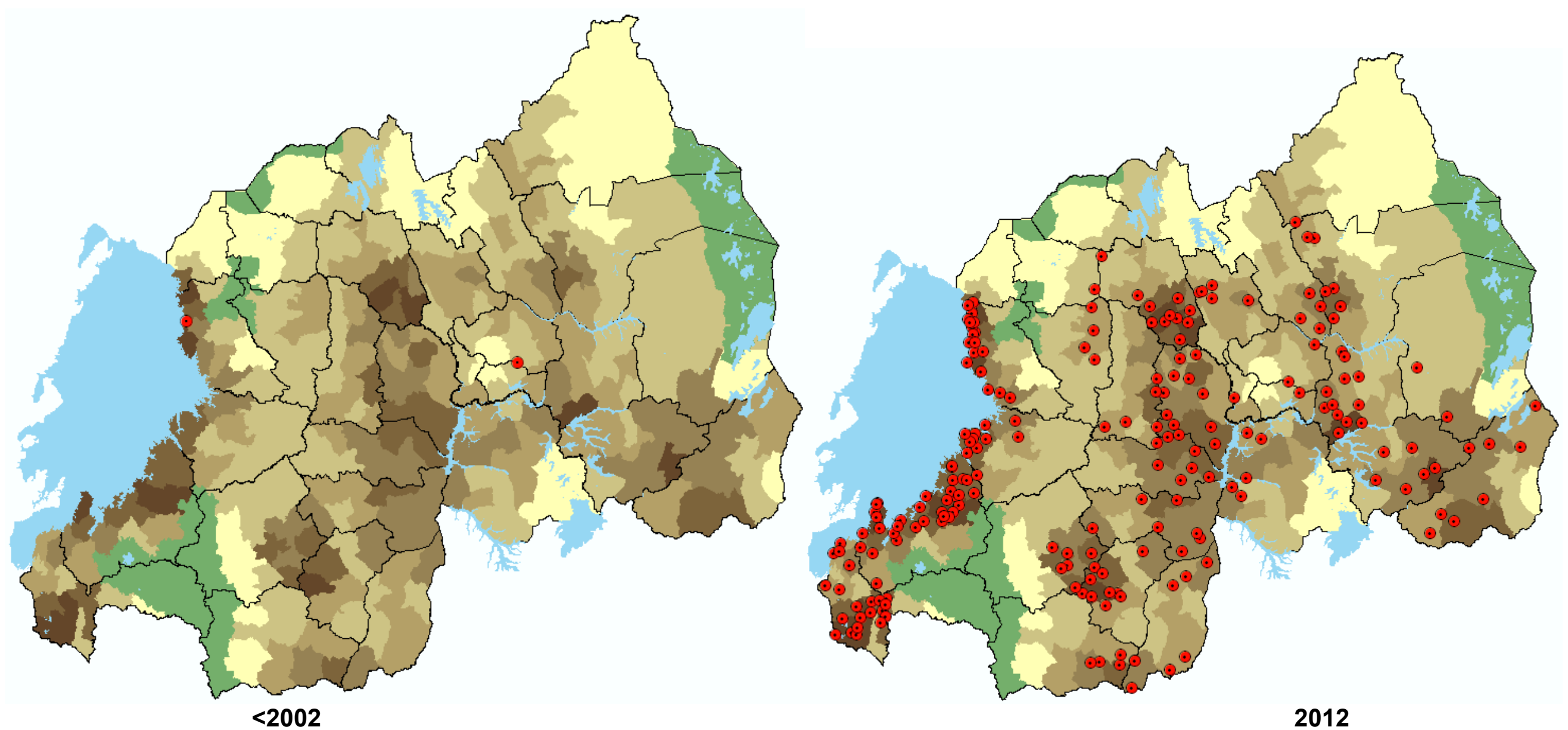

Notes: This figure illustrates, the spatial and temporal placement of mills in Rwanda. Prior to 2002 there were only 2 mills in Rwanda (denoted by red dots). By 2012 there were 214 mills built. Green shades indicate national parks, blue indicates water bodies, the background overlay is the number of coffee trees at the sector level (third administrative layer), the darker the shade of brown the higher the number of coffee trees in the sector. Source: author's survey of mils and various data sources from NAEB, Rwanda; see Data Appendix for additional details. 
FIGURE 2: INSTALLED CAPACITY OF MILLS IN THE 2012 SEASON

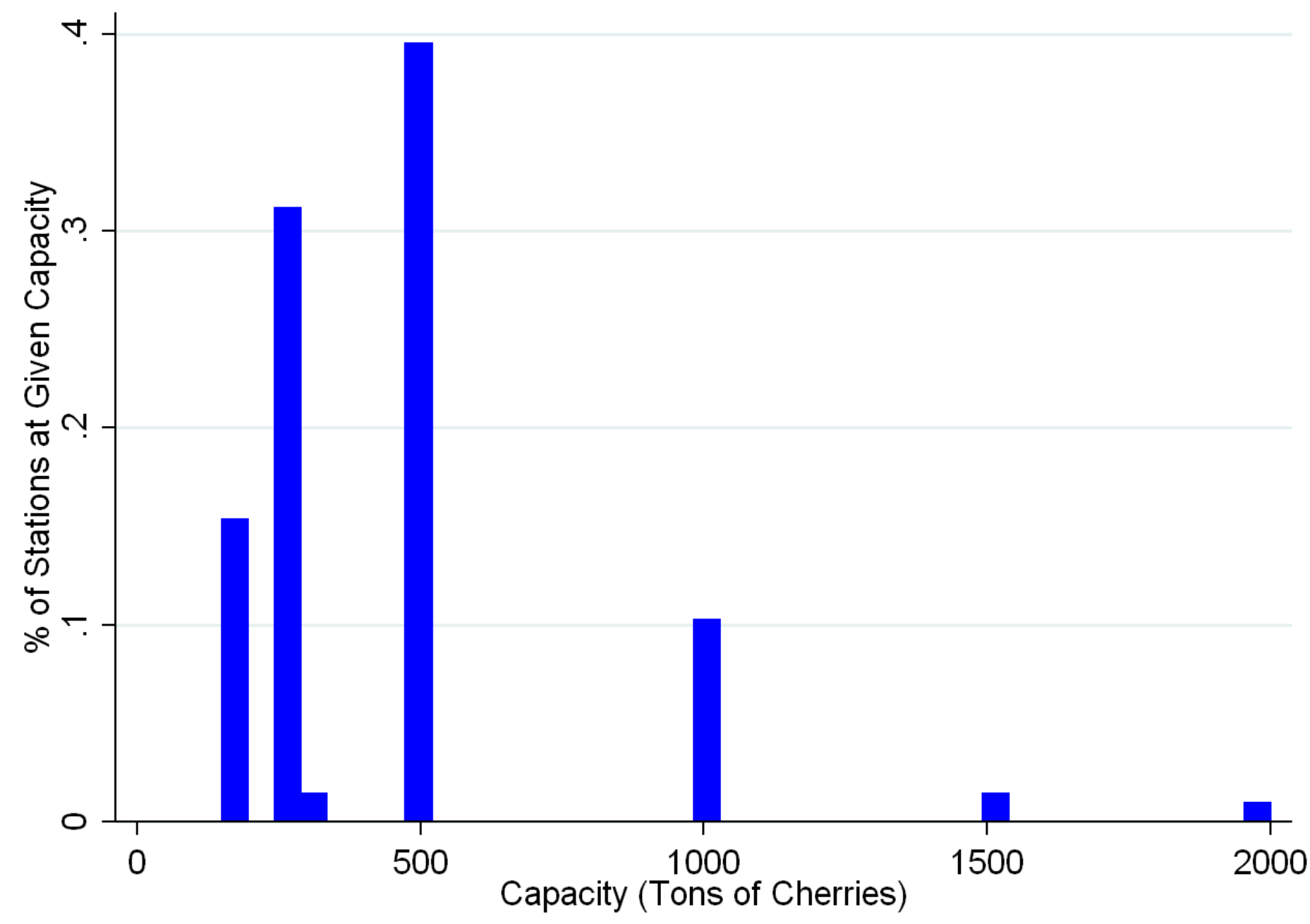

Notes: The figure plots the distribution of capacity installed by mills. The figure shows significant dispersion in capacity installed with many small stations. Source: author's survey of mills and NAEB, Rwanda, see Data Appendix for additional details. 
FIGURE 3: CORRELATIONS BETWEEN RELATIONAL CONTRACT PRACTICES
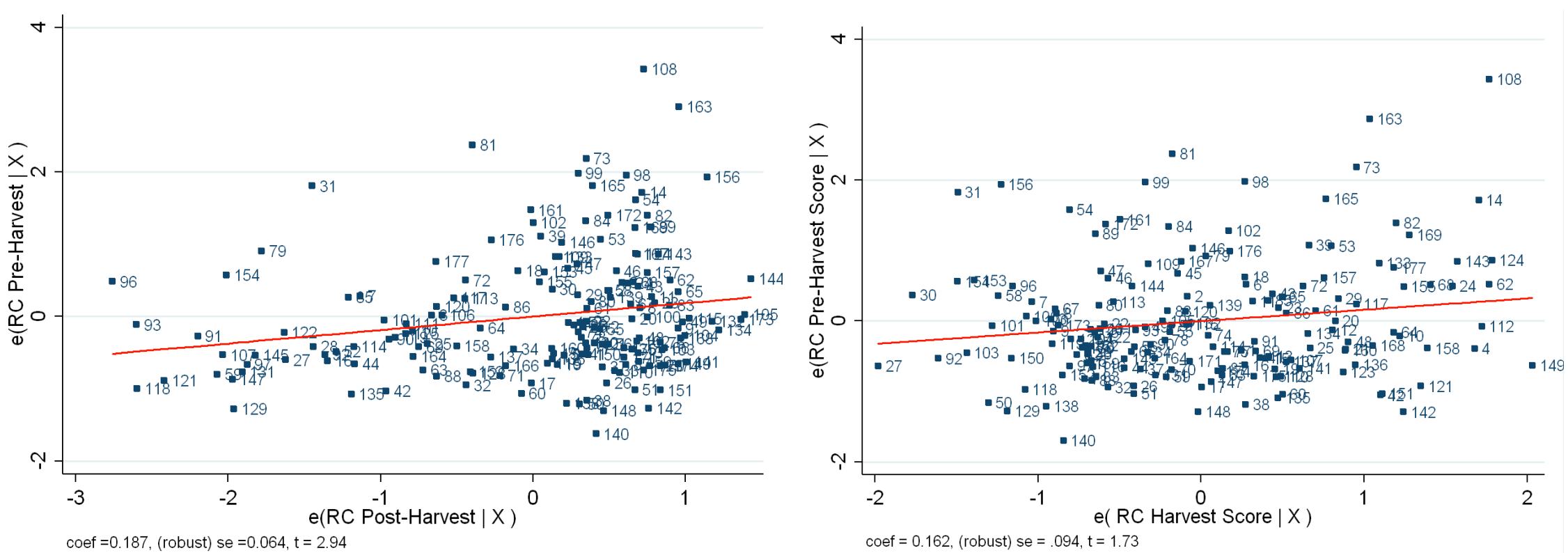

coef $=0.187$, (robust) se $=0.064, t=2.94$

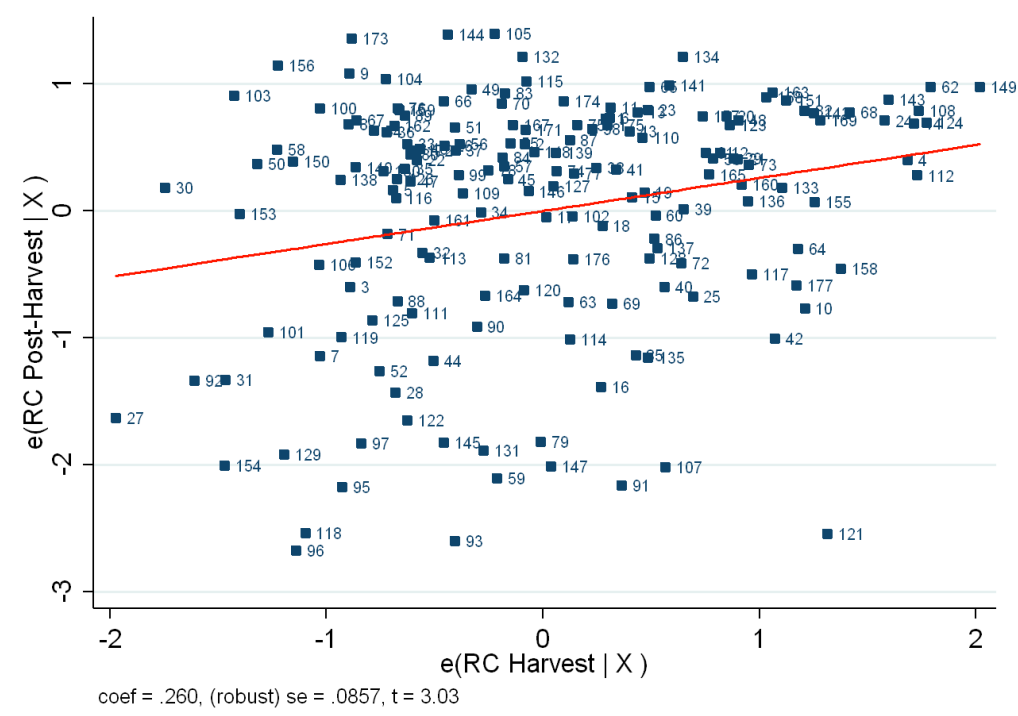

Notes: These figures display the conditional correlations between the different relational contract scores. Controls are mill and geographic characteristics within the mills catchment area. Unconditional correlations are: Corr(pre-harvest, harvest $)=0.211^{* * *}$; Corr(harvest, post-harvest $)=0.321^{* * *}$ and Corr (pre-harvest, post-harvest $)=0.221^{* * *}$. Source: author's mill survey. 


\section{FIGURE 4: DISPERSION IN CAPACITY UTILIZATION}

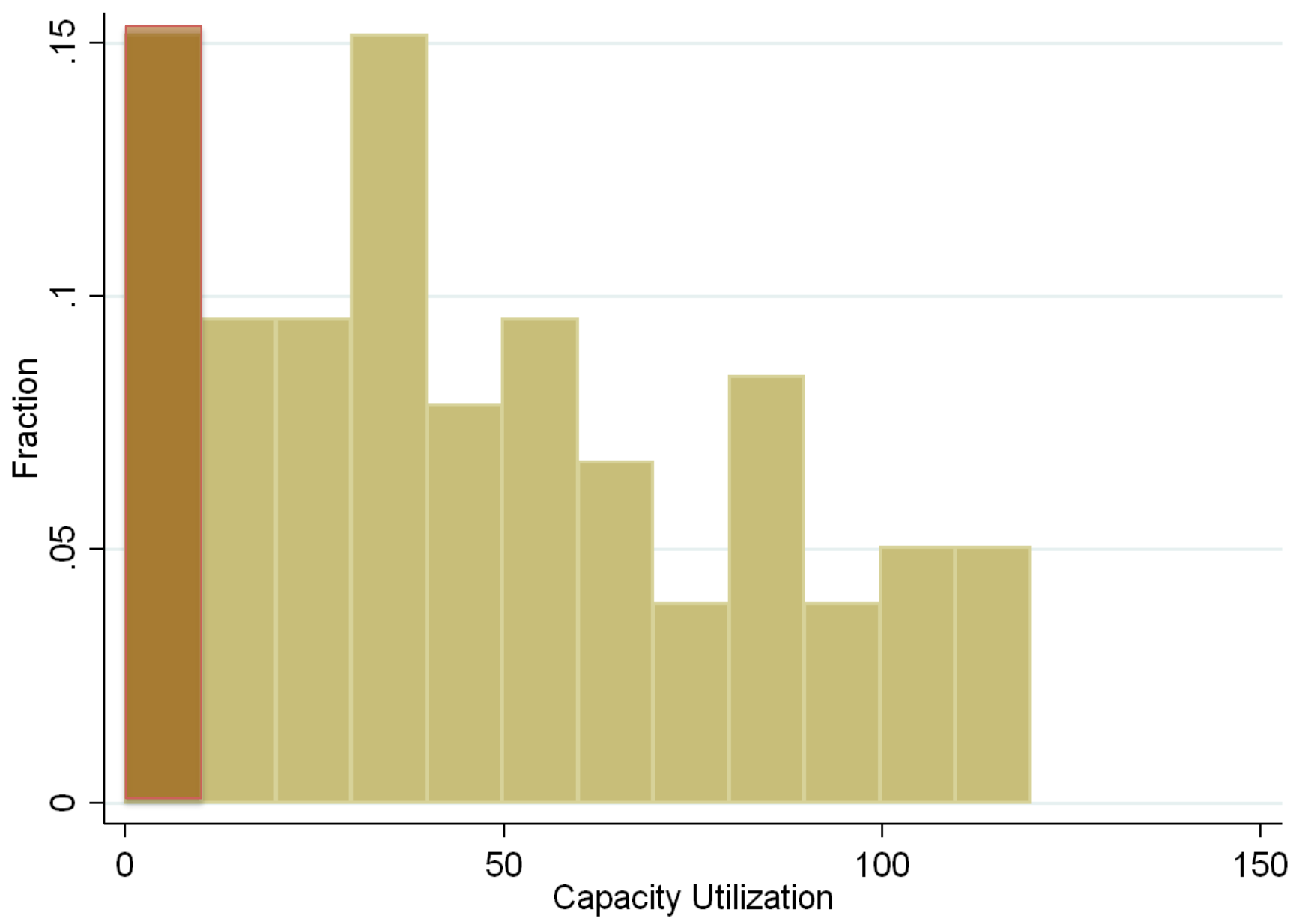

Notes: This figure displays the distribution of capacity utilization by mills for the 2012 season. In aggregate only $60 \%$ of the installed capacity is utilized. In the survey we conducted approximately $40 \%$ of the stations reported to have had days in which they wanted to purchase coffee cherries but could not. 
FIGURE 5:VALIDATING RELATIONAL CONTRACT SCORE:

UNIT COST OF PROCESSING AND UTILIZATION OF MILL

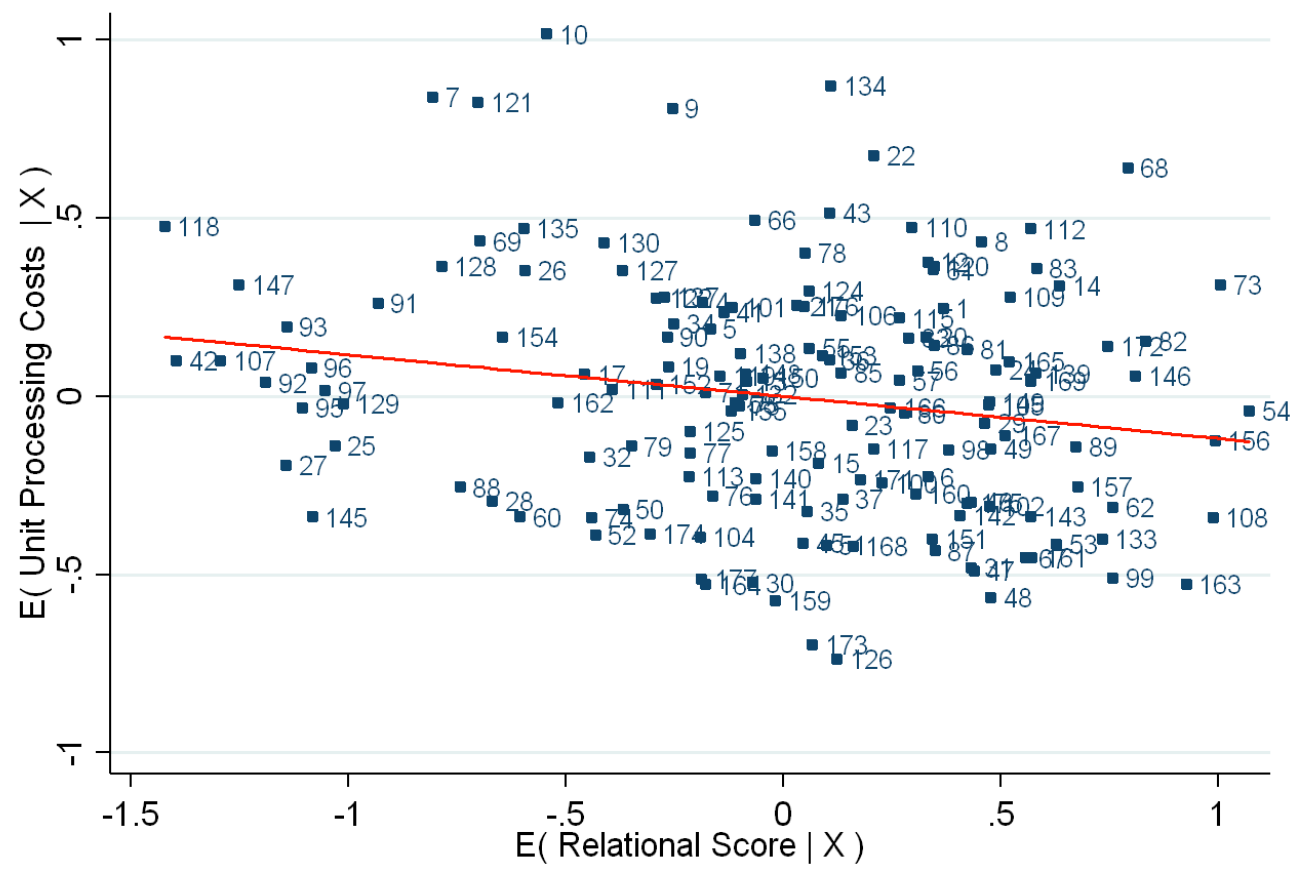

coef $=-0.12$, (robust) se $=0.05, t=-2.4$

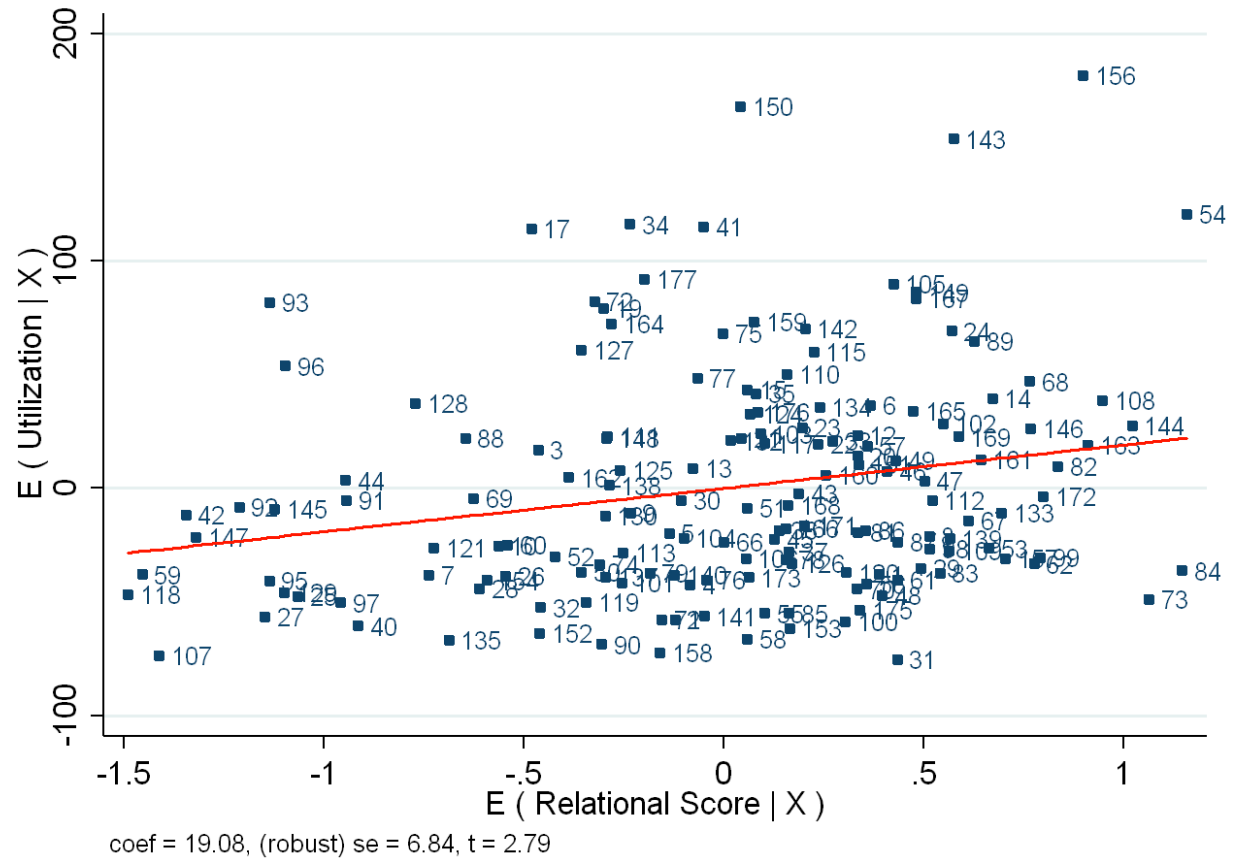

Notes: These figures show that the relational contract score correlates with mill performance measures, unit processing cost and utilization of capacity installed, conditional on a host of geographic characteristics and mill controls. Source: author's survey. 


\section{FIGURE 6: GRAPHICAL REPRESENTATION OF THE COMPETITION MEASURE}

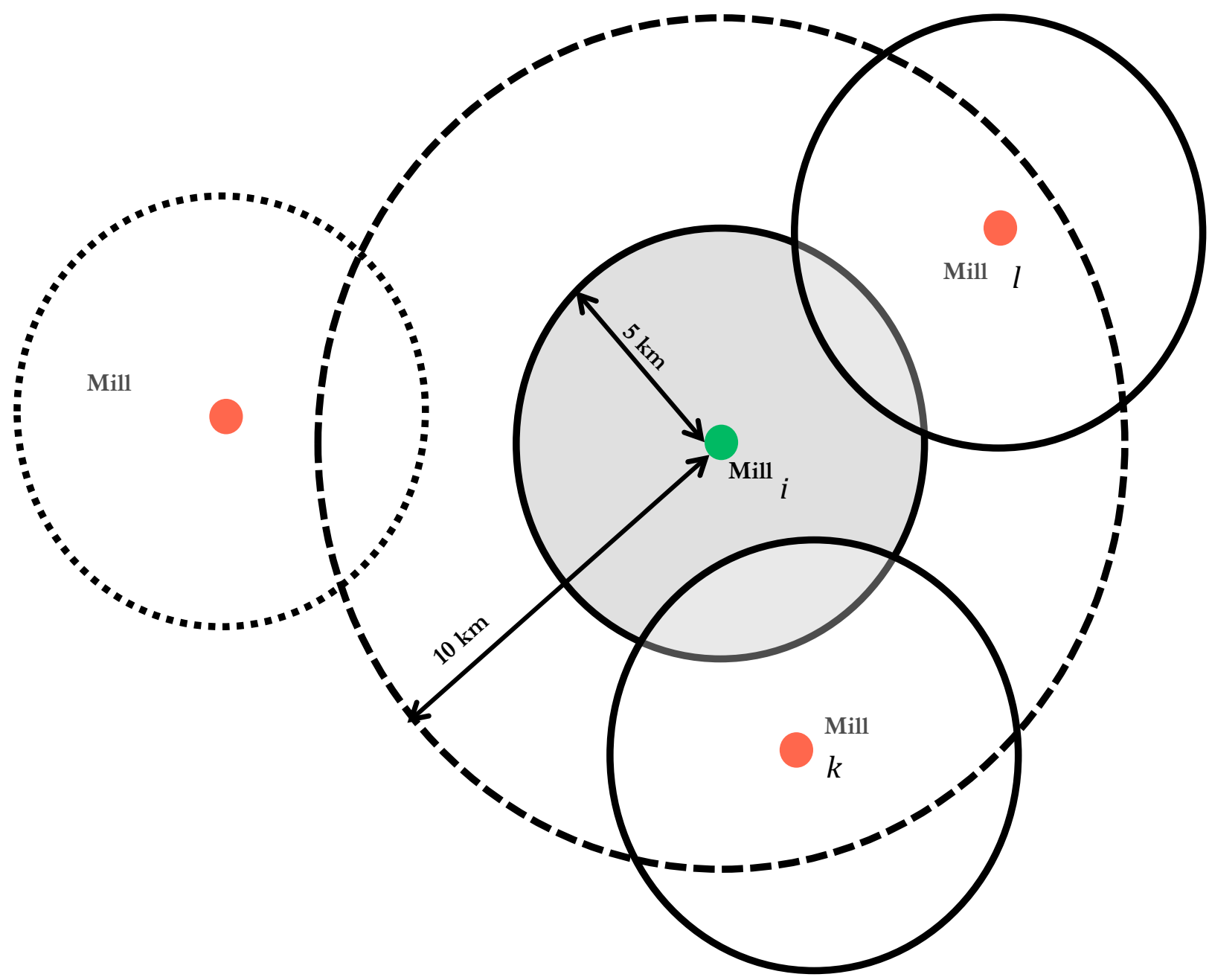

Notes: The figure shows the $5 \mathrm{~km}$ catchment area for mill i. Any mill within a $10 \mathrm{~km}$ radius of mill $\mathrm{i}$ will have a catchment area that overlaps (at least to some extent) with mill i's catchment area. The overlap is illustrated in the graph for mill $\mathrm{k}$ and $\mathrm{I}$. Our competition measure based on a $5 \mathrm{~km}$ catchment area therefore includes all mills within a $10 \mathrm{~km}$ radius. This is represented by the dashed circle in the figure. 
FIGURE 7: COMPETITION BETWEEN MILLS WITHIN 10 KM RADIUS

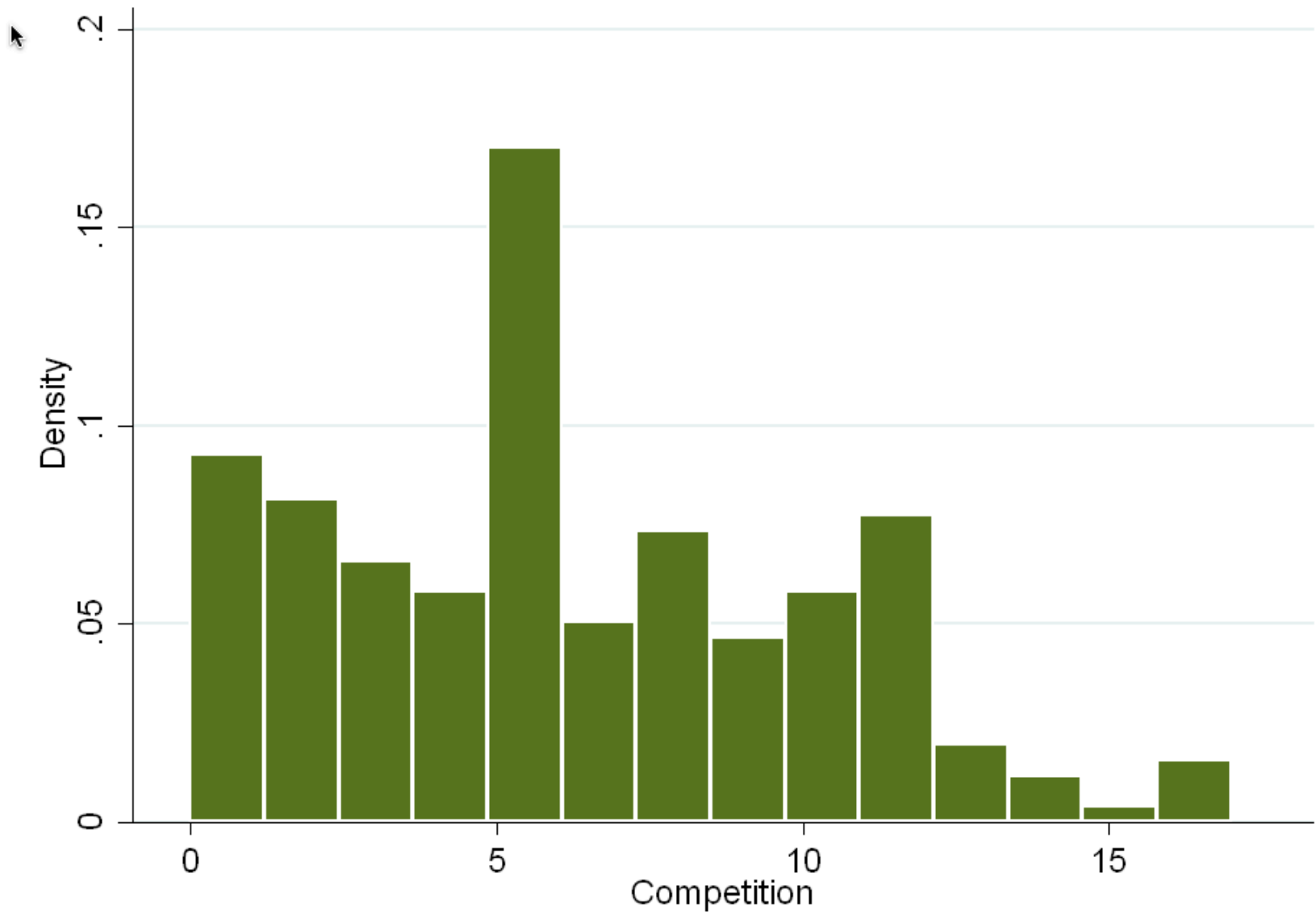

Notes: The figure plots the distribution of the number of competing mills within $10 \mathrm{~km}$ 's of each mill, the underlying data is the geo-coded coordinates of the mills. Source: author's calculation and mill survey 2012. 
FIGURE 8: ENGINEERING MODEL

Panel A, Criteria and Mills

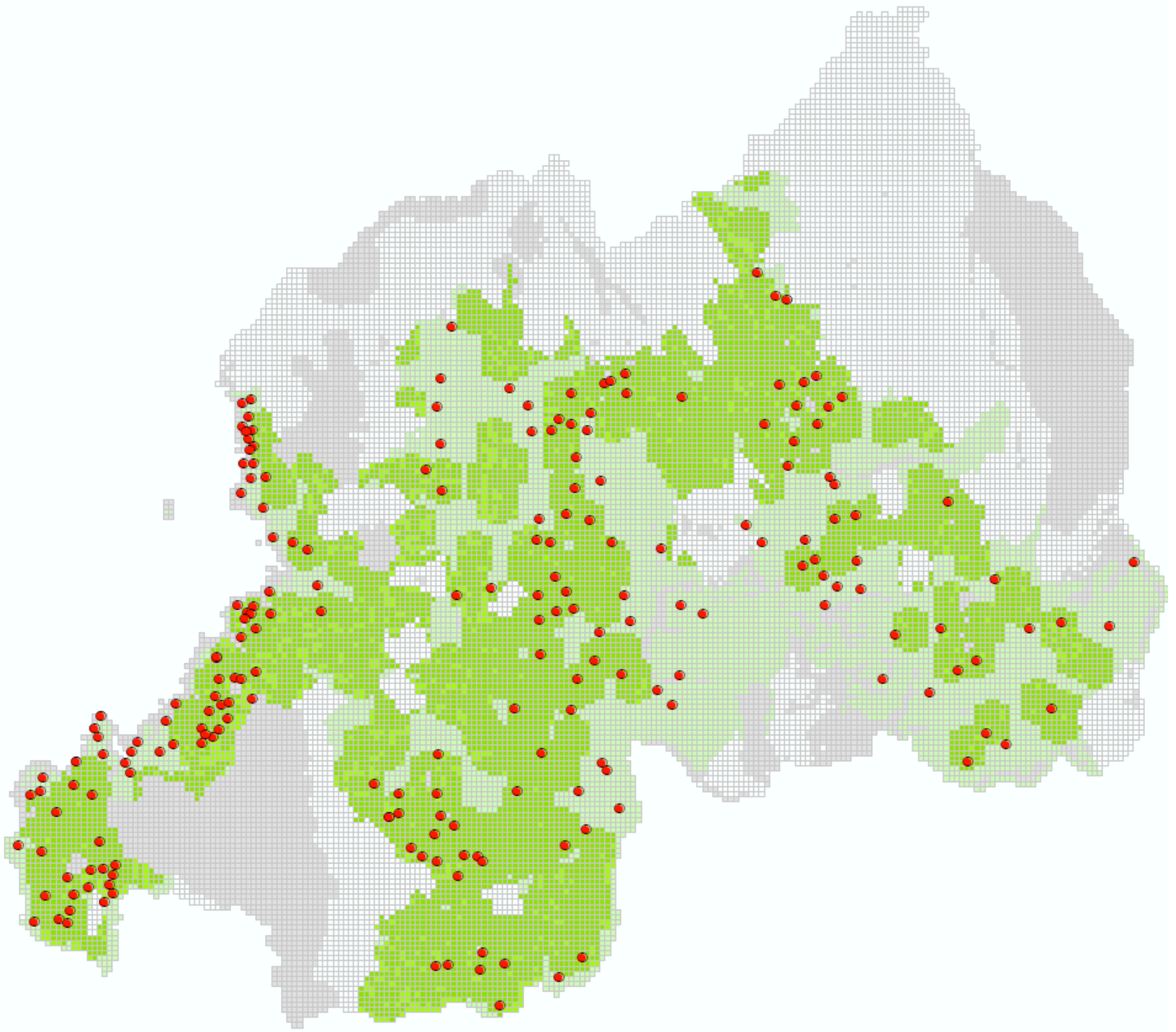

Notes: This figure illustrates the engineering model's criteria; the dark grey grid boxes are ineligible for mill placement due to presence of national parks, water body or are built up areas. The lightest green illustrates grid boxes that satisfy the number of trees necessary for mill placement, the brightest green areas highlight where the grid boxes satisfy all the criteria (trees, availability of water and roads). Red dots depict presence of a mill. Source: author's calculation on various GIS datasets, see Appendix for additional details. 
FIGURE 8: ENGINEERING MODEL

Panel B, Mill Placement and Presence of Coffee Trees

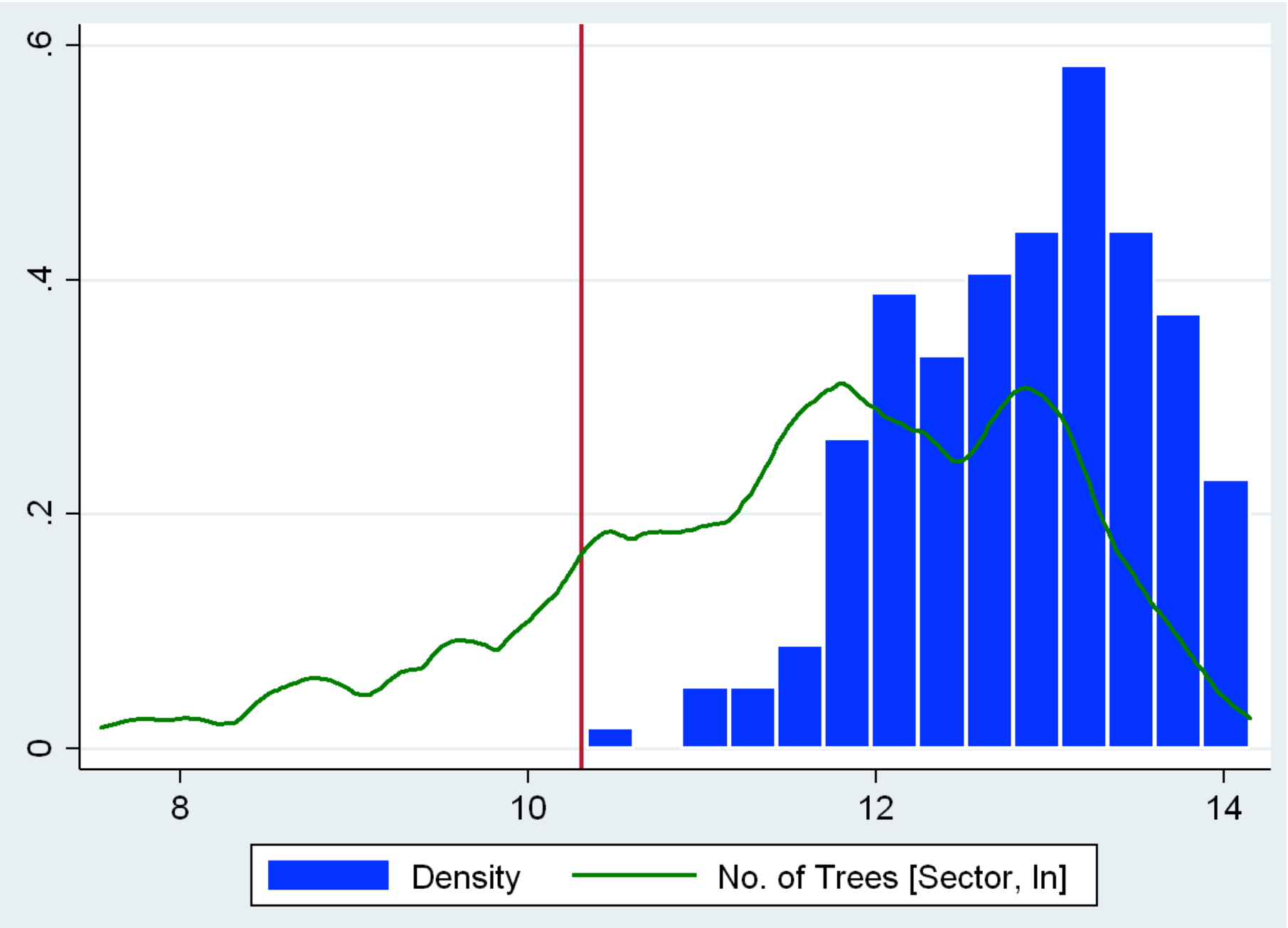

Notes: This figure plots the kernel density of coffee trees in all the administrative sectors of Rwanda (in green) that have coffee trees, and overlays on a histogram, that shows the number of coffee trees in the sector in which a mill is present (in blue). The red line indicates threshold from the engineering model, the minimum number of trees that should be available in a sector to attract a mill. Source: author's calculation, mill census and coffee census $2008 / 09$. 
FIGURE 8: ENGINEERING MODEL

Panel C, Mill Placement

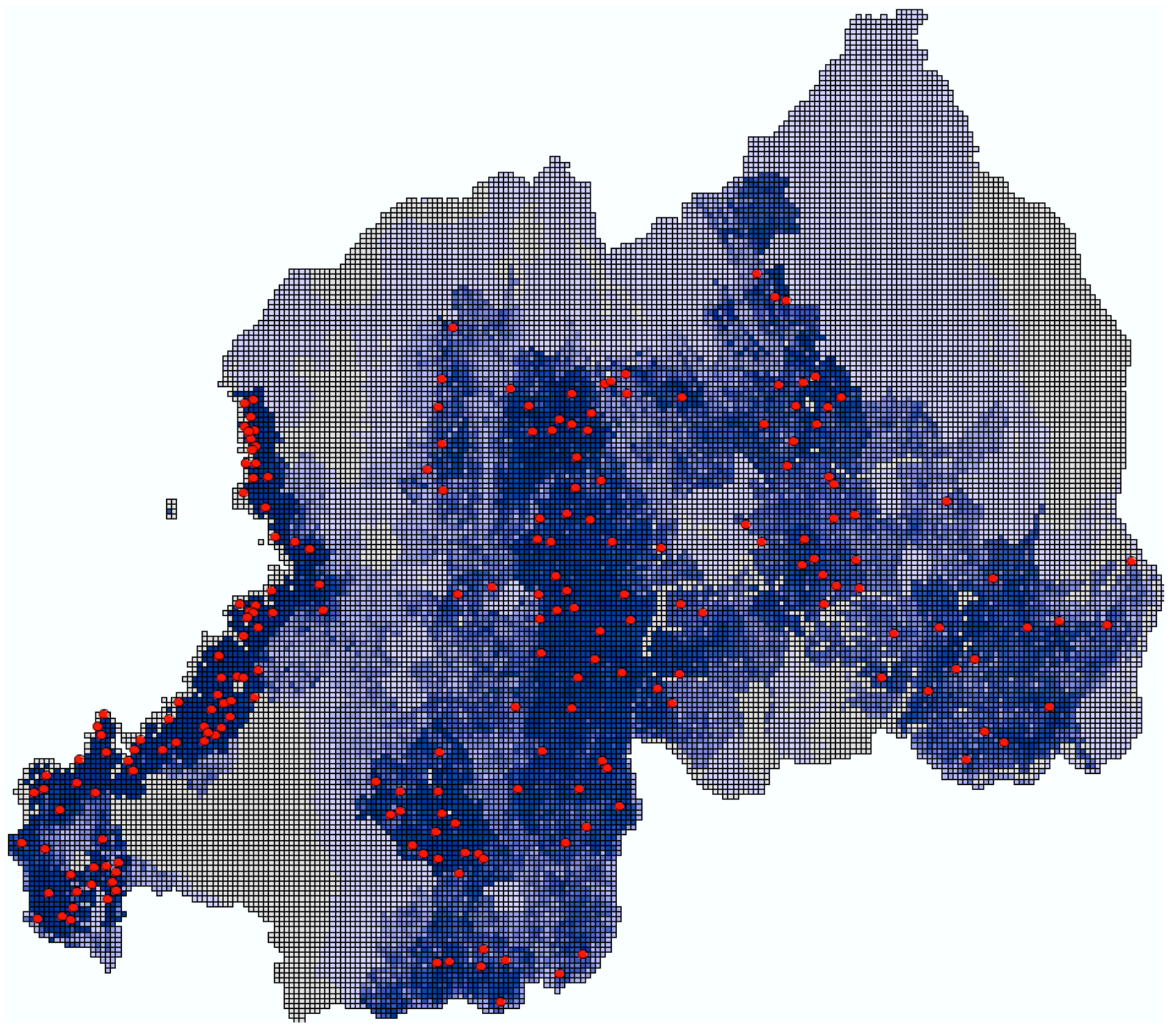

Notes: This figure illustrates, the predicted "score" for the placement of a wet mill in each grid box (1 square kilometre) in Rwanda using our model of mill placement, which is driven by engineering considerations for the optimal placement of mills. The darker the color higher the probability of mill placement. Red dots illustrate existing mills. 


\section{FIGURE 9: PARTIAL REGRESSION PLOTS, FIRST STAGE}

PANEL A, WITHOUT CONTROLS

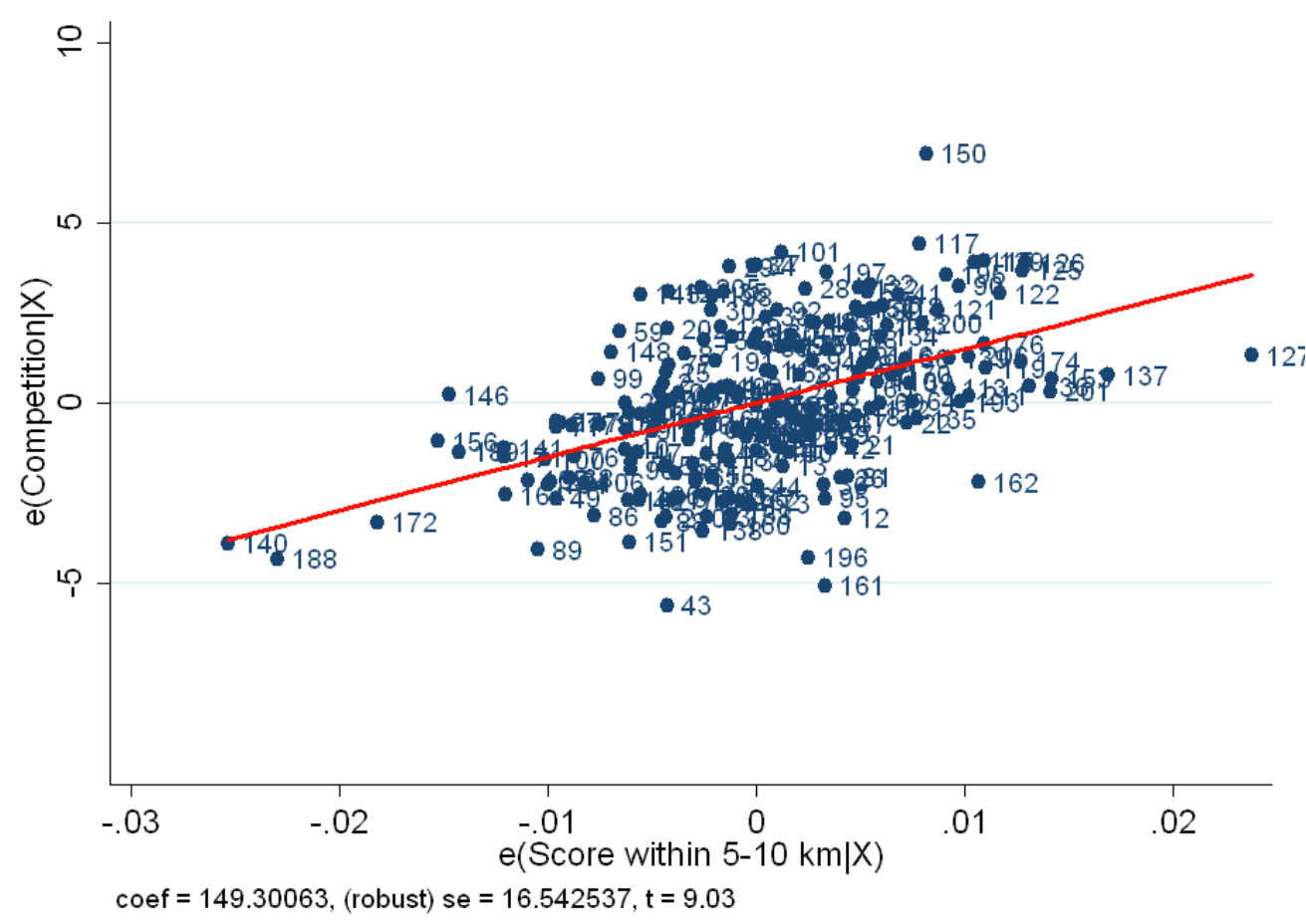

PANEL B, WITH CONTROLS

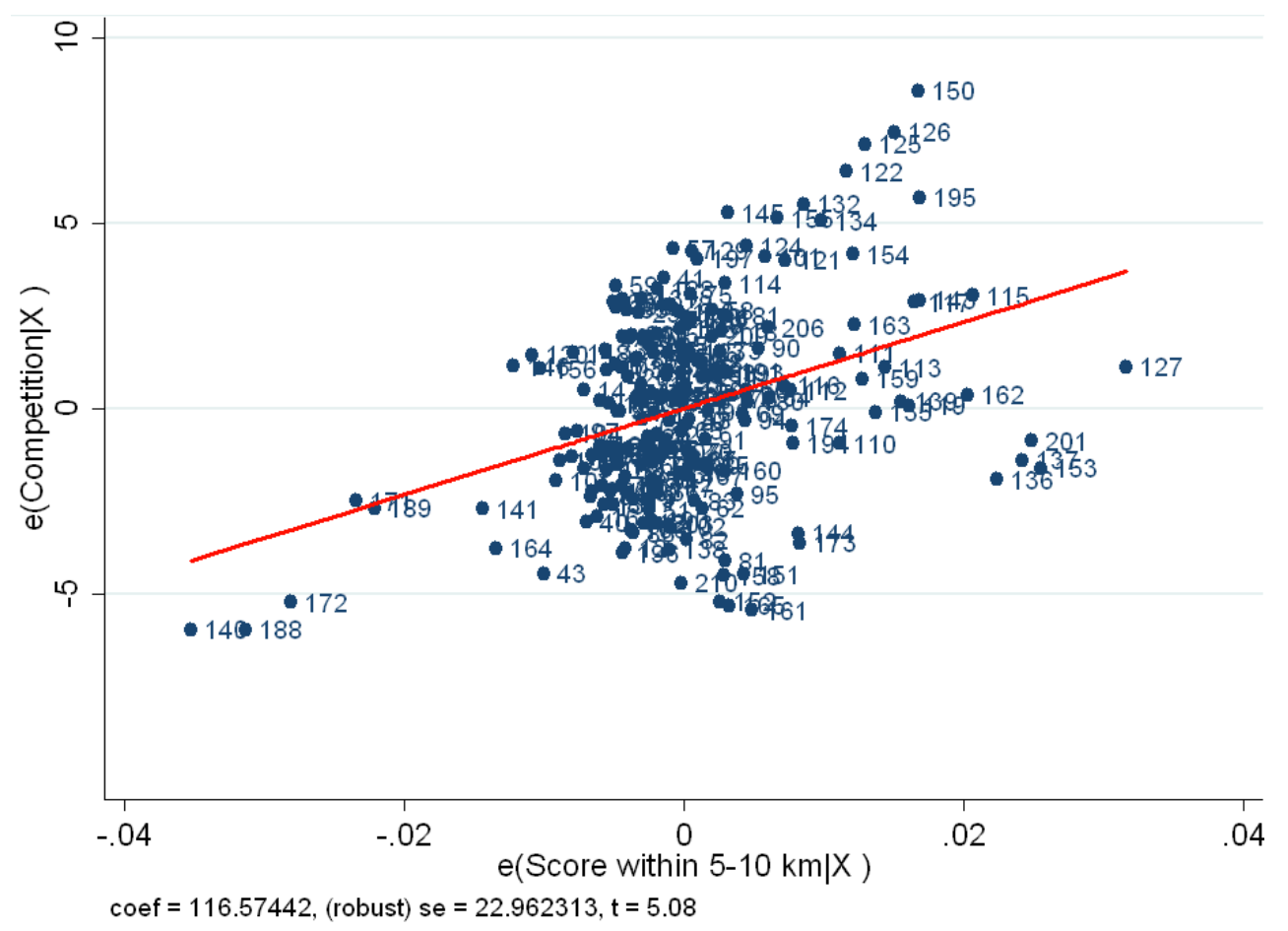

Notes: This figure plots the partial regression between competition (number of mill within $10 \mathrm{~km}$ of a mill) and the score within $5-10 \mathrm{~km}$. Controlling for the score $5-10 \mathrm{~km}$ and the presence of spring and roads, elevation, slope, suitability, latitude and longitude within $5 \mathrm{~km}$ as well as mill characteristics. 
FIGURE 10: REDUCED FORM - RELATIONAL CONTRACTS AND INSTURMENT

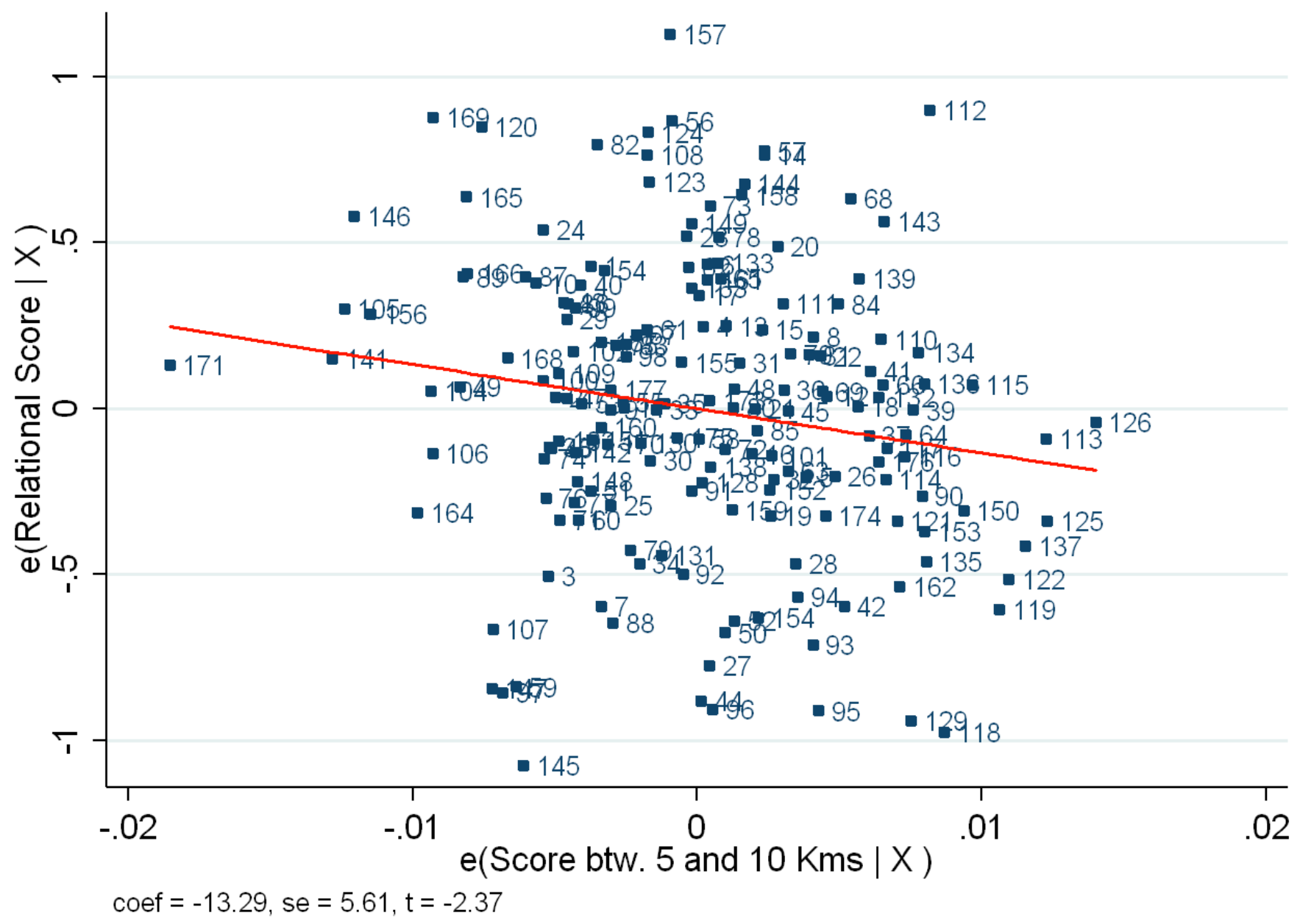

Notes: The Figure plots the reduced form relationship between the relational score and our instrument. The Figure is a partial regression plot in which all controls included in the second stage are accounted for. The Figure corresponds to Column 3 of Table 5. 
FIGURE 11: NON-PARAMETRIC ESTIMATED COEFFICIENTS

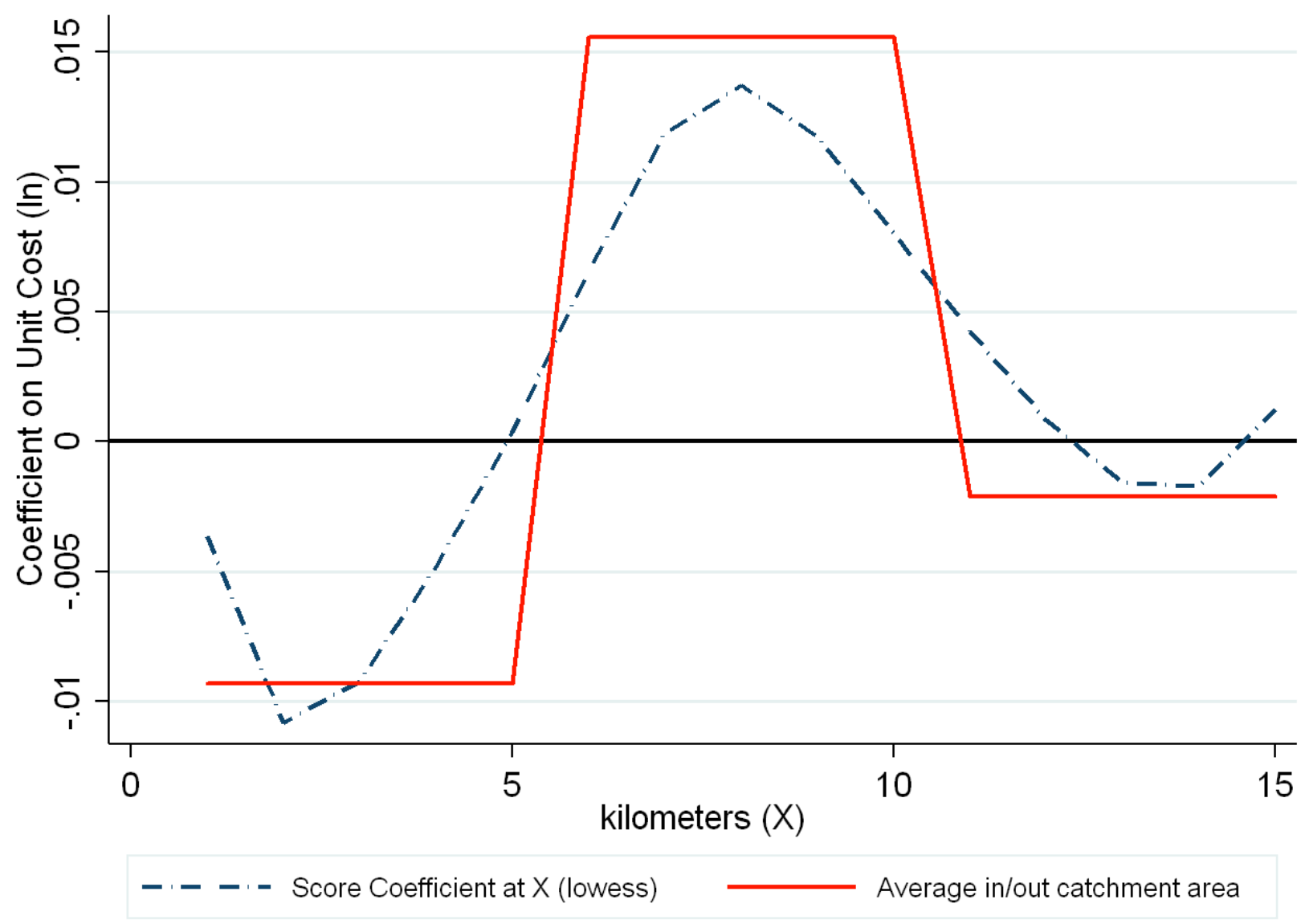

Notes: The Figure plots local polynomial estimates of a non-parametric version of the reduced form between the average suitability score at each $\mathrm{km}$ distance from the mill and operational costs (In). The dotted line illustrates the estimated coefficients while the continuous line represents the average of the reduced form coefficients at $5 \mathrm{kms}$ intervals, thereby reflecting the size of the catchment and surrounding areas in the baseline specification. The figure shows that a better suitability score is associated with lower unit costs in the proximity of the mill and with higher unit costs outside the catchment area. 
FIGURE 12: MILL ORDER OF ENTRY AND SCORE

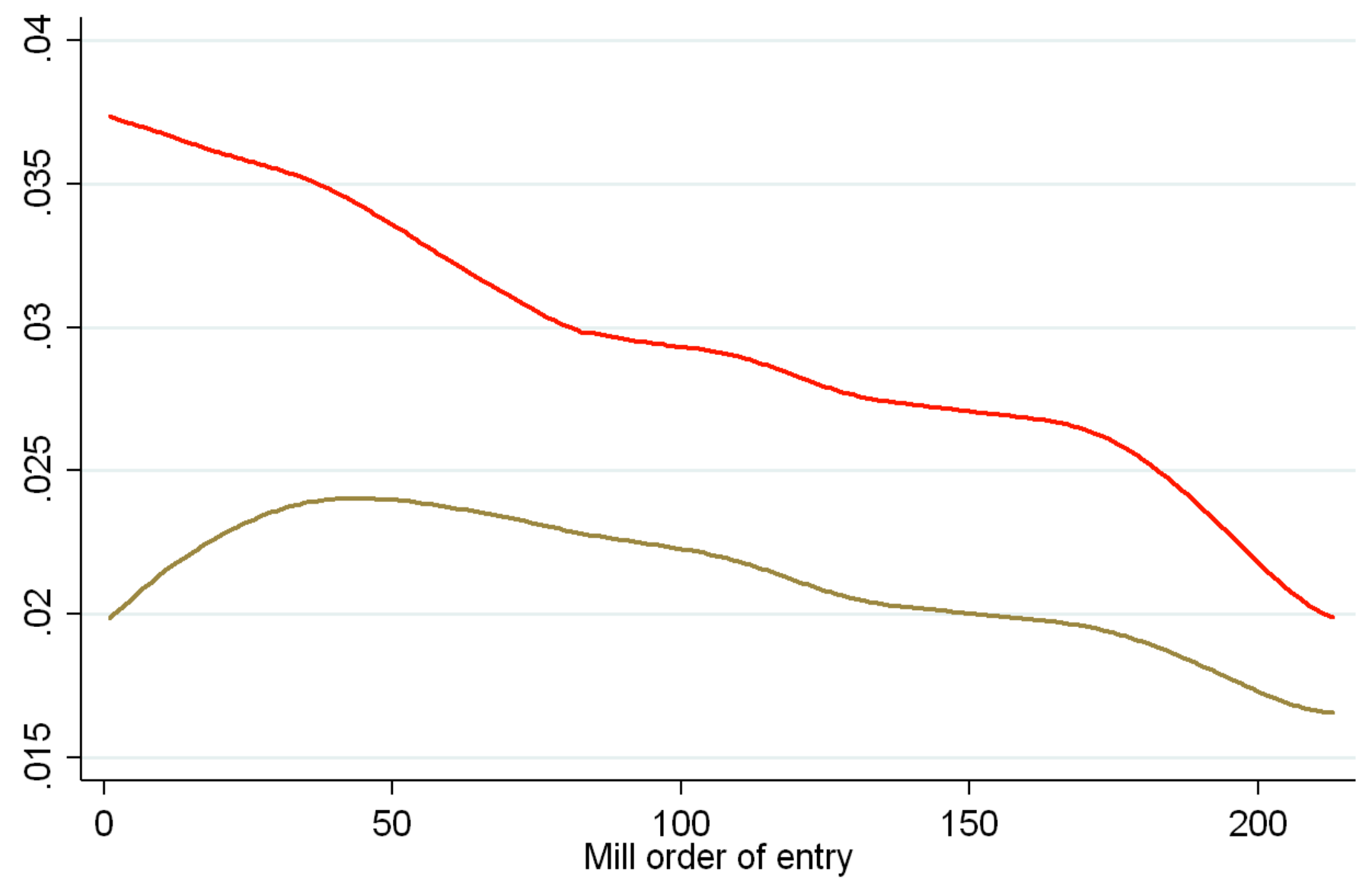

\section{Score within $5 \mathrm{Kms}$}

\section{Score between 5 and $10 \mathrm{Kms}$.}

Notes: The figure plots (lowess) average score within the catchment area $(<5 \mathrm{Kms})$ and around it (between 5 and $10 \mathrm{Kms}$ ) against the order of entry. The figure shows that earlier entrants located in better areas (higher average $<5 \mathrm{Kms}$ score) but do not appear to have chosen location according to average score between 5 and $10 \mathrm{Kms}$. Regressions results confirm that, once controlling for score within $5 \mathrm{Kms}$, score between 5 and 10 doesn't correlate with the order of entry. 


\section{APPENDIX FIGURE 1: DISPERSION IN TOTAL UNIT COSTS}
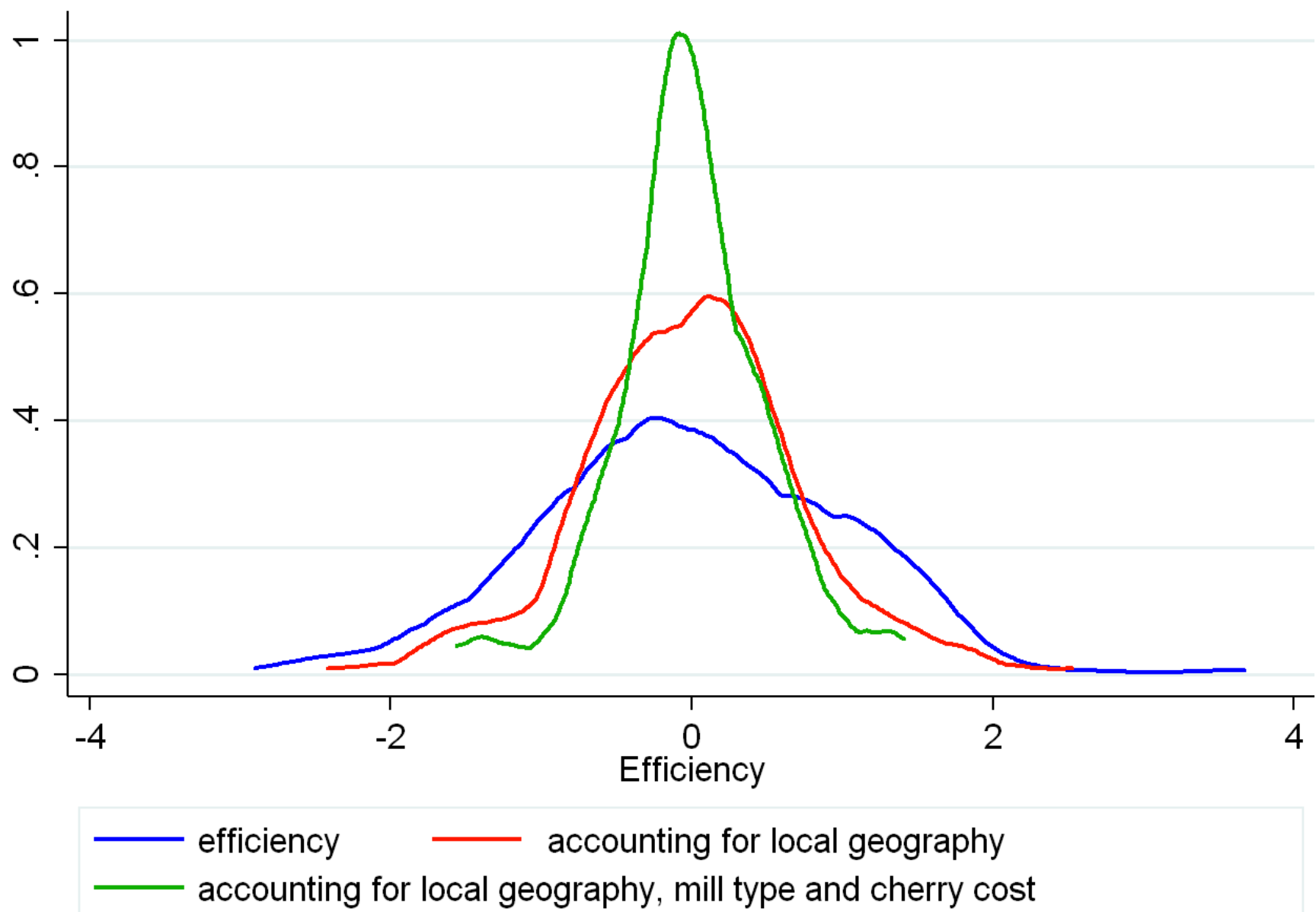

Notes: This figure shows the distribution (standardized) of efficiency, which we define as the total unit cost of obtaining one kilogram of parchment (in blue). We then control for local geography (in red) of the mill (elevation, slope, historical suitability of coffee, density of coffee trees in the sector, length of road and river), the type of mill (private or cooperative) and the local cost of purchasing cherries (in green). Source: author's calculation on mill survey and GIS data, various. 
TABLE 1: DESCRIPTIVE STATISTICS, BASIC MILL CHARACTERISTICS

\begin{tabular}{lccc}
\hline Variable: & Mean & Median & $\begin{array}{c}\text { Private vs } \\
\text { Cooperatives }\end{array}$ \\
\hline Cooperative (=1) & 0.54 & 1 & -- \\
Theoretical Capacity (Tons) & 447 & 500 & $162.59^{* * *}$ \\
End of Season Utlization Rate & $47.20 \%$ & $32.40 \%$ & $-11.36^{* * *}$ \\
Average Price Paid to Farmers (RWF) & 208.53 & 200.00 & $4.44^{* * *}$ \\
Output per worker & 3.98 & 3.11 & $3.4^{* *}$ \\
Workers per ton of capacity installed & 0.21 & 0.18 & $-0.04^{* *}$ \\
Production (Tons of Green Coffee) & 46.01 & 32.00 & $18.09^{* * *}$ \\
Cherries Purchased (Tons) & 294.82 & 199.91 & $120.40^{* * *}$ \\
Unit Costs [RWF per Kg] & 1793 & 1800 & $97.93^{* * *}$ \\
Altitude (m) & 1584 & 1571 & 1.615 \\
Historic Suitability for Coffee & 0.50 & 0.485 & 0.002 \\
Current Suitability for Coffee & 0.61 & 0.606 & -0.014 \\
Distance to nearest paved road (km) & 14.52 & 10.00 & 1.031 \\
\hline
\end{tabular}

Notes: Mill characteristics data obtained from survey of mill census in the 2012 harvest season.

Number of mills 178; see Data Appendix for additional details. 
TABLE 2: MEASURES OF RELATIONAL CONTRACTS

\begin{tabular}{|c|c|c|}
\hline Variable: & Mean & SD \\
\hline \multicolumn{3}{|c|}{ Panel A: Farmer Survey Module $(\mathrm{N}=890)$} \\
\hline \multicolumn{3}{|l|}{ Pre-Harvest } \\
\hline Received loans from mill & 0.173 & 0.378 \\
\hline Received fertilizers from mill & 0.176 & 0.381 \\
\hline Has received help for unexpected expense from mill in the past & 0.250 & 0.433 \\
\hline \multicolumn{3}{|l|}{ Harvest } \\
\hline Sold Cherries in Advance & 0.066 & 0.248 \\
\hline Sold Cherries on Credit & 0.157 & 0.300 \\
\hline \multicolumn{3}{|l|}{ Post-Harvest } \\
\hline Expects to Receive Help & 0.637 & 0.481 \\
\hline Received Second Payment & 0.695 & 0.404 \\
\hline \multicolumn{3}{|c|}{ Panel B: Manager Survey Module ( $\mathrm{N}=178)$} \\
\hline \multicolumn{3}{|l|}{ Pre-Harvest } \\
\hline Given Loans to Farmers & 0.159 & 0.365 \\
\hline Given Fertilizers to Farmers & 0.516 & 0.501 \\
\hline Given Training to Farmers & 0.272 & 0.445 \\
\hline \multicolumn{3}{|l|}{ Harvest } \\
\hline Has Purchased Cherries on Credit & 0.306 & 0.461 \\
\hline \multicolumn{3}{|l|}{ Post-Harvest } \\
\hline Has made Second Payment in Past & 0.459 & 0.499 \\
\hline Delayed Payment (i.e. non-spot) & 0.226 & 0.410 \\
\hline Mill provides loans to help farmers & 0.772 & 0.420 \\
\hline
\end{tabular}


TABLE 3: OLS ESTIMATES

COMPETITION AND UNPACKING RELATIONAL CONTRACTS

\begin{tabular}{|c|c|c|c|c|c|c|c|c|c|c|}
\hline & [1] & [2] & [3] & [4] & [5] & [6] & [7] & [8] & [9] & {$[10]$} \\
\hline & $\begin{array}{c}\text { PRE-HARVEST } \\
\text { FARMER }\end{array}$ & $\begin{array}{c}\text { PRE-HARVEST } \\
\text { MANAGER }\end{array}$ & $\begin{array}{c}\text { PRE- } \\
\text { HARVEST }\end{array}$ & $\begin{array}{l}\text { HARVEST } \\
\text { FARMER }\end{array}$ & $\begin{array}{l}\text { HARVEST } \\
\text { MANAGER }\end{array}$ & HARVEST & $\begin{array}{c}\text { POST-HARVEST } \\
\text { FARMER }\end{array}$ & $\begin{array}{c}\text { POST-HARVEST } \\
\text { MANAGER }\end{array}$ & $\begin{array}{c}\text { POST- } \\
\text { HARVEST }\end{array}$ & $\begin{array}{l}\text { RELATIONAL } \\
\text { CONTRACT }\end{array}$ \\
\hline Dependent Variable & $\begin{array}{c}\text { Received } \\
\text { Fertilizer from } \\
\text { Mill }\end{array}$ & $\begin{array}{l}\text { Fertilizer given to } \\
\text { Farmers }\end{array}$ & Z-SCORE & $\begin{array}{l}\text { Sold Cherries on } \\
\text { Credit }\end{array}$ & $\begin{array}{l}\text { Has purchased } \\
\text { cherries on credit }\end{array}$ & Z-SCORE & $\begin{array}{l}\text { Received Second } \\
\text { Payment }\end{array}$ & $\begin{array}{c}\text { Has made } \\
\text { Second Payment }\end{array}$ & Z-SCORE & Z-SCORE \\
\hline Competition & $\begin{array}{c}-0.075^{\star * *} \\
(0.024)\end{array}$ & $\begin{array}{l}-0.048^{*} \\
(0.029)\end{array}$ & $\begin{array}{l}-0.062^{* *} \\
(0.024)\end{array}$ & $\begin{array}{l}-0.003 \\
(0.003)\end{array}$ & $\begin{array}{c}-0.039 \\
(0.0031)\end{array}$ & $\begin{array}{l}-0.024 \\
(0.025)\end{array}$ & $\begin{array}{c}-0.129^{\star \star *} \\
(0.029)\end{array}$ & $\begin{array}{l}-0.051^{*} \\
(0.031)\end{array}$ & $\begin{array}{c}-0.089^{\star \star *} \\
(0.024)\end{array}$ & $\begin{array}{c}-0.059^{\star * *} \\
(0.014)\end{array}$ \\
\hline Geographical Controls & yes & yes & yes & yes & yes & yes & yes & yes & yes & yes \\
\hline Mill Controls & yes & yes & yes & yes & yes & yes & yes & yes & yes & yes \\
\hline Farmer Controls & yes & - & - & yes & - & - & yes & - & - & - \\
\hline Adjusted R square & 0.353 & 0.160 & 0.251 & 0.094 & 0.146 & 0.116 & 0.198 & 0.076 & 0.194 & 0.229 \\
\hline Observations & 890 & 178 & 178 & 890 & 178 & 178 & 890 & 178 & 178 & 178 \\
\hline
\end{tabular}

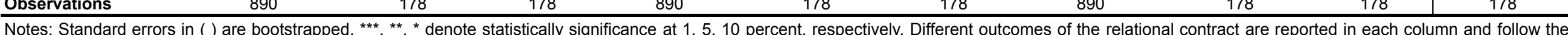

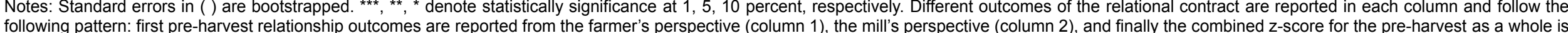

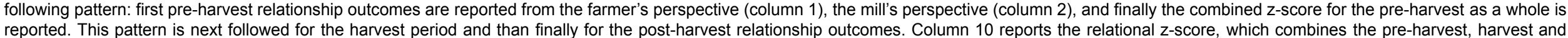

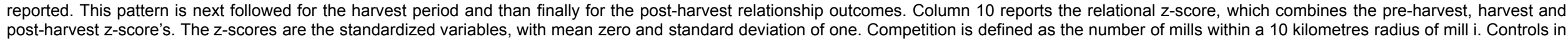

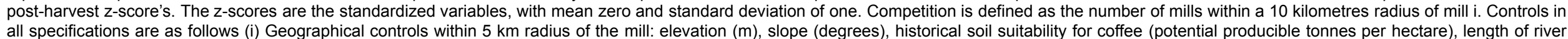

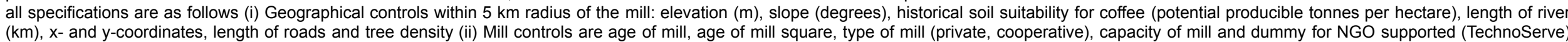
$(\mathrm{km}), x$ - and $y$-coordinates, length of roads and tree density (ii) Mill controls are age of mill, age of mill square,
and (iii) Farmer controls: age, gender, schooling attainment, distance to mill, cognitive ability and size of farm. 
TABLE 4: VALIDATING THE ENGINEERING MODEL OF OPTIMAL MILL PLACEMENT

\begin{tabular}{|c|c|c|c|c|}
\hline \multirow{3}{*}{$\begin{array}{l}\text { Model: } \\
\text { Dependent Variable: }\end{array}$} & \multicolumn{4}{|c|}{ Probit } \\
\hline & \multicolumn{4}{|c|}{ Mill in Grid Box=1 } \\
\hline & (1) & (2) & (3) & (4) \\
\hline Spring within $3 \mathrm{~km}$ of grid box at elevation window $=1$ & $\begin{array}{l}0.422^{* *} \\
(0.166)\end{array}$ & & $\begin{array}{l}0.423^{* *} \\
(0.166)\end{array}$ & $\begin{array}{c}-3.931^{* * *} \\
(0.107)\end{array}$ \\
\hline Untarred Local Road within $1 \mathrm{~km}$ of grid box $=1$ & & $\begin{array}{l}0.362^{* * *} \\
(0.137)\end{array}$ & $\begin{array}{c}0.362^{* * *} \\
(0.137)\end{array}$ & $\begin{array}{l}0.336^{* *} \\
(0.137)\end{array}$ \\
\hline $\begin{array}{l}\text { (Spring within } 3 \mathrm{~km} \text { of grid box at elevation window = } \\
1)^{\star}(\text { Untarred Local Road within } 1 \mathrm{~km} \text { of grid box }=1)\end{array}$ & & & & $\begin{array}{l}4.379^{* * *} \\
(0.264)\end{array}$ \\
\hline $\begin{array}{l}\text { Controls: Geographical Polynomials } \\
\text { Controls: Geographical Polynomials \& Interactions } \\
\text { Pseudo R2 }\end{array}$ & $\begin{array}{c}\text { yes } \\
\text { yes } \\
0.120\end{array}$ & $\begin{array}{c}\text { yes } \\
\text { yes } \\
0.121\end{array}$ & $\begin{array}{c}\text { yes } \\
\text { yes } \\
0.124\end{array}$ & $\begin{array}{c}\text { yes } \\
\text { yes } \\
0.125\end{array}$ \\
\hline Observations & 13970 & 13970 & 13970 & 13970 \\
\hline
\end{tabular}

Notes: Standard errors in ( ) are clustered at the sector level. ${ }^{* * *},{ }^{* *},{ }^{*}$ denote statistically significance at $1,5,10$ percent, respectively. The unit of analysis is 1 square kilometer (Grid Box). Sample of gridboxes with at least 30,000 coffee trees and potential for agriculture; grid boxes that are on land cover that is built-up, natural forest, runway or completely submerged in water body is excluded. Geographical controls are elevation, slope, historic coffee suitability, river (length), tree density in the sector, $x$ - and $y$ - coordinates. Cubic polynomials of the geographic controls as well as all there interactions are included. Spring within $3 \mathrm{~km}$ of grid box, with elevation window of 10 to $30 \mathrm{~m}$, at least $20 \%$ of the grid area to be in the elevation window. 
TABLE 5: IV ESTIMATES - COMPETITION AND RELATIONAL CONTRACTS

\begin{tabular}{|c|c|c|c|c|}
\hline & & FIRST STAGE & REDUCED FORM & IV \\
\hline & [1] & [2] & [3] & [4] \\
\hline Model & OLS & OLS & OLS & 2SLS \\
\hline Dependent Variable & $\begin{array}{c}\text { Relational Contract } \\
\text { (Z-Score) }\end{array}$ & Competition & $\begin{array}{c}\text { Relational Contract } \\
\text { Score (Z-Score) }\end{array}$ & $\begin{array}{c}\text { Relational Contrac } \\
\text { (Z-Score) }\end{array}$ \\
\hline Competition & $\begin{array}{l}-0.044^{* *} \\
(0.015)\end{array}$ & & & $\begin{array}{l}-0.085^{\star *} \\
(0.041)\end{array}$ \\
\hline Score within 5-10 km of Mill (predict) & & $\begin{array}{c}151.40^{* * *} \\
(23.642)\end{array}$ & $\begin{array}{c}-13.29 * * \\
(5.61)\end{array}$ & \\
\hline $\begin{array}{l}\text { Score within } 5 \mathrm{~km} \text { of Mill (predict) } \\
\text { Eng Model Criteria } \\
\text { Geographical Controls } \\
\text { Mill Controls }\end{array}$ & $\begin{array}{l}\text { yes } \\
\text { yes } \\
\text { yes } \\
\text { yes }\end{array}$ & $\begin{array}{l}\text { yes } \\
\text { yes } \\
\text { yes } \\
\text { yes }\end{array}$ & $\begin{array}{l}\text { yes } \\
\text { yes } \\
\text { yes } \\
\text { yes }\end{array}$ & $\begin{array}{l}\text { yes } \\
\text { yes } \\
\text { yes } \\
\text { yes }\end{array}$ \\
\hline Adjusted R square & 0.170 & 0.762 & 0.159 & 0.210 \\
\hline Observations & 178 & 178 & 178 & 178 \\
\hline
\end{tabular}

Notes: Standard errors in ( ) are bootstrapped. ${ }^{* * *},{ }^{* *},{ }^{*}$ denote statistically significance at $1,5,10$ percent, respectively. Column 4 , reports 2 SLS estimation. Competition is defined as the number of mills within a 10 kilometer radius of mill. Competition in column 4 is instrumented by the average Score (predict) from the engineering model within $5-10 \mathrm{~km}$ radius of mill. All specifications conditional on controlling for the Score (predict) within $5 \mathrm{~km}$ radius of mill i. Controls in all specifications are (i) Engineering model (presence of spring within $3 \mathrm{~km}$ of grid at the elevation window of -30 to $-10 \mathrm{~m}$, and roads within $1 \mathrm{~km}$ ), Geographical controls within $5 \mathrm{~km}$ radius of mill i: elevation $(\mathrm{m})$, slope (degrees), historical soil suitability for coffee (potential producible tonnes per hectare), length of river $(\mathrm{km}) ; \mathrm{x}$ - and $\mathrm{y}$-coordinates, length of roads and tree density. Mill controls are age of mill, age of mill square, type of mill (private, cooperative), capacity of mill and NGO supported (TechnoServe). 
TABLE 6: IV ESTIMATES

COMPETITION AND UNPACKING RELATIONAL CONTRACTS

\begin{tabular}{|c|c|c|c|c|c|c|}
\hline & [1] & [2] & [3] & [4] & {$[5]$} & {$[6]$} \\
\hline & $\begin{array}{l}\text { PRE-HARVEST } \\
\text { FARMER }\end{array}$ & $\begin{array}{l}\text { PRE-HARVEST } \\
\text { MANAGER }\end{array}$ & $\begin{array}{l}\text { HARVEST } \\
\text { FARMER }\end{array}$ & $\begin{array}{l}\text { HARVEST } \\
\text { MANAGER }\end{array}$ & $\begin{array}{c}\text { POST-HARVEST } \\
\text { FARMER }\end{array}$ & $\begin{array}{c}\text { POST-HARVEST } \\
\text { MANAGER }\end{array}$ \\
\hline Dependent Variable & $\begin{array}{l}\text { Received Fertilizer } \\
\text { from Mill }\end{array}$ & $\begin{array}{c}\text { Fertilizer given to } \\
\text { Farmers }\end{array}$ & $\begin{array}{c}\text { Sold Cherries on } \\
\text { Credit }\end{array}$ & $\begin{array}{l}\text { Has purchased } \\
\text { cherries on credit }\end{array}$ & $\begin{array}{c}\text { Received Second } \\
\text { Payment }\end{array}$ & $\begin{array}{c}\text { Has made Second } \\
\text { Payment }\end{array}$ \\
\hline \multicolumn{7}{|l|}{ PANEL A: IV } \\
\hline \multirow{2}{*}{ Competition } & $-0.178^{* * *}$ & $-0.055^{\star}$ & $-0.082^{*}$ & $-0.062^{*}$ & $-0.192^{* * *}$ & $-0.097^{* *}$ \\
\hline & $(0.072)$ & $(0.033)$ & $(0.048)$ & $(0.036)$ & $(0.072)$ & $(0.066)$ \\
\hline \multicolumn{7}{|l|}{ PANEL B: OLS } \\
\hline \multirow{2}{*}{ Competition } & $-0.010^{*}$ & $-0.025^{\star}$ & -0.002 & -0.018 & $-0.038^{* * *}$ & -0.021 \\
\hline & $(0.006)$ & $(0.015)$ & $(0.006)$ & $(0.014)$ & $(0.008)$ & $(0.014)$ \\
\hline Score within $5 \mathrm{~km}$ of Mill (predict) & yes & yes & yes & yes & yes & yes \\
\hline Eng Model Criteria & yes & yes & yes & yes & yes & yes \\
\hline Geographical Controls & yes & yes & yes & yes & yes & yes \\
\hline Mill Controls & yes & yes & yes & yes & yes & yes \\
\hline Farmer Controls & yes & - & yes & -- & yes & -- \\
\hline Adjusted R square & 0.137 & 0.006 & 0.239 & 0.079 & 0.152 & 0.173 \\
\hline Observations & 890 (farmer) & 178 (mill) & 890 (farmer) & 178 (mill) & 890 (farmer) & 178 (mill) \\
\hline
\end{tabular}

Notes: Standard errors in ( ) are bootstrapped. ${ }^{* * *},{ }^{* *},{ }^{*}$ denote statistically significance at $1,5,10$ percent, respectively. Panel A, columns report 2 SLS estimation. Panel B, columns report OLS estimation, with only the Competition variable being reported. Competition in Panel B is defined as the number of mills within a 10 kilometre radius of mill i. Competition in Panel A is instrumented by the average Score (predict) from the engineering model within 5-10 km radius of mill i. All specifications are conditional on controlling for the Score (predict) within $5 \mathrm{~km}$ radius of mill i. Controls in all specifications are (i) Engineering model criteria and Geographical controls within $5 \mathrm{~km}$ radius of mill i: elevation (m), slope (degrees), historical soil suitability for coffee (potential producible tonnes per hectare), length of river (km); $x$ - and $y$-coordinates, presence of spring, roads, and tree density. Responses in this table are both from the Farmer and Manager's survey. Mill controls an a f mill, age of mill square, type of mill (private coperative), capacity of mill and NGO supported (TechnoServe). Farmer controls are age, gender, years of schooling, distance to mill, cognitive tests, membership in a cooperative and number of trees owned (log). 
TABLE 7 : COMPETITION AND TRUST

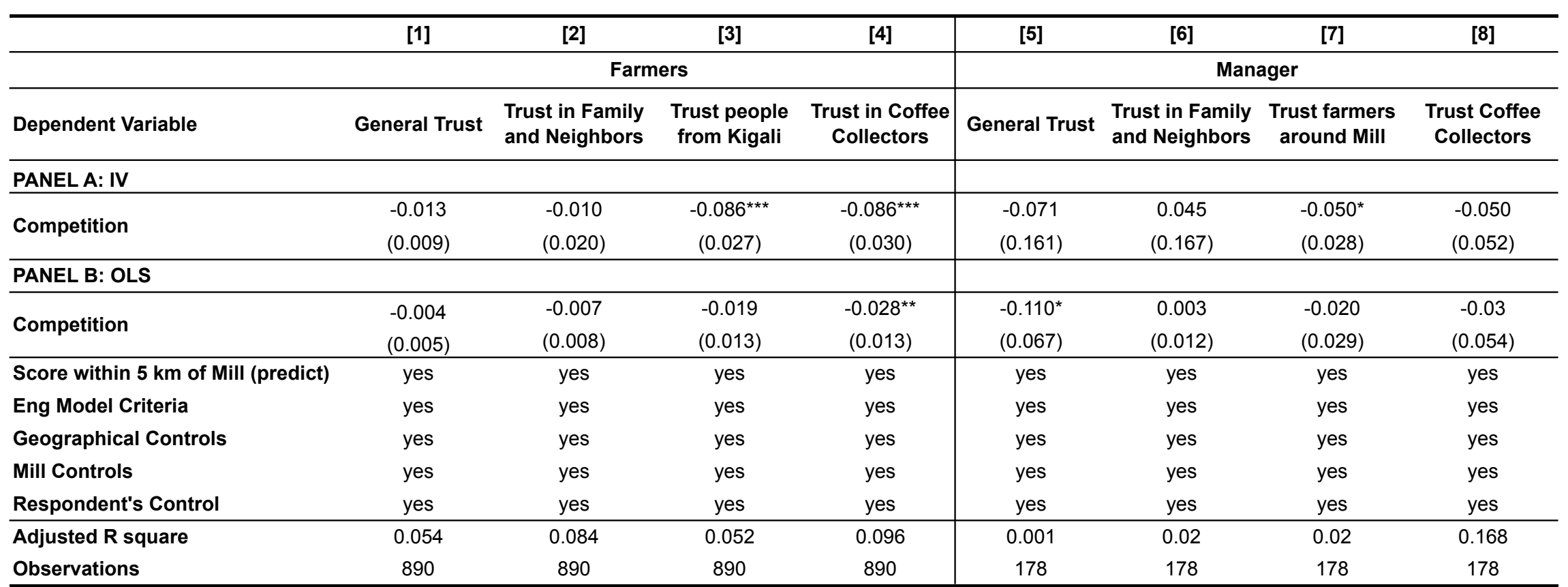

Notes: Standard errors in ( ) are bootstrapped. ${ }^{* * *},{ }^{* *},{ }^{*}$ denote statistically significance at $1,5,10$ percent, respectively. Panel A, columns report 2 SLS estimation. Panel B, columns report

OLS estimation, with only the Competition variable being reported. Competition in Panel B is defined as the number of mills within a 10 kilometer radius of mill $i$. Competition in Panel A is instrumented by the average Score (predict) from the engineering model within $5-10 \mathrm{~km}$ radius of mill $i$. All specifications are conditional on controlling for the Score (predict) within $5 \mathrm{~km}$ radius of mill $i$ Controls in all specifications are (i) Engineering model criteria and Geographical controls within $5 \mathrm{~km}$ radius of mill $i$ e elevation (m), slope (degrees), historical soil suitability for coffee of mill i. Controls in all specifation from the from the Famer years of schooling, distance to mill, cognitive
experience and training received. 
TABLE 8: ROBUSTNESS CHECKS

\begin{tabular}{|c|c|c|c|c|c|c|c|c|}
\hline & (1) & (2) & (3) & (4) & (5) & (6) & (7) & (8) \\
\hline \multicolumn{9}{|l|}{ PANEL A: IV } \\
\hline $\begin{array}{l}\text { Dependent } \\
\text { Variable: }\end{array}$ & \multicolumn{8}{|c|}{ Relational Contract Score } \\
\hline \multirow{2}{*}{ Competition } & $-0.085^{\star *}$ & $-0.136^{\star}$ & $-0.036^{\star}$ & $-0.051^{*}$ & $-0.075^{\star *}$ & $-0.111^{\star *}$ & $-0.623^{*}$ & $0.025^{\star * *}$ \\
\hline & $(0.041)$ & $(0.075)$ & $(0.019)$ & $(0.031)$ & $(0.035)$ & $(0.036)$ & $(0.436)$ & $(0.011)$ \\
\hline \multicolumn{9}{|l|}{ PANEL B } \\
\hline $\begin{array}{l}\text { First Stage (Dep. } \\
\text { Variable): }\end{array}$ & $\begin{array}{l}\text { N. of mills within } \\
10 \mathrm{Km}\end{array}$ & $\begin{array}{l}\text { N. of mills within } \\
7 \mathrm{Km}\end{array}$ & $\begin{array}{l}\text { N. of mills within } 15 \\
\text { Km }\end{array}$ & $\begin{array}{l}\text { N. of mills around } \\
\text { catchment area }\end{array}$ & $\begin{array}{l}\text { N. of mills within } \\
7 \mathrm{Km} \text { by road }\end{array}$ & $\begin{array}{l}\text { N. of mills within } \\
10 \mathrm{Km}\end{array}$ & $\begin{array}{l}\text { Capacity Installed } \\
\text { within } 10 \mathrm{Km} \text { (log) }\end{array}$ & $\begin{array}{l}\text { (-) Distnace to the } \\
\text { 7th nearest mill }\end{array}$ \\
\hline \multirow[t]{2}{*}{ Instrument } & $151.40^{* \star *}$ & $80.295^{\star \star \star}$ & $320.58^{* * *}$ & $220.26^{\star * *}$ & $32.638^{*}$ & \multirow{2}{*}{--} & $19.23^{\star \star *}$ & $-103.15^{\star \star \star}$ \\
\hline & $(23.21)$ & $(18.996)$ & $(34.761)$ & $(20.52)$ & $(17.309)$ & & $(2.37)$ & $(14.35)$ \\
\hline$\underline{F-t e s t}$ & 42.469 & 22.485 & 65.662 & 52.71 & 21.578 & 10.19 & 8.84 & 47.4 \\
\hline Instrument: & $\begin{array}{c}\text { Average Score btw. } \\
5-10 \mathrm{~km}\end{array}$ & $\begin{array}{c}\text { Average Score btw. } \\
3-7 \mathrm{~km}\end{array}$ & $\begin{array}{c}\text { Average Score btw. } \\
7-15 \mathrm{~km}\end{array}$ & $\begin{array}{l}\text { Av. Score around } \\
\text { catchment area }\end{array}$ & $\begin{array}{l}\text { Average score btw. } \\
3-7 \mathrm{Km} \text { by road }\end{array}$ & $\begin{array}{l}\text { Components of score } \\
\text { btw. } 5-10 \mathrm{Km}\end{array}$ & $\begin{array}{c}\text { Average Score btw. } \\
5-10 \mathrm{~km}\end{array}$ & $\begin{array}{c}\text { Average Score btw. } \\
5-10 \mathrm{~km}\end{array}$ \\
\hline Observations & 178 & 178 & 178 & 178 & 178 & 178 & 178 & 178 \\
\hline \multicolumn{9}{|c|}{$\begin{array}{l}\text { Notes: Standard errors in ( ) are bootstrapped. }{ }^{* * *},{ }^{* *},{ }^{*} \text { denote statistically significance at } 1,5,10 \text { percent, respectively. Controls in all specifications are (i) Engineering model criteria and Geographical controls } \\
\text { within } 5 \mathrm{~km} \text { radius of mill i: elevation (m), slope (degrees), historical soil suitability for coffee (potential producible tonnes per hectare), length of river (km); } x-\text { and y-coordinates, presence of spring (average within } \\
5 \mathrm{~km} \text { of mill i), roads (average within } 5 \mathrm{~km} \text { of mill i). Mill controls are age of mill, age of mill square, type of mill (private, cooperative) and NGO supported (TechnoServe). Column } 1 \text { reproduces the baseline } \\
\text { specification of Column } 4 \text {, Table } 5 \text {. Column } 2 \text { considers a catchment area with radius of } 3.5 \mathrm{kms} \text {. and competition from mills within } 7 \mathrm{kms} \text {. Column } 3 \text { considers a catchment area with radius of } 7 \mathrm{kms} \text {. and } \\
\text { competition from mills within } 15 \mathrm{kms} \text {. Column } 4 \text { defines the size of the catchment area as the area around the mill that has the potential to produce twice as many tons of cherries than those needed by the mill to } \\
\text { operate at full capacity. Column } 5 \text { defines the catchment area to be the convex hull of the points that can be reached traveling } 7 \mathrm{kms} \text {. by road from the mill. Column } 6 \text { uses as instruments the four different criteria } \\
\text { of the engineering model, averaged across all grids in the area surrounding the catchment area. Column } 7 \text { measures competition using the total capacity installed by mills within } 10 \mathrm{kms} \text {. radius. Column } 8 \\
\text { measures competition as distance to the seventh nearest station. }\end{array}$} \\
\hline
\end{tabular}


TABLE 9: COMPETITION AND MILL OUTCOMES

\begin{tabular}{|c|c|c|c|c|c|c|c|}
\hline & [1] & [2] & [3] & [4] & [5] & [6] & [7] \\
\hline Dependent Variable & $\begin{array}{l}\text { Unit Costs } \\
\text { (Ln) }\end{array}$ & $\begin{array}{l}\text { Cherry Prices } \\
\text { (Ln) }\end{array}$ & $\begin{array}{l}\text { Conversion } \\
\text { Ratio (Ln) }\end{array}$ & $\begin{array}{l}\text { Processing } \\
\text { Unit Costs } \\
\text { (Ln) }\end{array}$ & $\begin{array}{l}\text { Capacity } \\
\text { Utilization }\end{array}$ & $\begin{array}{l}\text { Weeks Mill } \\
\text { Processed }\end{array}$ & $\begin{array}{l}\text { Days w/out } \\
\text { enough } \\
\text { cherries }\end{array}$ \\
\hline \multicolumn{8}{|l|}{ PANEL A: IV } \\
\hline Competition & $\begin{array}{c}0.035^{\star * \star} \\
(0.014)\end{array}$ & $\begin{array}{l}-0.001 \\
(0.009)\end{array}$ & $\begin{array}{c}0.002 \\
(0.004)\end{array}$ & $\begin{array}{l}0.069^{\star *} \\
(0.029)\end{array}$ & $\begin{array}{l}-7.791^{\star \star} \\
(3.922)\end{array}$ & $\begin{array}{l}-0.229 \\
(0.424)\end{array}$ & $\begin{array}{l}0.056^{*} \\
(0.029)\end{array}$ \\
\hline \multicolumn{8}{|l|}{ PANEL B: OLS } \\
\hline Competition & $\begin{array}{l}0.009^{\star *} \\
(0.005)\end{array}$ & $\begin{array}{c}0.002 \\
(0.004)\end{array}$ & $\begin{array}{c}0.002 \\
(0.002)\end{array}$ & $\begin{array}{c}0.015 \\
(0.012)\end{array}$ & $\begin{array}{l}-1.239 \\
(1.372)\end{array}$ & $\begin{array}{c}0.06 \\
(0.162)\end{array}$ & $\begin{array}{l}0.033^{* *} \\
(0.016)\end{array}$ \\
\hline Score within $5 \mathrm{~km}$ of Mill (predict) & yes & yes & yes & yes & yes & yes & yes \\
\hline Eng Model Criteria & yes & yes & yes & yes & yes & yes & yes \\
\hline Geographic Controls & yes & yes & yes & yes & yes & yes & yes \\
\hline Mill Controls & yes & yes & yes & yes & yes & yes & yes \\
\hline Adjusted R square & 0.071 & 0.342 & 0.105 & 0.045 & 0.012 & 0.181 & 0.234 \\
\hline Observations & 178 & 178 & 178 & 178 & 178 & 178 & 178 \\
\hline
\end{tabular}

Notes: Standard errors in ( ) are bootstrapped. ${ }^{* * *},{ }^{* *},{ }^{*}$ denote statistically significance at 1,5, 10 percent, respectively. Panel A, columns report 2 SLS estimation. Panel B, columns report OLS estimation, with only the Competition variable being reported. Competition in Panel $B$ is defined as the number of mills within a 10 kilometer radius of mill $i$. Competition in Panel $A$ is instrumented by the average Score (predict) from the engineering model within $5-10$ $\mathrm{km}$ radius of mill $i$. All specifications are conditional on controlling for the Score (predict) within $5 \mathrm{~km}$ radius of mill $i$. Controls in all specifications are (i) Engineering model criteria and Geographical controls within $5 \mathrm{~km}$ radius of mill $i$ : elevation $(\mathrm{m})$, slope (degrees), historical soil suitability for coffee (potential produceable tonnes per hectar), length of river $(\mathrm{km}) ; x$ - and $y$-coordinates, presence of spring (average within $5 \mathrm{~km}$ of mill $i$ ), roads (average within $5 \mathrm{~km}$ of mill $i$ ). Responses in this table are from the Manager's survey. Mill controls are age of mill, age of mill square, type of mill (private, cooperative) and NGO supported (TechnoServe). 
TABLE 10: COMPETITION AND FARMER OUTCOMES

\begin{tabular}{|c|c|c|c|c|c|c|}
\hline & [1] & [2] & [3] & [4] & [5] & [6] \\
\hline Dependent Variable & Prices (Ln) & $\begin{array}{c}\text { Share Sold as } \\
\text { Cherries }\end{array}$ & $\begin{array}{l}\text { Self financed } \\
\text { Inputs (RWF) }\end{array}$ & Total Yields & $\begin{array}{c}\text { Reason for } \\
\text { Home } \\
\text { Processing: } \\
\text { Allows Saving }\end{array}$ & $\begin{array}{c}\text { Job } \\
\text { Satisfaction } \\
\text { (Z-score) }\end{array}$ \\
\hline \multicolumn{7}{|l|}{ PANEL A: IV } \\
\hline \multirow{2}{*}{ Competition } & 0.001 & $-0.014^{*}$ & 2569.060 & -0.011 & $0.057^{* \star *}$ & $-0.208^{\star * \star}$ \\
\hline & $(0.003)$ & $(0.007)$ & $(1878.12)$ & $(0.052)$ & $(0.016)$ & $(0.036)$ \\
\hline \multicolumn{7}{|l|}{ PANEL B: OLS } \\
\hline \multirow{2}{*}{ Competition } & 0.002 & -0.006 & $2525.01^{* * *}$ & $0.050^{* *}$ & 0.011 & $-0.056^{* * *}$ \\
\hline & $(0.002)$ & $(0.004)$ & $(727.39)$ & $(0.024)$ & $(0.007)$ & $(0.015)$ \\
\hline Score within $5 \mathrm{~km}$ of Mill (predict) & yes & yes & yes & yes & yes & yes \\
\hline Eng Model Criteria & yes & yes & yes & yes & yes & yes \\
\hline Geographical Controls & yes & yes & yes & yes & yes & yes \\
\hline Mill Controls & yes & yes & yes & yes & yes & yes \\
\hline Farmer Controls & yes & yes & yes & yes & yes & yes \\
\hline Adjusted R square & 0.366 & 0.084 & 0.2579 & 0.178 & 0.045 & 0.066 \\
\hline Observations & 890 & 890 & 890 & 890 & 890 & 890 \\
\hline
\end{tabular}

Notes: Standard errors in ( ) are bootstrapped. ${ }^{* * *},{ }^{* *},{ }^{*}$ denote statistically significance at $1,5,10$ percent, respectively. Panel A, columns report 2 SLS estimation. Panel B, columns report OLS estimation, with only the Competition variable being reported. Competition in Panel B is defined as the number of mills within a 10 kilometre radius of mill $i$. Competition in Panel $A$ is instrumented by the average Score (predict) from the engineering model within $5-10$ $\mathrm{km}$ radius of mill i. All specifications are conditional on controlling for the Score (predict) within $5 \mathrm{~km}$ radius of mill i. Controls in all specifications are (i) Engineering model criteria and Geographical controls within $5 \mathrm{~km}$ radius of mill i: elevation $(\mathrm{m})$, slope (degrees), historical soil suitability for coffee (potential producible tonnes per hectare), length of river $(\mathrm{km}) ; \mathrm{x}$ - and $\mathrm{y}$-coordinates, presence of spring (average within $5 \mathrm{~km}$ of mill i), roads (average within $5 \mathrm{~km}$ of mill i). Responses are from the Farmer's survey. Mill controls are age of mill, age of mill square, type of mill (private, cooperative) and NGO supported (TechnoServe). Farmer controls are age, gender, years of schooling, distance to mill, cognitive tests, member in a cooperative and number of trees owned (In). In column 6, the components of the Job Satisfaction (z-score) are: ranking from 1-4 (4 being strongly agree) in the job I always to do what I am best at, the pay is good, I learn continuously new things, at the place I work I am treated with respect, I have a lot of freedom to decide how to do my work and I find work not stressful. 
TABLE 11: COMPETITION AND QUALITY OF COFFEE

\begin{tabular}{|c|c|c|c|c|c|c|c|c|c|}
\hline & [1] & [2] & [3] & [4] & [5] & [6] & [7] & [8] & [9] \\
\hline Test & \multicolumn{3}{|c|}{ Physical Examination } & \multicolumn{6}{|c|}{ Cupping Laboratory post Roasting } \\
\hline Attribute Responsibility & $\begin{array}{l}\text { Mill and } \\
\text { Farmer }\end{array}$ & Mill & Farmer & Farmer & Genetic & Mill & Mill & $\begin{array}{l}\text { Mill and } \\
\text { Farmer }\end{array}$ & $\begin{array}{l}\text { Mill and } \\
\text { Farmer }\end{array}$ \\
\hline \multicolumn{10}{|l|}{ PANEL A: IV } \\
\hline Dependent Variable & $\begin{array}{c}\text { Conversion } \\
\text { Parchment to } \\
\text { Green Coffee } \\
(\%)\end{array}$ & $\begin{array}{l}\text { Ideal } \\
\text { Moisture } \\
\text { Range }\end{array}$ & $\begin{array}{l}\text { Bean Size } \\
16.05+(\%)\end{array}$ & $\begin{array}{c}\text { Severe Insect } \\
\text { Damage }\end{array}$ & Shell & Floaters & Broken & $\begin{array}{l}\text { Total } \\
\text { Cupping } \\
\text { Points }\end{array}$ & $\begin{array}{c}\text { Speciality } \\
\text { Grade }(80+)\end{array}$ \\
\hline Competition & $\begin{array}{c}0.015 \\
(0.044)\end{array}$ & $\begin{array}{c}0.003 \\
(0.041)\end{array}$ & $\begin{array}{c}-0.096^{\star *} \\
(0.041)\end{array}$ & $\begin{array}{l}0.084^{* *} \\
(0.040)\end{array}$ & $\begin{array}{c}0.008 \\
(0.033)\end{array}$ & $\begin{array}{c}0.097 \\
(0.111)\end{array}$ & $\begin{array}{c}0.144 \\
(0.161)\end{array}$ & $\begin{array}{c}-0.24 \\
(0.186)\end{array}$ & $\begin{array}{l}-0.016 \\
(0.026)\end{array}$ \\
\hline \multicolumn{10}{|l|}{ PANEL B: OLS } \\
\hline Competition & $\begin{array}{l}-0.006 \\
(0.018)\end{array}$ & $\begin{array}{l}-0.019 \\
(0.015)\end{array}$ & $\begin{array}{l}-0.010 \\
(0.015)\end{array}$ & $\begin{array}{l}0.043^{* * *} \\
(0.016)\end{array}$ & $\begin{array}{c}0.003 \\
(0.012)\end{array}$ & $\begin{array}{c}0.046 \\
(0.044)\end{array}$ & $\begin{array}{c}0.03 \\
(0.093)\end{array}$ & $\begin{array}{c}0.066 \\
(0.088)\end{array}$ & $\begin{array}{c}0.003 \\
(0.012)\end{array}$ \\
\hline Score within $5 \mathrm{~km}$ of Mill (predict) & yes & yes & yes & yes & yes & yes & yes & yes & yes \\
\hline Eng Model Criteria & yes & yes & yes & yes & yes & yes & yes & yes & yes \\
\hline Geographical Controls & yes & yes & yes & yes & yes & yes & yes & yes & yes \\
\hline Mill Controls & yes & yes & yes & yes & yes & yes & yes & yes & yes \\
\hline Adjusted R square & 0.040 & 0.300 & 0.031 & 0.171 & 0.075 & 0.123 & 0.179 & 0.109 & 0.031 \\
\hline Observations & 178 & 178 & 178 & 178 & 178 & 178 & 178 & 178 & 178 \\
\hline
\end{tabular}


TABLE 12: COMPETITION AND MANAGEMENT CHARACTERISTICS

\begin{tabular}{|c|c|c|c|c|c|c|c|c|}
\hline & (1) & (2) & (3) & (4) & (5) & (6) & (7) & (8) \\
\hline Dependent Variable & Age & Education & $\begin{array}{l}\text { Cognitive } \\
\text { Tests }\end{array}$ & $\begin{array}{c}\text { Tenure at } \\
\text { Mill } \\
\text { (years) }\end{array}$ & $\begin{array}{l}\text { Months } \\
\text { work } \\
\text { fulltime at } \\
\text { Mill }\end{array}$ & $\begin{array}{l}\text { Received } \\
\text { Training? }\end{array}$ & $\begin{array}{l}\text { Income } \\
\text { from Mill } \\
(\log )\end{array}$ & $\begin{array}{l}\text { Incentive } \\
\text { from Mil }\end{array}$ \\
\hline \multicolumn{9}{|l|}{ PANEL A: IV } \\
\hline Competition & $\begin{array}{l}-0.161 \\
(1.066) \\
\end{array}$ & $\begin{array}{c}0.035 \\
(0.094) \\
\end{array}$ & $\begin{array}{l}-0.014 \\
(0.063)\end{array}$ & $\begin{array}{c}0.145 \\
(0.157) \\
\end{array}$ & $\begin{array}{c}-0.08 \\
(0.341) \\
\end{array}$ & $\begin{array}{l}-0.039 \\
(0.050) \\
\end{array}$ & $\begin{array}{c}0.040 \\
(0.051) \\
\end{array}$ & $\begin{array}{l}-0.003 \\
(0.033) \\
\end{array}$ \\
\hline \multicolumn{9}{|l|}{ PANEL B: OLS } \\
\hline Competition & $\begin{array}{l}-0.375 \\
(0.362)\end{array}$ & $\begin{array}{c}0.035 \\
(0.094)\end{array}$ & $\begin{array}{l}-0.008 \\
(0.027)\end{array}$ & $\begin{array}{l}-0.014 \\
(0.063)\end{array}$ & $\begin{array}{c}0.024 \\
(0.113)\end{array}$ & $\begin{array}{l}-0.006 \\
(0.015)\end{array}$ & $\begin{array}{l}-0.040 \\
(0.051)\end{array}$ & $\begin{array}{l}-0.002 \\
(0.011)\end{array}$ \\
\hline Score within $5 \mathrm{~km}$ of Mill (predict) & yes & yes & yes & yes & yes & yes & yes & yes \\
\hline Eng Model Criteria & yes & yes & yes & yes & yes & yes & yes & yes \\
\hline Geographical Controls & yes & yes & yes & yes & yes & yes & yes & yes \\
\hline Mill Controls & yes & yes & yes & yes & yes & yes & yes & yes \\
\hline Adjusted R square & 0.108 & 0.121 & 0.079 & 0.227 & 0.299 & 0.135 & 0.503 & 0.111 \\
\hline Observations & 178 & 178 & 178 & 178 & 178 & 178 & 178 & 178 \\
\hline
\end{tabular}

2SLS estimation. Panel B, columns are OLS estimation, with only the Competition variable being reported. Competition is defined as the number of mills within a 10 kilometre radius of mill $\mathrm{i}$. Competition is instrumented by the average Score (predict) from the engineering mode within $5-10 \mathrm{~km}$ radius of mill i. All specifications are conditional on controlling for the Score (predict) within $5 \mathrm{~km}$ radius of mill $i$. Controls in all specifications are (i) Engineering model criteria and Geographical controls within $5 \mathrm{~km}$ radius of mill i: elevation (m), slope (degrees), historical soil suitability for coffee (potential producible tonnes per hectare), length of river $(\mathrm{km})$; $\mathrm{x}$ - and y-coordinates, presence of spring source, length of roads and tree density. Mill controls are age of mill, age of mill square, type of mill (private, cooperative), mill capacity and NGO supported (TechnoServe). Responses are from the Manager Survey. 
TABLE 13: Mill UNIT COST AND SUBSEQUENT ENTRY IN 2013 AND 2014

\begin{tabular}{|c|c|c|c|c|}
\hline & $(1)$ & $(2)$ & $(3)$ & (4) \\
\hline Dependent Variable: & \multicolumn{4}{|c|}{ Entry of New Mills in the Sector in the Years 2013 and 2014} \\
\hline \multirow[t]{2}{*}{ Unit Costs of Mill in Sector (2012) } & -0.006 & -0.024 & 0.024 & 0.05 \\
\hline & $(0.172)$ & $(0.171)$ & $(0.168)$ & $(0.166)$ \\
\hline \multirow[t]{2}{*}{ Capacity in Sector, 2012} & 58.96 & 54.62 & 0.067 & -6.86 \\
\hline & $(42.42)$ & $(44.46)$ & $(0.054)$ & $(55.15)$ \\
\hline \multirow[t]{2}{*}{ Unit Costs of Neighbours, 2012} & & 0.08 & 4.589 & 0.08 \\
\hline & & $(0.06)$ & $(58.68)$ & $(0.06)$ \\
\hline \multirow[t]{2}{*}{ Capacity in Neighbouring Sectors, 2012} & & 3.07 & $-15.74^{*}$ & $-16.72^{*}$ \\
\hline & & $(7.88)$ & $(8.36)$ & $(9.09)$ \\
\hline \multirow[t]{2}{*}{ Average Score in Sector } & & & $5.48^{\star * *}$ & $3.43^{*}$ \\
\hline & & & $(1.61)$ & $(1.81)$ \\
\hline Eng Model Criteria \& Geographical Controls & no & no & no & yes \\
\hline Adjusted R square & 0.08 & 0.101 & 0.14 & 0.15 \\
\hline Observations & 416 & 416 & 416 & 416 \\
\hline
\end{tabular}


APPENDIX TABLE 1: DISPERSION AND BREAKDOWN IN UNIT COSTS

\begin{tabular}{|c|c|c|c|c|}
\hline Variable: & Unit Costs & $\begin{array}{l}\text { Physical } \\
\text { Efficiency }\end{array}$ & Cherry Prices & $\begin{array}{l}\text { Other Unit } \\
\text { Costs }\end{array}$ \\
\hline p75 - p25 Ratio & 1.22 & 1.04 & 1.11 & 1.66 \\
\hline p90 - p10 Ratio & 1.51 & 1.1 & 1.32 & 2.34 \\
\hline $\begin{array}{c}\text { \% Variation explained by: } \\
\text { Geography }\end{array}$ & 27 & 34 & 41 & 30 \\
\hline Technology & 8 & 6 & 7 & 4 \\
\hline Physical Efficiency & 10 & -- & {$[4]$} & [ 3 ] \\
\hline Cherry Prices & 5 & [4] & -- & [7] \\
\hline \% Variation Unexplained: & 50 & 60 & 52 & 57 \\
\hline
\end{tabular}

Notes: For Cherry costs: R75/25=1.15; R90/10=1.28; above we tabulate the dispersion in terms of comparing the top 10 percentile with the bottom 10 percintle as well as the top 25 percentile with the bottom 25 percentile. The unit cost is the cost (in RfW) in processing to obtain 1 kilogram of parchment. Unit cost can be broken down into its various components the physical efficiency (conversion of $\mathrm{x} \mathrm{kgs}$ of cheeries for $1 \mathrm{~kg}$ of parchment, the cost of purchasing cherries and other unit costs (labor, capital, procurement and transport). Source: author's survey of mills. 
APPENDIX TABLE 2: COMPETITION AND MILL OUTCOMES: LABOR COSTS

\begin{tabular}{|c|c|c|c|c|c|}
\hline & [1] & [2] & [3] & [4] & [5] \\
\hline Dependent Variable & $\begin{array}{l}\text { Unit Labour } \\
\text { Costs }\end{array}$ & $\begin{array}{l}\text { Days with too } \\
\text { many workers }\end{array}$ & $\begin{array}{l}\text { Days with too } \\
\text { few workers }\end{array}$ & $\begin{array}{l}\text { Daily Wage } \\
\text { (Ln) }\end{array}$ & $\begin{array}{l}\text { Difficuilt in } \\
\text { Hiring }\end{array}$ \\
\hline \multicolumn{6}{|l|}{ PANEL A: IV } \\
\hline Competition & $\begin{array}{c}0.144^{* * *} \\
(0.043)\end{array}$ & $\begin{array}{c}0.246^{\star * *} \\
(0.096)\end{array}$ & $\begin{array}{l}0.164^{* *} \\
(0.076)\end{array}$ & $\begin{array}{l}-0.012 \\
(0.011)\end{array}$ & $\begin{array}{l}0.0855 \\
(0.081)\end{array}$ \\
\hline \multicolumn{6}{|l|}{ PANEL B: OLS } \\
\hline Competition & $\begin{array}{c}0.064^{* * *} \\
(0.024)\end{array}$ & $\begin{array}{l}0.081^{* *} \\
(0.036)\end{array}$ & $\begin{array}{c}0.034 \\
(0.028)\end{array}$ & $\begin{array}{l}-0.004 \\
(0.004)\end{array}$ & $\begin{array}{c}0.028 \\
(0.030)\end{array}$ \\
\hline Score within $5 \mathrm{~km}$ of Mill (predict) & yes & yes & yes & yes & yes \\
\hline Eng Model Criteria & yes & yes & yes & yes & yes \\
\hline Geographic Controls & yes & yes & yes & yes & yes \\
\hline Mill Controls & yes & yes & yes & yes & yes \\
\hline Adjusted R square & 0.191 & 0.177 & 0.070 & 0.195 & 0.024 \\
\hline Observations & 178 & 178 & 178 & 178 & 178 \\
\hline \multicolumn{6}{|c|}{$\begin{array}{l}\text { Notes: Standard errors in ( ) are bootstrapped. }{ }^{* * *},{ }^{* *},{ }^{*} \text { denote statistically significance at } 1,5,10 \text { percent, respectively. Panel } \\
\text { A, columns report } 2 S L S \text { estimation. Panel B, columns report OLS estimation, with only the Competition variable being reported. } \\
\text { Competition in Panel B is defined as the number of mills within a } 10 \text { kilometer radius of mill } i \text {. Competition in Panel A is } \\
\text { instrumented by the average Score (predict) from the engineering model within } 5-10 \mathrm{~km} \text { radius of mill } i \text {. All specifications are } \\
\text { conditional on controlling for the Score (predict) within } 5 \mathrm{~km} \text { radius of mill } i \text {. Controls in all specifications are (i) Engineering } \\
\text { model criteria and Geographical controls within } 5 \mathrm{~km} \text { radius of mill } i \text { : elevation (m), slope (degrees), historical soil suitability for } \\
\text { coffee (potential produceable tonnes per hectar), length of river }(\mathrm{km}) ; x-\text { and } y \text {-coordinates, presence of spring (average within } \\
5 \mathrm{~km} \text { of mill } i \text { ), roads (average within } 5 \mathrm{~km} \text { of mill } i \text { ). Responses in this table are from the Manager's survey. Mill controls are } \\
\text { age of mill, age of mill square, type of mill (private, cooperative) and NGO supported (TechnoServe). }\end{array}$} \\
\hline
\end{tabular}




\section{Data Appendix}

\section{Data Description: Mill Census 2012}

The empirical analysis uses survey data collected through a census of mills. The survey was designed by the authors in collaboration with the National Agricultural Exporting Board and was implemented between May and July 2012. The survey aimed to cover all operating mills in the 2012 harvest season, four survey teams each including six team members were trained by one of the authors to administer the survey and cover the whole of Rwanda over the season.Upon previous appointment, face-to-face interviews were conducted, the average survey completion time was 5 hours per mill, and a team was able to survey two mills a day.

Modules included surveying (i) the manager (and owner if necessary) for general questions about the mill (separate modules for private or cooperative mills, mill history, assets owned by the mill, donor assistance, operational activity, procurement of cherries, relationship with farmers, employment, access to finance, marketing and capital invested) and the manager itself (socio-economic characteristics, canonical World Value Survey questions, employment history, earnings from station and income profile, incentive payments, raven and numerical test), (ii) the main collector of cherries in the locality for the wet mill (raven and numerical tests, questions on the socio-economic characteristics, history of the relationship with the manager and mill as well as their asset ownership), (iii) random selection of five farmers (chosen by the coffee board's district officer, survey team choose random letter for last name and provided to district officer in advance of reaching the mill) who were asked about their socio-economic characteristics, raven and numerical tests were conducted, various questions related to their coffee production (ownership of trees, past and current production and sales), expectation on prices, membership in cooperatives, interlinked transactions, input and canonical trust questions and (iv) four random workers were also interviewed at the mill, chosen on the spot by the survey team on arrival at the mill, questions covered, raven and numerical tests, canonical World Value Survey questions, socio-economic questions, earnings from wet mill and relationship with the manager. Sample of coffee lots were also taken from each mill (mills were advised to provide their best lot) to be physically examined and cupped in the coffee board's laboratory in Kigali. Lastly a GPS module of the mill collected information on the location.

During the visit we obtained photographic copies of the mill's records, including attendance records, wage bills, payments for cherry deliveries as well as sales and loan contracts. Summary from these documents allowed a careful checking of unit costs figures. We haven't digitalized the photographic records. We have used them to check some of the responses from the survey. When the mill's manager was only in charge of production and sourcing, we followed up with interviews with owners in Kigali to elicit information about marketing and financial aspects. 


\section{Data Description: Administrative and GIS}

Several ancillary data sources were obtained from coffee board as well as other agencies (Ministry of Agriculture, Rwanda Natural Resources Authority, Ministry of Infrastructure, Rwanda Meteorological Agency, TechnoServe, National University of Rwanda - Butare). GIS tools allows us to divide Rwanda into a one square kilometer grid (Rwanda's size is approx. 25,000 square kilometer). We are able to assign each square kilometer, its geographic characteristics (altitude, slope, historical coffee suitability, different types of roads and rivers) by extracting data from using remote sensing technologies on ortho-photos of the country. Using a detailed Geographic Information System (GIS) dataset extracted from ortho-photos (aerial pictures at the $0.25 \mathrm{~m}$ ) we are able to map out all the rivers of different hierarchies in Rwanda, in particular our interest is on the small rivers which form the end points of springs. From this master river database we first isolate the smallest rivers and obtain their origins by triangulating information on elevation using the Shutter Radar Topography Mission raster data which allows us at $10 \mathrm{~m}$ resolutions to ascertain the origins of rivers and hence end points of springs. We than overlay this on a GIS map of Rwanda that has spliced the country into 1 square kilometer grid boxes (henceforth, grid). This allows us to determine whether a grid has a spring and also allows us to determine the distance to the closet spring. 